\title{
EXAMINING FORMS OF CAPITAL: THE SATISFACTION WITH THE EDUCATION AND THE HIGHER EDUCATION OPPORTUNITIES OF THE CHILDREN OF LATINO FAMILIES IN THREE RURAL COMMUNITIES IN MISSOURI
}

\author{
A Dissertation \\ presented to \\ the Faculty of the Graduate School \\ at the University of Missouri-Columbia \\ In Partial Fulfillment \\ of the Requirements for the Degree \\ Doctor of Philosophy \\ by \\ APHIRADEE WONGSIRI \\ Dr. Stephen Jeanetta, Dissertation Supervisor \\ DECEMBER 2017
}


(C) Copyright by Aphiradee Wongsiri 2017

All Rights Reserved 
The undersigned, appointed by the dean of the Graduate School, have examined the dissertation entitled

EXAMINING FORMS OF CAPITAL: THE SATISFACTION WITH THE EDUCATION AND THE HIGHER EDUCATION OPPORTUNITIES OF THE CHILDREN OF LATINO FAMILIES IN THREE RURAL COMMUNITIES IN MISSOURI

Presented by

Aphiradee Wongsiri

a candidate for the degree of doctor of philosophy and hereby certify that, in their opinion, it is worthy of acceptance.

Dr. Stephen Jeanetta, Chair

Dr. Jere L. Gilles

Dr. Hua Qin

Dr. Corinne Valdivia 


\section{DEDICATION}

This book is dedicated to my parents for their love and support throughout my life.

Specially, I could not have completed this book without her endless support and encouragement, thank you mom. 


\section{ACKNOWLEDGMENTS}

First of all, I would like to sincerely thank my advisor, Dr. Steve Jeanetta, for his guidance and encouragement throughout this study, especially for his confidence in me. He has always been patient and willing to assist me with any situation so that I always end up with a positive attitude. Furthermore, Dr. Steve has always supported me mentally and financially along my academic journey. Without his great support, I could not have seen the light of success at MU.

I am truly thankful to Dr. Jere Gilles for accepting me to the department, providing the necessary information and support I needed to be successful in the program and serving on my dissertation and sharing his perspectives in the development of this study. He encouraged me at various stages during my development as a rural sociologist.

I would also like to thank Dr. Hua Qin for serving as a member of my doctoral committee. His comments and questions were very beneficial in improving my dissertation. Dr. Hua also inspired me to become a better scholar.

I am grateful to my doctoral committee member Dr. Corinne Valdivia for providing me good advice and suggestions. I learned a lot from her insights. She gave me opportunities to discuss with her many of the results presented in this study. Moreover, Dr. Corinne helped me generate new ideas throughout this study. I believed I learned from the best. 
I have to thank my parents for raising and giving me better education opportunities to make my dreams come true. Their endless support and encouragement pushed me to succeed and reach out for my academic goals. My brother, younger sister, and sister-in-law receive my well-deserved thanks for sending me their caring as I worked through the struggles of being a doctoral student.

To all my friends, thank for your understanding and great emotional support in many moments of my academic hardship. 


\section{TABLE OF CONTENTS}

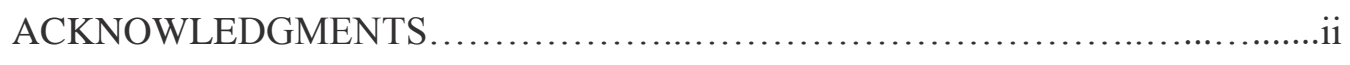

LIST OF ILLUSTRATIONS..............................................vi

LIST OF TABLES .................................................viii

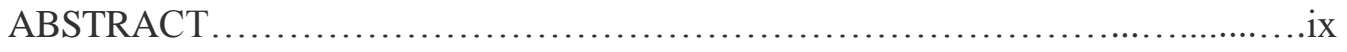

Chapter

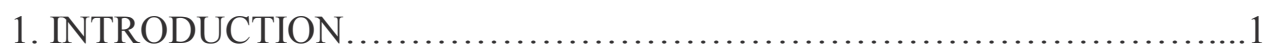

Background

Purpose of Study

2. LITERATURE REVIEW $\ldots \ldots \ldots \ldots \ldots \ldots \ldots \ldots \ldots \ldots \ldots \ldots \ldots \ldots \ldots \ldots \ldots . . . \ldots$

Definition of Key Concepts

Forms of Capital

Human Capital

Social Capital

Cultural Capital

Financial Capital

Community Perceptions

Gender Perspective

Parental Satisfaction with the Education of Children

Conceptual Framework of the Study

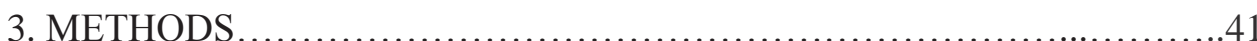

Study Area and Communities

Population and Sample

Survey Instrument

Measurement of Variables 


\section{TABLE OF CONTENTS}

Qualitative Data

Data Analyses

4. FINDINGS

Descriptive Statistics

Analytic Statistics

Forms of Capital of the Survey Respondents (Individual Level)

Forms of Capital of the Latino Household (Household Level)

Community Perceptions (Community Level)

Gender of the Survey Respondents

5. DISCUSSION ...................................................... 77

Forms of Capital of the Survey Respondents (Individual Level)

Forms of Capital of the Latino Household (Household Level)

Community Perceptions (Community Level)

Gender of the Survey Respondents

6. CONCLUSION ....................................................... 90

Implication for Community Development and Practice

Limitations of the Study

Future Research

\section{APPENDIX}

1. Description of Variables and Coding Scheme Used in the Ordinal Logistic Regression (Appendix A)...................102

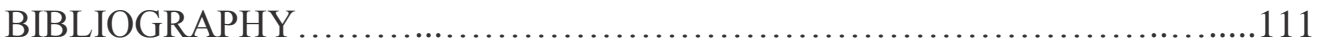

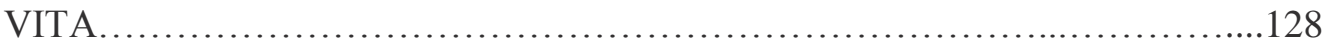




\section{LIST OF ILLUSTRATIONS}

Figure Page

1. Percentage of Adults Aged 25 through 29 Years of Age

by Selected Levels of Educational Attainment

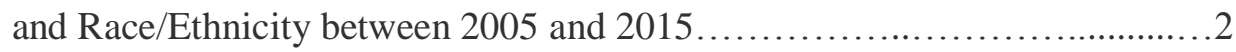

2. A Network with Closure................................................. 16

3. The Presence and Absence of Human and Social Capital

in the Family.................................................... 19

4. Bronfenbrenner's Ecological Model of Human Development....................35

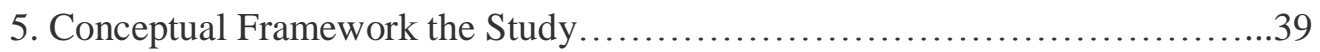

6. Map of Study Communities in Missouri.................................41

7. Process of Sample Selection in the Present Study .........................44

8. Collapsing Outcome Variables from Ten Ordered

Categories to Five Ordered Categories..................................55 


\section{LIST OF TABLES}

Table

Page

1. Four Orientations based on the Degree of Identification

with Both Ones' Own Ethnic Group and Majority

Group

2. Proportion of Latino Population by County

between 1990 and 2014

3. School Demographic Data between 2008 and 2009

in Three Rural Communities by Race/Ethnicity....

4. Lists of Variables Included in

Ordinal Logistic Regression Models

5. Multicollinearity Testing with Tolerance

and Variance Inflation Factors (VIF) 56

6. Summary of Pearson's Correlation Coefficient. .58

7. Test of Parallel Lines for Satisfaction

with the Education of the Children of Latino Families

in Three Communities

8. Test of Parallel Lines for Satisfaction

with the Higher Education Opportunities of the Children of Latino Families in Three Communities... .60

9. Descriptive Statistics for Variables Included in Ordered Logistic Regression Models 


\section{LIST OF TABLES}

Table

10. Ordinal Logistic Regression Results and Satisfaction with the Education of the Children of Latino Families

in Three Communities.............................................65

11. Ordinal Logistic Regression Results and Satisfaction

with the Higher Education Opportunities of the Children

of Latino Families in Three Communities................................66 


\title{
EXAMINING FORMS OF CAPITAL: THE SATISFACTION WITH THE EDUCATION AND THE HIGHER EDUCATION OPPORTUNITIES OF THE CHILDREN OF LATINO FAMILIES IN THREE RURAL COMMUNITIES IN MISSOURI
}

\author{
Aphiradee Wongsiri \\ Dr. Stephen Jeanetta, Dissertation Supervisor
}

\begin{abstract}
This study aimed to investigate how forms of capital relate to satisfaction with the education and the higher education opportunities of the children of Latino families in three rural communities in Missouri. The specific research questions are: (1) What are the forms of capital of the survey respondents predict satisfaction with the education and the higher education opportunities of the children of Latino families? (2) What are the forms of capital of the Latino household that predict satisfaction with the education and the higher education opportunities of the children of Latino families? (3) What are the community perceptions that predict satisfaction with the education and the higher education opportunities of the children of Latino families? (4) How does the gender of the survey respondents relate to satisfaction with the education and the higher education opportunities of the children of Latino families?

An ordinal logistic regression was used to identify predictors of satisfaction of Latino families. The results indicated that the forms of capital which were possessed by the survey respondents and by the Latino household were significantly associated with satisfaction with the education and the higher education opportunities of the children of Latino families. Community acceptance and being male were significantly related to satisfaction with the higher education opportunities of the children. Additionally, the survey respondents who lived in community A were negatively associated with satisfaction with the education of the children.
\end{abstract}




\section{CHAPTER I}

\section{INTRODUCTION}

\section{I.i. Background}

In the United States, Latinos have made a significant progress in terms of educational attainment in these last 10 years. Between 2004 and 2013, the number of Latinos receiving an associate degree or higher degree increased $71 \%$ from 3.8 million to 6.5 million (Santiago, 2015). Although the levels of Latino educational attainment have increased, educational attainment of Latinos continues to be lower than other ethnic groups (Chapa \& Valencia, 1993; Santiago, 2015). Between 2005 and 2015, the percentage of young adults (25 through 29 years of age) who completed at least high school rose from $92.8 \%$ to $95.4 \%$ among Whites, from $87.0 \%$ to $92.5 \%$ among Blacks, from $63.3 \%$ to $77.1 \%$ among Hispanic, and from $95.5 \%$ to $95.8 \%$ among Asians. During this 10-year period, the change in the percentage of those who completed at least high school was more likely to increase among Hispanics than the other three groups. Furthermore, the percentage of young adults who earned a bachelor's degree or higher increased within the period of 2005 to 2015 from $34.5 \%$ to $43.0 \%$ among Whites, from $17.6 \%$ to $21.3 \%$ among Blacks, from $11.2 \%$ to $16.4 \%$ among Hispanics, and from $62.1 \%$ to $66.0 \%$ among Asians (Snyder, Brey, \& Dillow, 2016) (See Figure $1)$. 


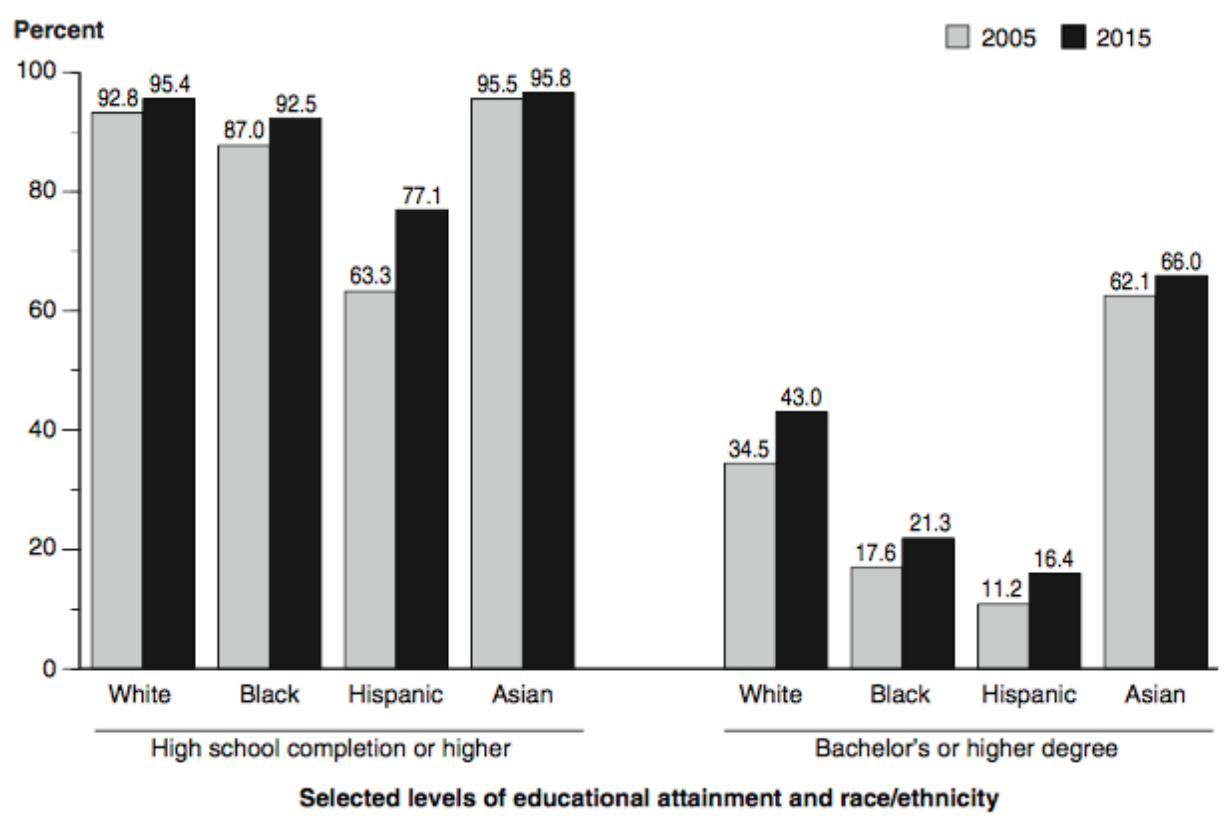

Figure 1. Percentage of adults aged 25 through 29 years of age by selected levels of educational attainment and race/ethnicity between 2005 and 2015. Adapted from "Digest of education statistics 2015 (NCES 2016-2014)" by T. D. Snyder and S. A. Dillow, 2016, National Center for Education Statistics, Institute of Education Sciences, p.17. Copyright 2016 U.S. Department of Education. Washington, DC.

Low educational attainment of Latino children is influenced by a lack of economic and social resources based on the backgrounds of Latino parents including their socioeconomic status, educational attainment, language proficiency, or race/ethnicity (Coleman \& Hoffer, 1987; Wojtkiewicz \& Donato, 1995; StantonSalazar, 1997; Edles, 2002; Lee \& Bowen, 2006; Scheider, Martinez \& Owens, 2006; Plunkett et al. 2009; Baum \& Flores, 2011). For example, Wojikiewicz and Donato (1995) indicated that strong influences on the educational attainment of Latinos came in two forms - general and specific (p.560). First, general characteristics included family background factors, such as socioeconomic status, and aspects of family structure, such as number of siblings and absent parents. For instance, parents with higher educational attainment and higher income were able to provide a home environment to support and encourage the education of their children. Thus, general 
characteristics are important for Latinos and all racial and ethnic minorities. The second, included specific characteristics were more common among Latinos than other ethnic groups: being foreign-born, having non-English language background, and having a short duration of U.S. residence. For example, being foreign-born reduced the likelihood of Latinos graduating from high school.

Latino children were significantly less likely to have parents with higher education. As illustrated, in 2012, only 24\% of Hispanic children ages 6 through 18, had parents who completed an associate or higher degree. In comparison, 67\% of Asian, $58 \%$ of White, and $33 \%$ of African-American children had parents who received an associate degree or higher degree (Santiago, 2015). As a result, the educational attainment of Latinos in the United States has fallen into a pattern of underachievement affecting on the educational attainment of their children (Ceballo, 2004). Although Latino parents have low educational attainment, they place high value in education for their children and motivate their children to succeed academically (Ceballo, 2004; Plunkett et al., 2009; Santiago, 2015).

The findings of National Household Education Survey showed that $91 \%$ of Hispanic parents expected their children to earn some levels of higher education (Santiago, 2015). This is because the parents placed a high value on the importance of education for the future of their children. Ceballo (2004) indicated that Latino parents viewed American education as the best and as the only way for their children to escape from poverty. Moreover, American education can be a great opportunity for the next generation. However, many empirical studies have indicated that there have been barriers to Latino parents' engagement in the schooling of their children and other educational activities (Ceballo, 2004; Bámaca-Colbert \& Gayles, 2010). As a matter of fact, newly arrived Latino immigrants with little to no education are more likely to be 
unfamiliar with how to navigate the American educational system (Ceballo, 2004). Low educational attainment was the main factor influencing Latino immigrants' discomfort with the school system preventing them from becoming involved in their children's education. Furthermore, Ceballo (2004) cited in Lott's study: Low-Income Parents and the Public Schools, indicated that the most important issue preventing Latino parents from becoming more involved in the school and educational activities of their children was that many teachers and school administrators have continued to reproduce negative stereotypes about poverty-stricken parents or recent immigrants. These misperceptions described poor parents as being apathetic, uninvolved, uninterested, and uncaring toward their children's education (Ceballo, 2004; Altschul, 2011).

Language and cultural barriers between Spanish-speaking parents and Englishspeaking teachers have also been important barriers to parental involvement in school (Altschul, 2011). Information about schools, applying to schools, applying for financial aid, or teacher effectiveness and background, is generally not available in Spanish. These are some examples of the types of information influencing children's outcomes; therefore, it has been difficult for immigrant parents to access school information because of their lack of English language proficiency (Kao, 2004). Kao (2004) argued that even if immigrant parents had completed a high level of education, without being fluent in either the language or the social norms of main-stream of American society, they would not be useful to their children. It is certainly challenging for parents who experience economic, cultural, social, and linguistic barriers to engaging with schools if language translation is not provided (Altschul, 2011).

As has been noted, it is necessary for Latino parents to seek appropriate strategies in order to address the hardships and challenges associated with the education 
of their children. However, there are ways families can help their children achieve their educational goals even when they lack some traditionally key resources (such as having a higher income and educational attainment) which makes it easier to facilitate the educational goals of their children. All families have resources they can leverage to achieve the goals of the family, known as "family capital."

The notion of family capital concentrates on the various components of capital that involve in shaping life opportunities. To be more specific, family capital is defined as the total resources the family members possesses including components of human, social, and financial capital (Danes et al., 2009). In return, these components of capital are fostered in characteristics of individuals and developed in families, particularly through the relationship between parents and children. Therefore, family capital helps acknowledge and highlights the ways that families directly influence the life opportunities of their children and their outcomes into adulthood (Swartz, 2008). If we could better understand these resources that families possess and explore how they leverage those resources to achieve family goals, such as higher education opportunities for the children, then the strategies that build on those resources could make these goals widely attainable.

The study of parental satisfaction with child education based on forms of capital is limited. Recent studies have investigated parental satisfaction in terms of parents' involvement in the education of their children (Lee \& Bowen, 2006; Friedman, Bobrowski, \& Markow, 2007; Kelesidou et al., 2017). This study explores how the various forms of capital affect the satisfaction of Latino families with the education of their children. Many studies fail to examine the various forms of capital on education; they have investigated forms of capital separately. In order to better understand the context of education for Latino families, this study adds cultural capital as the cultural 
capital of first generation of Latino immigrant families reflects their values, beliefs, and identities which helps them adapt to their receiving culture as minority group members. These values and traditions play an important role in defining the educational goals of family members as well as shaping how they view education and the educational process. Exploring the role of cultural capital as an element of family capital may help us better understand how the values, beliefs and identities of Latino immigrant families help their children achieve their educational goals. Therefore, four forms of capital are included in this study: human, social, cultural, and financial capital. Together, it is hypothesized that these four forms of capital have an impact on parental satisfaction with child education and child higher education opportunities in Latino families.

\section{I.ii. Purpose of Study}

The purpose of this study is to determine whether the four forms of capital mentioned above influence satisfaction of Latino families ${ }^{1}$ with the education and the higher education opportunities available to their children. This is because the forms of capital are potential assets that parents can leverage to help their children access educational opportunities. The more forms of capital parents have, the greater the ability of parents to influence school decisions so as to meet their expectations for the education of their children (Noguera, 2001). Furthermore, this study aims to motivate the academic community to further develop indicators to help measure forms of capital in other important areas of family life, such as health, politics, and economic development. The terms Latino and Hispanic are interchangeably used in this study.

\footnotetext{
${ }^{1}$ Throughout this proposal, "Latino families" include parents who are born outside of the United States (first generation or foreign-born) as well as those parents born in the United States (second generation or native-born). Additionally, the first-generation families can include children who are born outside of the United States, while the children from the second generation are born in the United States, but their parents are born aboard and immigrated to the United States.
} 
The specific research questions are:

(1) What are the forms of capital of the survey respondents predict satisfaction with the education and the higher education opportunities of the children of Latino families?

(2) What are the forms of capital of the Latino household that predict satisfaction with the education and the higher education opportunities of the children of Latino families?

(3) What are the community perceptions that predict satisfaction with education and the higher education opportunities of the children of Latino families?

(4) How does the gender of the survey respondents relate to satisfaction with the education and the higher education opportunities of the children of Latino families? 


\section{CHAPTER II}

\section{LITERATURE REVIEW}

The literature review in this chapter focuses on the four forms of capital (human, social, cultural, and financial capital) and parental satisfaction with the education of children. This chapter includes six sections: (1) definition of key concepts of family and family capital; (2) discussion of the four forms of capital: human, social, cultural, and financial capital; (3) discussion of community perceptions; (4) gender perspective; (5) parental satisfaction with the education of children; and (6) conceptual framework of the study.

\section{II.i. Definition of Key Concepts}

The family is a basic unit of study in various social science disciplines (e.g. sociology, psychology, economics, anthropology, and social work). Family itself plays an important role in research because of family influences on the development, behavior, and well-being of the individual (Sharma, 2013). Various definitions of the family explain the variety of domestic arrangements among human societies (Chudhuri, 2011). In the context of family therapy, family has been proposed as "people who have a shared history and shared future, bound by blood, legal and/or historical ties" (as cited in Poutziouris, Smymios \& Klein, 2008, p.125).

The United States Census Bureau (2015, n.p.) defined family as "a group of two people or more (one of whom is the householder) related by birth, marriage, or adoption and residing together." Based on this definition, the family constitutes a single household and members interact with each other in their respective social positions. 
This single household may include husband and wife, father and mother, son and daughter, or brother and sister (Chudhuri, 2011).

Another definition of family was based on Murdock's definition, where the family was defined as "a social group characterized by common residence, economic cooperation, and reproduction including at least two opposite sex adults who maintain a socially approved sexual relationship established and defined by marriage customs, and one or more children" (as cited in Hendrix, 1975, p.126). Both the definitions by the U.S. Census Bureau and Murdock defined family in terms of family structure: the nuclear family unit. For Murdock, the nuclear family has four main functions (Hendrix, 1975, p. 127): (1) the sexual function; (2) the economic function; (3) the procreative function; and (4) the educational function. Likewise, Belcher, Peckuonis, and Deforge (2011) stated that three basic family functions are consistent with Murdock's four functions of the nuclear family. The three basic functions the family are: (1) procreation and protection of offspring; (2) socialization of its members; and (3) transmission of culture. In general, families can be classified along several dimensions (BangkokUNESCO 1992, p.8). For example, by marriage (e.g. monogamous, polygamous, or group), by location (e.g. patrilocal, matrilocal, avunculocal, or nonlocal), by authority (patriarchy or matriarchy), by descent and inheritance (e.g. patrilineal, matrilineal, bilateral, or double), and kin composition (e.g. nuclear or joint). According to these family dimensions of families, the organization of marriage seemed to shape dominant notions of gender (Valdivia \& Gilles, 2001). Cultural norms in society have gravitated the fathering role to their economic ability to support a family (Engle, 2001).

Within the family, capital was gendered and crucial for creating livelihoods (Valdivia \& Gilles, 2001). Capital became resources or assets in the family including human capital, social capital, financial capital, and cultural capital (Valdivia \& Gilles, 
2001; Belcher, Peckuonis, \& Deforge, 2011; Flora \& Flora, 2013). Particularly, these four forms of capital were essential to the development and well-being of children (Belcher, Peckuonis \& Deforge, 2011). Family capital became "an emergent system capacity created when family members collectively engage in household production activities" (Imig, 2017, n.p). To be more specific, family capital was conceptually defined as "the total resources of owning family members with components of human, social, and financial capital" (Danes et al., 2009, p.199). Consequently, family capital was viewed as the accumulation of family resources, that is, that investments and efforts that can be mobilized to advance achievement (Swartz, 2008). The idea of family capital emphasized the different structures of capital that shaped life changes and sustained the structure in families as well as the relationships between parents and children (Swartz, 2008). This is because family capital was defined as a primary source of social solidarity which promoted productivity for family members, specifically for the outcomes and life chances of children (Swartz, 2008; Danes et al., 2009).

Martin (2013) stated that all forms of family capital could be aggregated over time, could be used to facilitate actions, and could be converted into other forms of family capital. This means that families have to produce forms of capital through investment of their times and resources. In return, the outcomes of time investments can become forms of capital which can be utilized to create livelihoods - thus giving meaning to a person's world and improving well-being. The use of forms of capital generates benefits which may be appropriated by individuals, families, communities, or markets (Valdivia \& Gilles, 2001).

Forms of capital have helped families access to resources in order to "use in building livelihoods and give them the capability to be and to act" (Bebbington, 1999, p.2022). Forms of capital in this study is identified as substantial resources which 
included human, social, cultural, and financial capital to explain satisfaction with the education and the higher education opportunities of the children of Latino families.

\section{II.ii. Forms of Capital}

\section{II.ii.i. Human Capital}

Generally, human capital is a core concept in economics and in social sciences (Brian, 2007). Human capital is attributed to the works of Johnson, Schultz, and Becker. According to Johnson, laborers have become capitalists from "the acquisition of knowledge and skills that had economic value" rather than from "a diffusion of the ownership of corporation stocks" (Lin, 2002, p.8). This means laborers with knowledge and skill could demand from the payment from the capitalists beyond the exchange value of their labor (Lin, 2002).

However, Schultz's investment in human capital stated that "the failure to treat human resources explicitly as a form of capital, as a produced means of production, [and] as the product of investment, [which] has fostered the retention of the classical notion of labor as [only] a capacity to do manual work requiring little knowledge and skill, a capacity with which, according to this notion, [all] laborers are endowed about equally" (as cited in Lin, 2002, p.9). Becker argued that human capital differed from physical capital because human capital was the added value embedded in the laborers themselves that was organized and measured by education, training, and experience (Lin, 2002). In this sense, although human capital was explained as the increase of productivity, human capital could not be explained by financial capital or technological improvement (Beaulieu, 1992). Coleman (1988) indicated that a "physical capital is created by changes in materials to form tools that facilitate production" (p. S100). Like a physical capital, human capital "is created by changes in persons that bring about 
skills and capabilities that make them able to act in new ways" (Coleman, $1988 \mathrm{p}$. S100). Both physical and human capital facilitated productive activity. Thus, the concept of human capital places a constructive relationship between human capital and productivity. Along these lines, human capital has been frequently measured by proxies to account for an individual's profitability (Danes et al., 2009).

Human capital has included knowledge, experiences, abilities, energies, and family values that are made available to promote the education of children in the family (Danes et al., 2009; Sorenson \& Bierman, 2009; Flora \& Flora, 2013). Many research findings have illustrated that human capital is significantly associated with a child's education (Coleman \& Hoffer 1987; Beaulieu, 1992; Lee \& Bowen, 2006; Baum \& Flores, 2011). In particular, when the human capital of spouses is included, the stocks of family human capital would increase (Sorenson \& Bierman, 2009). However, Bobonis (2008) argued that within the family, fathers and mothers are free to maximize their personal human capital depending upon their own preferences for toward the best use of resources within the family.

According to Coleman and Hoffer in Public and Private High School the Impact of Community (1987), there are different ways of measuring the human capital of students' families. For example, the educational level of the parents influenced their children's educational outcomes directly. Coleman and Hoffer (1987) asserted that parents who had a high level of educational attainment also had a high level of human capital. In this sense, children who had parents with a high level of educational attainment were more likely to do better in school than those children whose parents had a low level of educational attainment (Coleman \& Hoffer, 1987; Beaulieu, 1992). Although these parents with a high level of human capital, human capital may be less effective if parents lacked a high amount of interaction with their children. Time spent 
with parents is an important factor in child's development. Moreover, parent-child shared time could enhance opportunities for parents to monitor their children's activities (David et al., 2015).

Many empirical research findings were consistent with Coleman and Hoffer's findings on the importance of parental educational attainment. For example, Espinoza (2012) indicated that the social class backgrounds of the parents had great implications for the educational attainment of their children. Even before kindergarten, children whose parents were highly educated tended to demonstrate educational readiness skills, such as knowing their letters, identifying color, or counting up to 20. Likewise, Baum and Flores (2011) examined the determinants of success in higher education of immigrant parents and their children. Their findings showed that the educational attainment of a child was strongly associated with the education of their parents. In addition, $\mathrm{Li}$ (2007) indicated that the educational status of parents was associated with the social and cultural resources that benefited the education of their children, such as engaging their children in a variety of within-family and within-community interactions and relationships.

Human capital characteristics in this study not only focus on the level of education, English proficiency, and employment status, but also include life satisfaction, which is an important component of subject well-being (Diener et al.,1985). Life satisfaction has been referred to as a "cognitive, judgmental process" (Diener et al., 1985, p.71). Beutell (2006) defined life satisfaction as "an overall assessment of feelings and attitudes about one's life at a particular point in time raging from negative to positive" (p.1). Judgments of satisfaction were based on a "comparison of one's circumstances with what is thought to be an appropriate standard" (Diener et al., 1985, p.71). In other words, the individuals consider their satisfaction with their life 
as a whole or with respect to specific domains of life such as family, environment, friends, and self (Suldo, Riley, \& Shapffer, 2006; Prasoon \& Chaturvedi, 2016). In particular, life satisfaction has been used as an important indicator of quality of life along with other indicators of mental and physical health (Beutell, 2006; Prasoon \& Chaturvedi, 2016).

According to a report by Deaton and Stone in evaluative and hedonic well-being among those with and without children at home (2014), Americans aged between 34 to 46 who had children at home were likely to rate their life satisfaction at higher levels than those who did not. Furthermore, the results indicated that the following socioeconomic characteristics were more likely to be associated with life satisfaction: higher educational attainment, higher income, better health, more religious, being married, being female, and being Hispanic. Americans with children at home reported experiencing on average more emotional highs than those without children. In such cases, people who had children perceived that having children would make their life better even taking into account - the new responsibilities of parenthood, financial costs, the joys and disappointments as well as the children themselves. Empirical studies on gender and life satisfaction found that women had an average level of life satisfaction in all age groups. Overall life satisfaction would decrease with an increase in age and the overall life satisfaction of women would increase when there was an increase in family income (Prasoon \& Chaturvedi, 2016). Nikolaou (2012) stated that marital happiness was important for child development because it influenced parenting preferences and choices of spouses. For instance, happy mothers may enhance the quantity and quality of children investments. In addition, happiness may lead to marriage which strengthens happiness and leads to child skill development based on the attachment of the mother to her children. 


\section{II.ii.ii. Social Capital}

Social capital has been internationally routinized into daily conversation and community studies, particularly in public policy discourse (Nahapiet \& Ghoshal, 1998; Woolcock, 2010). Social capital is rooted in various concepts including those of social support, social networks, and social relations (Lin, 1999; Grant, 2001). Danes et al. (2009) emphasized that social capital was embodied in relationships between individuals and social institutions, while human capital was embodied in individuals themselves (Danes et al., 2009). Theoretically, a relationship between social capital and human capital has been important. Lin (2002) stated that social capital, according to Bourdieu and Coleman, may assist in producing human capital; for example, obtaining opportunities to achieve better education, knowledge credentials, trainings, and skills depends on well-connected parents and social ties. In other words, human capital fosters social capital.

Regarding the interaction between human capital and social capital in the context of education, Coleman and Hoffer (1987) presented the distinction between human capital and social capital exhibited by Figure 2 as a network with closure. Figure 2 represents relationship between four individuals $-\mathrm{A}, \mathrm{B}, \mathrm{C}$, and D which indicated that human capital exists in the nodes; at the same time, social capital manifests itself as the lines connecting the nodes. In this sense, social capital and human capital are constantly supported. That is to say, if B were a child and A was the parent of the child, then $\mathrm{A}$ is useful for the cognitive development of B so there must be capital in both in the node and the link. This human capital is held by A while social capital is held in the existence of the relationship between A and B. 


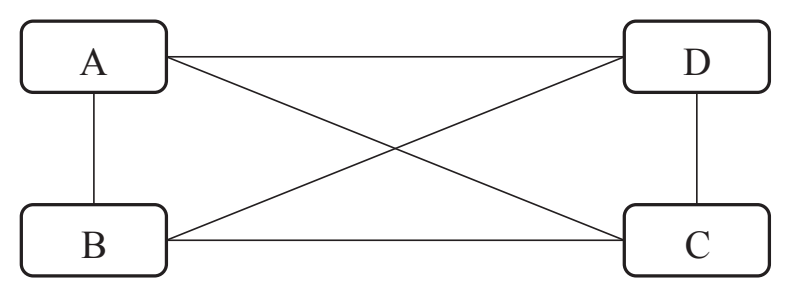

Figure 2. A network with closure. Adapted from "Public and private high schools: the impact of communities" by J. S. Coleman and T. Hoffer, 1987, p.222. Copyright 1987 by Basic Books, Inc.

Moreover, Coleman and Hoffer (1987) further emphasized that certain kinds of social capital appeared only in networks with a high level of closure. For a network, such as in Figure 2, the existence of relationships between A, B, C, and D revealed that "two can discuss a third's behavior and develop a consensus about what is proper or appropriate behavior, that is, develop social norms" (Coleman \& Hoffer, 1987, p.222). For example, if $\mathrm{A}$ and $\mathrm{D}$ were parents of $\mathrm{B}$ and $\mathrm{C}$, then $\mathrm{A}$ and $\mathrm{D}$ as parents cultivate norms about appropriate behavior for their children - B and C. In contrast, if the network could not present closure, such that A and D, who had parent-child connections to $\mathrm{B}$ and $\mathrm{C}$, respectively, did not have connections to one another, then norms to control and constrain the actions of $\mathrm{B}$ and $\mathrm{C}$ would be unable develop. Therefore, the human capital possessed by parents strongly affects the outcomes for their children.

Coleman and Hoffer (1987) defined the social capital of family as "the relations between children and parents (when families include other members, relationships with them as well)" (p.223). In this sense, Coleman and Hoffer (1987) asserted that when the human capital possessed by parents is not harmonized by social capital embodied in family relations, social capital is then irrelevant to the educational attainment of the child, that is, when parent has a small amount of human capital. A good example can be illustrated by a public school district in the United States where textbooks for school 
use were purchased by the families of the children. In this case the families of Asian immigrant families purchased two copies of each textbook - one for the children and one for the mother. This is because an Asian immigrant mother purchased an extra copy for her own use so she could maximize her ability to help her child do well in school. This example showed that human capital existed in the family, but social capital did not (Coleman \& Hoffer, 1987).

Furthermore, Coleman and Hoffer (1987) presented the absence of social capital within the family as "deficiencies" in the family. There are two forms of this deficiency in the family - structural and functional. The structural deficiency is due to "the physical absence of family members" (p.224). The two fundamentals of structural deficiency consist of single parent families and families in which the mother worked before children entered elementary school. The nuclear family itself could be considered as "structurally deficient" (p.224) due to the lack of social capital between grandparents or close relatives and the children of the household.

On the other hand, functional deficiency is due to "the absence of strong relations between children and parents" (p.224) in spite of the parents' physical existence in the household. This might result from the embeddedness of children in a youth community, from the embeddedness of the parents in relationships with other adults which either do cross generations or utilize outside resources. In this sense, whatever human capital presented itself in the parents, the children did not profit from it due to the absence of social capital (Coleman \& Hoffer, 1987).

The distinction between human capital and social capital existing in families has been categorized in two ways - traditional disadvantage and family deficiencies. The traditional disadvantage is to "the absence of resources embodied in the parents" illustrated by the education of parents and low socioeconomic level/racial-ethnic 
minority status. In other words, traditional disadvantage showed that low levels of human capital influenced economic success. In contrast, family deficiencies are "the absence of social capital" - expressed as the weakness of connection between the adult members of the family and the children (Coleman \& Hoffer, 1987, p.224).

Figure 3 represents the presence and absence of human capital and social capital within the family (Coleman \& Hoffer, 1987, p.224-225). There are two dimensions of human capital and social capital illustrated in this example which exist in four types of families. Cell 1 represents families with a high education, high economic level, and strong relations within the family. The resources of these families were accessible to their children and helped their educational and social development. This type of family has strong human capital and social capital. Cell 2 shows families in which adult members are well-educated and independently capable, but for a variety of reasons were separated. This separation created difficulties for these adult members to create connections across generations. This means that the resources of these adult members are unable to assist in the psychological health and social and educational development of their children compared to those parents who were not separated. This type of family is becoming increasingly common. Cell 3 represents families where the parents have low socioeconomic levels and low levels of education, but they hold a strong set of relationships within the family. This family model is frequently found among immigrant families who emigrated from developing countries to developed countries. Cell 4 represents families which are poor, uneducated, and disorganized, with children feeling threatened by the personal disorganization of their parents. 
Social Capital

(Strong vs. deficient families)

\begin{tabular}{cc|c|c|}
\multicolumn{1}{c}{} & \multicolumn{2}{c}{ Yes } \\
\cline { 3 - 3 } $\begin{array}{c}\text { Human Capital } \\
\text { (Traditional advantage of } \\
\text { background) }\end{array}$ & Yes & 1 & 2 \\
\cline { 3 - 4 } & No & 3 & 4 \\
\cline { 2 - 4 } & & &
\end{tabular}

Figure 3. The presence and absence of human and social capital in the family. Adapted from "Public and private high schools: the impact of communities" by J. S. Coleman and T. Hoffer, 1987, p.223. Copyright 1987 by Basic Books, Inc.

This study reviewed social capital as "a property of networks, a collection of relation qualities, through which individuals can access resources" rather than as individual characteristics (Shoji et al., 2014, p.601). This is because, as Lin (2002) asserted that personal resources in the modern family unit are extremely limited, so social ties both direct and indirect, while embedded in the ties of one's networks, are important mechanisms to enhance an individual's access to resources. Likewise, Stanton-Salazar (1997) emphasized that an individual gains access to valuable resources and opportunities by using social networks, relationships and personalities. Moreover, Sorenson and Bierman (2009) indicated that the heart of social capital is a moral structure in which the "family member holds beliefs about themselves and how family members should relate to one another and to the larger community" (p.193). Focusing on the social capital of family, Danes and colleagues (2009) stated that family, according to Coleman's definition, was "the key institution through which social capital is transmitted via investment of time and effort, development of affective ties, and guidelines about acceptable and unacceptable behaviors" (p.202). In other words, family is a network of relationships represented by a form of family social capital that has been converted into socially valued resources and opportunities, thus, inter-family relationships matter (Stanton-Salazar, 1997). Strong inter-family networks are 
developed through personal relationships over the time to construct the basis of trust (Hoffman, Hoelscher, \& Sorenson, 2006).

Family social capital in this study has been categorized into two forms: (1) bonding social capital and (2) bridging social capital (Woolcock, 1998; Côté \& Healy, 2001). First, bonding social capital is defined as strong relationships among connected family members and close friends. Bonding social capital is based on homogenous networks that are similar in some forms (Hawkin \& Maurer, 2009; Ferlander, 2007; Uphoff et al., 2013). Second, bridging social capital refers to weak relationships within networks that are more loosely connected and are dissimilar in terms of social characteristics such as ethnicity/socio-economic status/age (Hawkin \& Maurer, 2009; Ferlander, 2007; Rouxel et al., 2015). In this sense, bridging networks may be good for connecting to external assets and for information diffusion (Putnam, 2001). Overall, the value of social networks in bonding ties highlights their tendency to offer emotional and instrumental support, while the value of social networks in bridging and linking ties focuses on the provision of a wider range of informational support (Ferlander, 2007). Family social capital through social networks has provided opportunities for Latino families to have information exchanges that facilitate outcomes desirable to group members (Goddard, 2003).

In theories of social capital, social trust is an indicator of social sodality and cohesion, specifically, social trust is both a result and cause of a high level of civic involvement (Rahn \& Transue, 1998). Furthermore, Rahn and Transue (1998) asserted that social trust served as a "constraint on immoral behavior. People who believe that others are trustworthy are themselves less likely to lie, cheat, or steal" (p.546). Likewise, Newton (2001) stated that trust made it possible to maintain peaceful and stable social relations which were fundamental for "collective behavior and productive 
cooperation" (p.202). Social trust serves as a vital mechanism to engage people and to get them involved in community activities - "people's connections with the life of their communities, not only with politics" (Putnam, 1996, p.1). Furthermore, Goddard (2003) explained that social trust provides group members confidence in the expectation that others would act reliably and competently. In Goddard's study, individuals engaged in relationships which were characterized by a high degree of social trust were more likely to exchange information and to act caringly toward one another than those who lacked trust.

\section{II.ii.iii. Cultural Capital}

Cultural capital in this study is based on a study conducted by Throsby wherein he defined cultural capital as "an asset that contributes to cultural value" (Throsby, 1999, p. 4). More importantly, cultural capital is "the stock of cultural value embodied in an asset" (Throsby, 1999, p.4). This "asset" can be categorized into two forms tangible and intangible. Tangible cultural capital existed in buildings, structures, and locations endowed with items of cultural significance, such as paintings, sculptures, or other objects (Throsby, 1999). In contrast, intangible cultural capital consists of the set of ideas, practices, beliefs, traditions, and values that contributed to identify and tie a given group of people together (Throsby, 1999). This study is specifically interested in the intangible cultural capital since this form is expected to reflect the cognitions, expectations, and performances of immigrants similar to natives (Prieto, Sagafi-nejad, \& Janamanchi, 2013).

As mentioned earlier, intangible cultural capital represents the set of values that play an important role in acculturation research (Leong \& Ward, 2006). Berry (2003) stated that acculturation was initially developed from a concern for "the effects of 
European domination of colonial and indigenous peoples" (p.17). Later, the focus was on how immigrants voluntarily and involuntarily changed after their entry and settlement into receiving societies (p.17). Currently, acculturation has been involved with "how ethno-cultural groups relate to each other and change as a result of their attempts to live together in culturally pluralistic societies" (p.17). Acculturation was proposed as a multidimensional process of moving from one cultural identity to another over time based on cultural practices, values, and identifications (Kang, 2006; Schwartz et al., 2010).

According to Berry's acculturation concept (2005), acculturation is divided into two levels - at the group level and at the individual level (p.698-670). First, the group level relates to changes in social structures and institutions, and in cultural practices. Second, the individual level relates to the behavioral repertoire of an individual. Therefore, acculturation represents a process of cultural and psychological changes over time that involve various forms of mutual accommodation, leading to long-term psychological, and sociocultural adaptations between two groups - the ethnic identity group and the mainstream cultural identity group. The practices of acculturation could take place in various contexts, such as time periods, communication styles, power, and forms of knowledge and knowing (Prieto, Sagafi-nejad, \& Janamanchi, 2013).

Furthermore, Berry (2005) further explained that while acculturation is a process that has endured for as long as there have been culturally different groups in contact with each other, longer-term adaptations to living in culture-contact setting takes various forms, such as learning each other's language, sharing each other's food preferences, adopting forms of dress, and social interactions based on the characteristics of each group. As a matter of fact, these adaptations created culture conflict and acculturative stress during intercultural interactions. Therefore, there were large group 
and individual preferences in the way that affected how individuals selected their acculturation (strategies) and the degree to which they reached satisfactory adaptations. In this sense, acculturation frequently proceeds at different rates and into different goals that sometimes lead to an increase of conflict and stress, which adds difficulty to the process of adaptation.

Valdivia et al. (2008) indicated that acculturation plays an important role in cultural capital because the concept of acculturation provides a framework for understanding "how individuals change or adapt their beliefs, attitudes, and behaviors" when they live in a new context (Valdivia et al., 2008, p.1320). Valdivia and Flores (2012) pointed out that a model of multidimensional acculturation has several strategies in acculturation (i.e. integration, assimilation, separation, or marginalization). During intergroup contact, the interactive acculturation model proposed that "interpersonal and inter-group relations, which may be harmonious, problematic, or conflictual, depending on the combination of acculturation orientations adopted by immigrant and host community members" (Bourhis et al., 2009, p.444). These acculturation strategies assumed that ethno-cultural groups and their members have the freedom to choose how they want to acculturate (Berry, 2003). Additionally, these acculturation strategies include the degree of adaptation to origin communities and receiving communities (Valdivia \& Flores, 2012). Based on the acculturation strategies employed, individuals and their groups can hold varying attitudes towards the four ways of acculturating (i.e. integration, assimilation, separation, or marginalization) and their actual behaviors may vary correspondingly (Berry, 1997). 
Zagefka and Brown (2002) further explained that the four acculturation strategies, according to Berry' acculturation framework, are: (1) the integration strategy refers to immigrants who wish to maintain their original cultural identify, but at the same time are interested in interacting with host community; (2) the separation strategy refers to immigrants who place a high value on maintaining their original cultural identity and tend to avoid interactions with host community; (3) the assimilation strategy refers to immigrants who do not choose to maintain their original cultural identity, but rather seek to assume the cultural identity of the host community; and (4) the marginalization refers to immigrants who are not connected to their original cultural identity and are unable to assume the cultural identity of the host community, as illustrated in Table 1.

Table 1

Four Orientations based on the Degree of Identification with Both Ones' Own Ethnic Group and the Majority Group

\begin{tabular}{|c|c|c|}
\hline \multirow{2}{*}{$\begin{array}{l}\text { Identification with majority } \\
\text { group }\end{array}$} & \multicolumn{2}{|c|}{ Identification with ethnic group } \\
\hline & Strong & Weak \\
\hline Strong & $\begin{array}{l}\text { Acculturated } \\
\text { Integrated } \\
\text { Bicultural }\end{array}$ & Assimilated \\
\hline Weak & $\begin{array}{l}\text { Ethnically identified } \\
\text { Ethnically embedded } \\
\text { Separated } \\
\text { Dissociated }\end{array}$ & Marginal \\
\hline
\end{tabular}

To better understand acculturation, individuals need to recognize the interactional context in which it occurs. Schwartz and colleagues (2014) asserted that the interactional context comprises of the characteristics of the immigrants themselves, the groups or countries from which they originated, their socioeconomic, resources in the receiving country and local community in which they have settled down, and 
fluency in the language of their host communities. These four ways of acculturating may help to better explain how Latino parents have adapted themselves in their new receiving context which may influence the education of their children. For example, the assessment of language use for English and Spanish by Latino parents has been associated with linguistic proficiency (e.g. how often did you speak English/Spanish). Kang (2006) asserted that language was viewed as one of the most important components of ethnic identity and has been measured across acculturation instruments. The current literature has shown that language competence has a positive impact on adjustment as measured by language use and proficiency.

Furthermore, ethnic identity in this study has been represented as cultural capital. Ethnic identity is defined as a "strong, positive perceive connection to one's ethnic group that promotes sharing of the predominant beliefs, attitudes, and values of that specific group" (Change \& Le, 2010, p. 486). In a cultural context, ethnic identity could be emphasized as language, behavior, values, and knowledge of ethnic group history (Phinney, 1990). Chiswick (2009) stated that there is an important relationship between religion, language, and ethnicity which was likely to connect to two aspects of group identity: one, passing on an ethnic language and the formation of religious human capital during childhood and two, youth as central functions of the family and community.

Ethnic identity has appeared to be an important issue in higher education in the United States (Brouillad \& Hartlaub, 2006). Empirical studies have shown that ethnic identity was associated with a child's education (Kao \& Tienda, 1995; Grindal \& Nieri, 2015; Schuller, 2015). In the context of immigrant parents, Schuller (2015) asserted that the way parents influence the academic achievement of their children has been affected by the degree of cultural integration of the parents. This can manifest itself in 
the sense of belonging the parents maintain to the host country and the cultural traits they retain from their country of origin. Furthermore, immigrant parents with a more grounded association to the host country (language and customs) may have been better able to motivate their children because they tend to be more fluent in the language of the host country and are more familiar with the local schooling system. They also tend to experience fewer problems with cultural differences (Schuller, 2015). Chiswick's model of ethnic identity in Schuller (2015) illustrated that parents who were deeply rooted in their own culture from their country of origin (minority identity) were likely to specialize in the development of ethnic skills of children which relies on cultural tension between majority and minority cultural identity.

Likewise, Kao and Tienda (1995) suggested that second-generation immigrant youth succeeded academically because they had the optimism of their immigrant parents and were more proficient in English. The children of immigrant parents may benefit from a strong parental ethnic identity because it increases individual well-being and self-esteem which are beneficial for the educational achievement of children (Schuller, 2015). For example, Guzman, Santiago-Rivera, and Hasse (2005) suggested that Latino youth who had more interaction with other ethnic groups (not just Whites) demonstrated more positive attitudes toward education, school, and had higher GPAs. However, Latino youth may also develop a strong ethnic identity, engage in ethnic behaviors, and hold a separate and distinct preference for or against interacting with members of other ethnic groups. Additionally, foreign and U.S born parents differ in the extent to which they supervised the behavior of their children. For example, immigrant parents tended to speak less to their children about their current school experiences or their plans for high school or higher education. Furthermore, foreign parents were less likely to have rules about maintaining a grade point average or about 
completing homework than native parents. In this sense, immigrant parents were more focused on nonacademic responsibilities such as household chores which tended to compete with academic responsibilities (Kao \& Tienda, 1995).

\section{II.ii.iv. Financial Capital}

The term financial capital has been defined as resources that may be converted into monetary instruments that are either highly liquid or could be easily converted into other asserts (Flora \& Flora, 2013). Danes and colleagues (2009) defined family financial capital as a combination of "monetary and physical assets" owned by family members (p.204). Financial assets refer to cash or assets readily converted into cash including the pooled-money of an entrepreneur or funds from financial institutions. Physical assets are less readily converted into cash, such as real estate, equipment, or production infrastructure. Therefore, financial capital provides families with the security and capacity to enhance their quality of living (Lerman \& McKernan, 2008).

In the context of education, family financial capital has been a crucial predictor for a child's academic success ( $\mathrm{Li}, 2007)$. Wealthy families are more likely to have the ability and the accessibility to resources that contribute to better learning opportunities for their children. For example, privileged parents can afford textbooks, summer enrichment camps, or tutoring for their children's education (Willingham, 2012). Parents with high financial capital were more likely to keep their children in school for longer than those with less family capital (Parcel \& Dufur, 2001). Likewise, according to Swartz (2009) adult children with wealthy families were more likely to receive a great deal of financial support than those from less advantaged backgrounds. For example, privileged parents are able to pay for their children's education, rent, health and car insurance, plus provide other monetary gifts, while less advantaged parents 
struggled with payments for essential items for their children. Many youths of working and lower-class families also had parents who invested in family time and geared those resources toward the success of their children (Swartz, 2009). This is because their parents were more limited in material resources, so the assistance the parents provided was generally through services, such as babysitting or co-residence in the parental home, while the adult children looked for a job, finished school, or saved money for a house (Swartz, 2009). Espinoza (2012) indicated that some children who came from low-socioeconomic status and racial/ethnic backgrounds did not complete high school. However, some disadvantaged children still found their way to college. The implication of disadvantaged children in educational achievement was seen as a result of social class backgrounds of their parents.

There has been an assumption which held that "the acquisition of educational goods and services purchased by the household are, in fact, an investment in human capital" (Huston, 1995, p.51). An increase in human capital could make the home and workplace productive both in quantity and quality. Thus, the level of expenditure is one indicator of the significance of education to the household (Huston, 1995). Household investments in child education creates both indirect and direct costs. The indirect or less visible costs are referred to as opportunity costs, known as forgone earnings. Direct or visible costs include tuition fees and expenditures on textbooks and stationery (Tilak, 2002). According to Fawcett's The Value of Children and the Transition to Parenthood cited in Pollmann-Schult (2014), there are three major types of cost in child development - time costs, psychological costs, and financial costs. Time costs refer to the great deal of time and attention given to children demand, generally manifesting itself as increased time spent on household chores and caregiving. Time costs also increased workload for women in most countries. Psychological costs manifest 
themselves in that the time spent parenting generates stress and strain. This study found that parents showed a higher prevalence of depression and anger than those who did not have a child. In addition, raising children is expensive and places significant stress on family finances which may lead to a decrease in life satisfaction. The financial costs of having children consist of direct costs - clothing, education, and nourishment - as well as opportunity costs, such as the unearned wages of parents who left their job or reduced their working hours (Pollmann-Schult, 2014, p.4). There are a variety of factors that influence household investment in education. In terms of economic factors, households primarily invested in the education of their children when they anticipated economic and non-economic benefits from education. The net economic benefits of education are assessed in terms of internal rates of return to education (Tilak, 2002). Additionally, if the income of the household is low, an effective demand for education could be low and could lead a serious under-investment in education for their children. As a result, households may or may not be willing to borrow money for children education (Tilak, 2002). However, when households spent fewer dollars on educational investments it did not mean they valued education less than households which allocated more dollars to education (Huston, 1995). These factors simply influenced household decision-making toward investment in education.

The allocation decisions made within a family are influenced by resources or assets that individual decision-makers bring to the family. For example, the distribution of income between partners can be allocated by each decision-maker to maximize his or her own utility (Bobonis, 2009). Bobonis (2009) indicated that among low and moderate-income households in Mexico, incomes of female partners went entirely into the common fund of the household because social norms obligated them to allocate their income to meet the collective rather than individual consumption needs. In 
contrast, male partners were more likely to control their own earned income, while contributing to a household common fund utilized to cover basic household expenditures. This strategy resulted in male partners controlling how much they contributed to household expenditures. This approach is considered a unitary household resource allocation strategy, whereby the household acts as one to create well-being for their members (Dozi, 2010). One of the most highly studied unitary approaches has been parental investment in child education, particularly in the context of human capital development. Unitary approaches have been used to assess the determinants of resource allocation to the education and health production in a household for each child (Dozi, 2010).

Although some minority or immigrant groups lack financial capital, they may rely on the human and social capital of family members and friends within their ethnic communities for support (Sorenson \& Bierman, 2009). This idea is consistent with Willingham's article: Why Does Family Wealth Affect Learning? Willingham (2012) stated that common knowledge in the current literature does not always turn out to be true, particularly for in the relationship between wealth and education. Although children from affluent families did significantly better in school than children from poor families, this effect was not necessarily because of household income alone. Willingham (2012) stated that money in low-income families was not a sudden boost to the academic achievement of their children; therefore, the effect of wealth might be indirect and might accrue over time. This happens because low-income families have other forms of capital, such as human capital or social capital, which provide opportunities for their children's education. For example, parents with a lot of social capital might have friends or relatives who provide them support for their children in school. In other words, financial capital alone is not a sufficient determinant for the 
educational achievement of children from low-income families; parents instead rely on exploring other forms of family capital to help their children achieve their educational goals.

\section{II.iii. Community Perceptions}

Community perceptions in this study are represented by the context of reception. The context of reception has been defined as the "acceptance and degree of openness versus hostility" in the local community (Schwartz et al., 2010, p.15). In this sense, the perceived context of reception could cause positive and negative impacts for Latino parents regarding satisfaction with the development of their children in school. In a positive context of reception, Latino parents and their children would be more welcomed by the community and school. On the other hand, if Latino parents and their children experienced discrimination or hostility, then they may be influenced about how they make a living and take decisions on the education of their children (Valdivia \& Flores, 2012; Schwartz et al., 2010; Adair, 2015).

Schwartz and colleagues in Perceived Context of Reception among Recent Hispanic Immigrants (2014) indicated that the perceived context of reception was associated with the cultural orientations of individuals. For example, in the huge monoculture of a receiving context, immigrants fluent in English and familiar with U.S. culture and institutions were more likely to have a positive experience in the local receiving context rather than those with poor English proficiency and unfamiliarity with U.S culture and institutions. The impact of perceived context of reception can have a negative impact on the academic achievement of children. For example, a negative impact might include immigrant parents that have trouble engaging with schools due to perceived discrimination in the school. Additional negative impacts could include 
immigrant parents feel unwelcome and lack the financial and social capital to navigate new educational, health, housing, and political institutions. As a result, immigrant parents are limited in their options as they attempt to make educational decisions based on what they believe is best for their children (Adair, 2015).

Additionally, empirical studies have shown that Latino immigrants with lower income and education were more likely to be discriminated against than those with high income and education (Perez, Fortuna, \& Alegria, 2008). Likewise, Adair (2015) pointed out that children of immigrants personally experienced discrimination through individualized treatment. For example, children of immigrant parents experienced three different forms of segregation in school settings, generally being segregated by race/ethnicity (Latino and non-Latino), language, and income.

Community perceptions have influenced the perception of Latino newcomers that experience the community through a community context. Perceptions of things such as U.S. immigration policies, socioeconomic systems, labor conditions, and perceptions of receiving members shaped newcomers' perception of their community (Dozi, 2010). In this sense, Bubolz et al. (1980) explained that community environments are perceived by individuals and that individuals depend on their environments in order to satisfy needs and desires. A lot of individual behavior was comprised of the "effort to cope with, adapt to, or change environments to achieve a better person-environment fit" (p.107). Thus, this present study uses a human ecological approach to explain how individuals interact with their community environments. These interactions may reveal something about the degree of well-being of the human or community environments in which they live (Bubolz et al., 1980). 
Bronfenbrenner (2009) stated that the ecological environment is viewed as "a set of nested structures" (p.3). There are four levels in the ecology of human development; (1) microsystem; (2) mesosystem; (3) exosystem; and (4) macrosystem. These four different ecological environments served as sources of external influence on the capacity of families to foster human development in their children (Bronfenbrenner, 1986) (See Figure 4).

The first level is a "microsystem" which is the inner most level. This is "the immediate setting containing the developing person," which could be a home or a classroom (Bronfenbrenner, 2009, p.3). Bronfenbrenner (1997) stated that a microsystem is "the complex of relations between the developing person and environment in immediate setting containing that person - e.g. home, school, or workplace. A setting is defined as a place with particular physical features in which the participants engaged in particular activities in particular roles (e.g. daughter, parent, teacher, or employee). for particular periods of time" (p.514). Although the processes operate across different settings, they are dependent on each other. For example, events at home can influence the progress of children in school (Bronfenbrenner, 1986). Thus, "the factors of place, time, physical features, activity, participant, and role establish the elements of a setting" (Bronfenbrenner, 1977, p.514).

The second level is the "mesosystem" which consists of "the interrelation among major settings containing the developing person at a particular point in his or her life" (Bronfenbrenner, 1977, p.515). Bronfenbrenner (1986) asserted that the psychological development of children is influenced by what occurs in the other environments in which children spend their time and by the events that occur in other settings in which their parents live their lives, specifically in places that children may rarely enter, such as the world of work of their parents (p.723). In addition, children 
seem to have limited access to the circle of friends and acquaintances part of the social network of their parents.

The third level is the "exosystem" which is, "an extension of mesosystem embracing other specific social structures, both formal and informal, that do not themselves contain the developing person but impinge upon or encompass the immediate settings in which that person is found, and thereby influence, delimit, or even determine what goes on there" (Bronfenbrenner, 1977, p.515). These structures consist of the major societal institutions that operate at a concrete local level. They incorporate among other structures, the world of work, the neighborhood, the mass media, government agencies, the distribution of goods and services, communication and transportation facilities, and informal social networks (Bronfenbrenner, 1977, p.515).

The final level is the "macrosystem" which represents "the overarching institutional patterns of the cultures or subculture, such as the economic, social, educational, legal, and political systems, of which micro-, meso-, and exo- systems are the concreate manifestations" (Bronfenbrenner, 1977, p.515). Macrosystems are conceived and examined in structural terms and as the carriers of information and ideology that provide meaning and inspiration to particular agencies, social networks, roles, activities, and their interrelationships (Bronfenbrenner, 1977, p.515). 


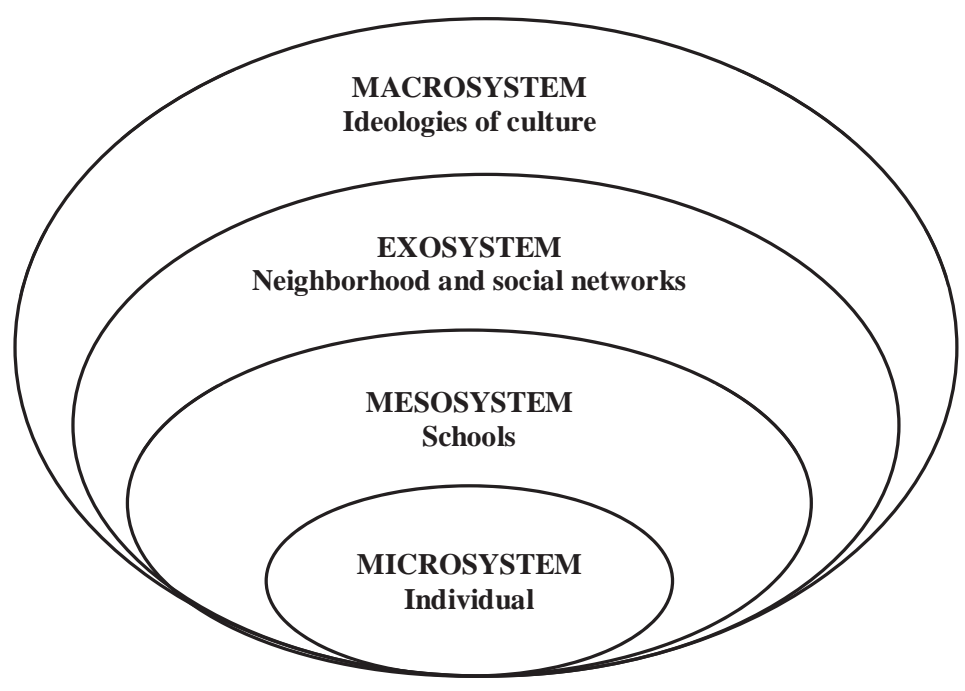

Figure 4. Bronfenbrenner's ecological model of human development. Developed from "Toward an experimental ecology of human development" by U. Bronfenbrenner, 1977, American Psychologist, 32(7), p. 513 - 514.

\section{II.iv. Gender Perspective}

Pollmann-Schult (2014) indicated that the costs of parenthood could vary between fathers and mothers since parents often turn to a traditional division of household labor where domestic household chores and caregiving are primarily accepted by mothers. On the other hand, fathers are viewed to be primarily responsible for the economic well-being of their households. In this sense, it appears that time costs for domestic household chores are disproportionally distributed to the overall costs of parenthood for women, while the financial costs for raising children are more relevant to men. Shin (2008) stated that females are considered to be the most stable and essential members for production and reproduction within the household. Nevertheless, the economic status of females is viewed as subordinate to that of male wage earners which are based upon traditional gender division of labor. Shin (2008) also found that individuals who lived in female-headed households tended to be in poverty more than 
those in other types of households. With respect to the feminization of poverty theory, there are several reasons for this situation. First, female-headed households have fewer adult wage earners because they lack a male partner. Therefore, they must depend more on welfare assistances outside of their household do than male-headed households. Second, average female earnings are lower than that of male-headed households due to differences in opportunities available to males and females in the labor market (Shin, 2008, p.4). Analysis of household budgets separated by gender of the household head indicated that female-headed households were more likely to expend a proportionally higher share of their spending on human capital development, such as education and health, compared to male-headed households (Khan \& Khalid, 2012). The literature on the division of household labor identifies the importance of time constraints, socioeconomic resources, and cultural orientations helps to better understand gendered practices and beliefs (Lam, McHale, \& Updegraff, 2012). Time constraints refer to couples who make rational decisions to assign more household chores to the spouses with more free time. Next, the spouse with more socioeconomic resources has more power to buy him/herself out of household chores according to the social exchange theory. Finally, cultural orientations suggest that culture influences behaviors and attitudes to justify the natural roles of women and men in the family (Lam, McHale, \& Updegraff, 2012).

\section{II.v. Parental Satisfaction with the Education of Children}

Although the relationship between parental satisfaction and the education of their children is intuitively clear, few studies have investigated what creates parental educational satisfaction (Friedman, Bobrowski, \& Markow, 2007). This is because most existing empirical studies have indicated that overall parental satisfaction was significantly associated with: school communication, parental involvement, academic 
achievement, curriculum, school environment, school safety, staff quality, and transportation (Friedman, Bobrowski, \& Markow, 2007). For example, parental involvement mediated the effect of poverty, parental educational attainment, and race/ethnicity on children's achievement. Thus, an increase of parental involvement has become a possible strategy for decreasing the achievement gap (Lee \& Bowen, 2006). Parental involvement at school included attending parent-teacher conferences, attending programs featuring students, and engaging in volunteer activities. Nevertheless, Coleman and Hoffer (1987) asserted that human capital was irrelevant to child outcomes because parents were either not involved in the lives of their children or the human capital employed by the parents was exclusively used at work or elsewhere outside the home.

Friedman and colleagues (2006) declared there are three predictors that influence overall parental satisfaction: (1) parents receiving adequate information from the school about their children including the level of involvement of the school and teachers in their child's education; (2) the adequacy of school; and (3) the quality of school leadership. Friedman's findings were consistent with Erickson's findings on parental satisfaction and alienation from schools. Erickson (1996) demonstrated that parental involvement in schools was significantly associated with an increased academic achievement of the children. This relationship was also impacted by the factor of race. Racial and ethnic minority groups of parents were less likely to become involved in the schools their children attended than white parents. White parents perceived their child's teacher to be better at understanding their needs as parents than the parents of minority groups. 
Erickson (1996) pointed out that a possible explanation for the low satisfaction of racial/ethnic parents in the education of their children. Racial/ethnic parents tend to report their actual levels of dissatisfaction in studies. For example, racial/ethnic parents do feel as entitled to positive interactions as White parents. In addition, they tend to perceive school personnel as "experts" or "authorities" on education to be unquestioned and these parents also possessed the cultural value to not call attention to oneself or express a negative opinion. These elements influenced some racial/ethnic parents not to complain despite feeling dissatisfaction (Erickson, 1996).

Friedman and colleagues (2006) revealed a measurement issue in many studies, counting for the satisfaction of minority group parents with the education of their children has not controlled for demographic variables. For example, factors such as parent education, gender, or the number of children in the school district were often not considered influential variables. In addition, there is an absence of studies with comprehensive samples that distinguish determinants of satisfaction of the parents or compare determinants of parents across different ethnic groups (Friedman, Bobrowski \& Geraci, 2006). Thus, there has been a knowledge gap in the existing literature that needs to be applied across ethnic groups. Understanding the similarities and differences among ethnic parental groups regarding school satisfaction is essential in appropriately understanding the data involved in researching this area. 
II.vi. Conceptual Framework of the Study

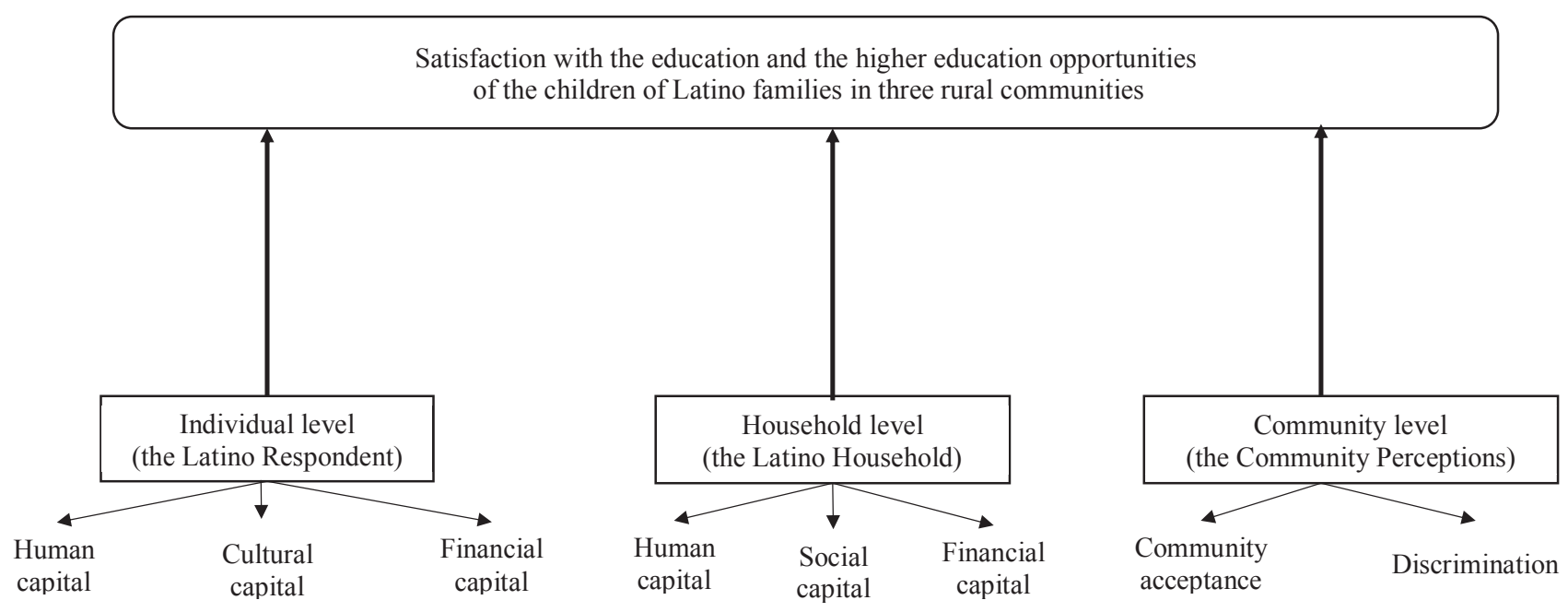

Figure 5. Conceptual Framework of the Study 
The conceptual framework (See Figure 5) is designed to examine how the different forms of capital and community perceptions influence satisfaction with the education and the higher education opportunities of the children of Latino families in three rural communities in Missouri.

The forms of capital in this framework are divided into two levels (individual and household) and this framework also includes community perceptions as community level. For the individual level, the forms of capital consist of human, cultural, and financial capital. For the household level, the forms of capital comprise of human, social, and financial capital. For the community level, community perceptions include factors such as community acceptance and discrimination. 


\section{CHAPTER III}

\section{METHODS}

\section{III.i. Study Area and Communities}

This study used a secondary data set taken from the "2008 Asset Accumulation Survey" conducted by a research team from the Cambio Center at the University of Missouri (Dozi, 2010). The survey was designed to investigate asset accumulation strategies of surveyed Latino immigrants living and working in three rural communities of Missouri, each in a different geographical area and with a unique pattern of industry (Dozi, 2010). Community A is located in Pettis County in the mid part of the state of Missouri where is the economy is heavily invested in poultry processing but has a number of employment opportunities in light manufacturing and agriculture. Community B is located in Sullivan County in the northern part of the state and is the location of a very large hog processing plant. Community $\mathrm{C}$ is located in Taney County in the southern part of the state where tourism is the primary growth industry (See Figure 6).

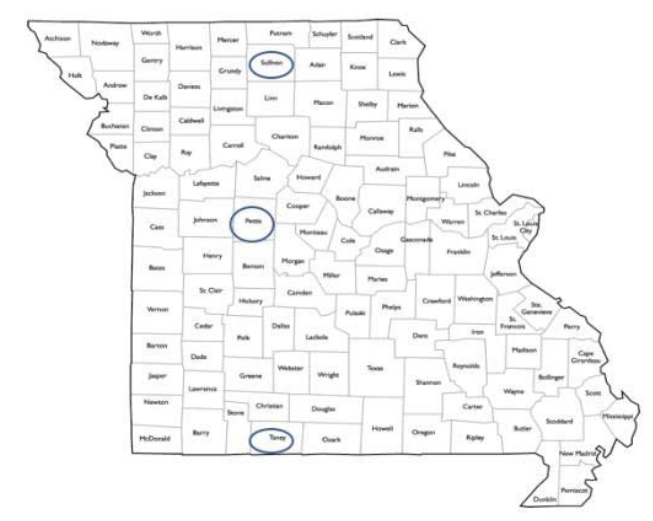

Figure 6. Map of Study Communities in Missouri

Source: http://www.worldatlas.com/webimage/countrys/namerica/usstates/counties/mocountymap.htm 
Three rural communities in Missouri were purposefully selected for the "2008 Asset Accumulation Survey" to ensure they had varying social and economic characteristics. These three communities represented a diversity of pull factor drawing newcomer immigrants to their communities.

\section{III.ii. Population and Sample}

The asset survey was conducted in 2008 and was enumerated by bilingual interviews (English and Spanish). The target population in this survey was the Latino immigrant. The total population of Pettis County in 2014 was 42,225 with Latinos comprising $8 \%$ of the population. In this same year, the population in Sullivan County was 6,411 and the population of Taney County was 54,230. Latinos accounted for $18 \%$ and $5 \%$ of these populations respectively. The Latino population in all three communities was $\leq 1 \%$ until the mid-1990s but have since seen rapid growth. Each community has been working in different ways to integrate this new population into the social, economic, and cultural fabric of their community, as shown in Table 2.

Table 2

Proportion of Latino Population by County between 1990 and 2014

\begin{tabular}{lccccccccc}
\hline \multirow{2}{*}{ County } & \multicolumn{3}{c}{ Latino population } & \multicolumn{2}{c}{ Total county population } & \multicolumn{2}{c}{$\begin{array}{c}\text { Hispanics as percent of } \\
\text { county population }\end{array}$} \\
\cline { 2 - 10 } & 1990 & 2000 & 2014 & 1990 & 2000 & 2014 & 1990 & 2000 & 2014 \\
\hline Pettis & 268 & 1,527 & 3,523 & 35,437 & 39,403 & 42,225 & $1 \%$ & $4 \%$ & $8 \%$ \\
Sullivan & 28 & 634 & 1,130 & 6,326 & 7,219 & 6,411 & $<0.5 \%$ & $9 \%$ & $18 \%$ \\
Taney & 194 & 962 & 2,981 & 25,561 & 39,703 & 54,230 & $1 \%$ & $2 \%$ & $5 \%$ \\
\hline
\end{tabular}

Note: Pew Research Center Hispanic Trends, 2017 
However, most Latino newcomers who lived in the three rural areas were a hidden and highly vulnerable population (Dozi, 2010). Thus, a snowball sampling technique was utilized to connect to the hidden population and include them in the survey. The main purpose of using this technique was to obtain participants in a population where "some degree of trust is required to initiate contact." Under these circumstances, a "chain referral" technique was used to help the research team gain and access to the hidden Latino population in the three targeted communities (Atkinson \& Flint, 2001, p.2). In addition, the Latino immigrant population in the asset survey were recruited to match characteristics representative of the population for each community reflected in the U.S. Census (Dozi, 2010).

There were two stages of sample selection in this survey. The first step was to contact local leaders and trusted organizations in each of three targeted communities (churches, community centers, and minority-serving organizations, among others) to identify potential participants based on their suggestions. Trust was needed to convince people to participate in the study and relationships were developed through "referrals" that were made by trusted local leaders, their acquaintances and/or peers. The second step was to interview all suggested participants and use referrals from the first group of participants to identify others who met the criteria needed to match the population profile of the community that could participate in the survey (Dozi, 2010). The total number of available participants in the survey across all three communities was 460 .

Data from the 2008 Asset Accumulation Survey were used in this study to examine how forms of capital affected satisfaction with the education and the higher education opportunities of the children of Latino families. This study is interested in Latinos with children in their family and used that subset of the participants in the 2008 Asset Accumulation Survey $(\mathrm{N}=460)$. The unit of analysis in this study is a family 
consisting of "a householder and one or more other people living in the same household who are related to the householder by birth, marriage, or adoption" (Lofquist, 2012, p.4). Children of the household may include biological children, adopted children, or stepchildren.

The procedures for selecting the sample from the available lists consisted of two stages, as illustrated in Figure 7. The first stage was to identify Latinos with children of any age as long as there was a parent-child relationship in the family. Narrowing the focus of the study according to this characteristic decreased the number of possible participants in the next stage of sample selection from 460 to 313 . The second stage was to choose Latinos who had children in school at any level so that only Latinos with children in school were considered as subjects for this study. There were 56 survey participants that were not included in this study because they had children at of a very young age (1-2 years old) $(n=15)$, had employed children $(n=32)$, or could not be considered because this information was missing $(n=9)$. Thus, the total sample of this study is 257 which reflected the true proportion in the population of Latinos with certain characteristics (Creswell, 2013).

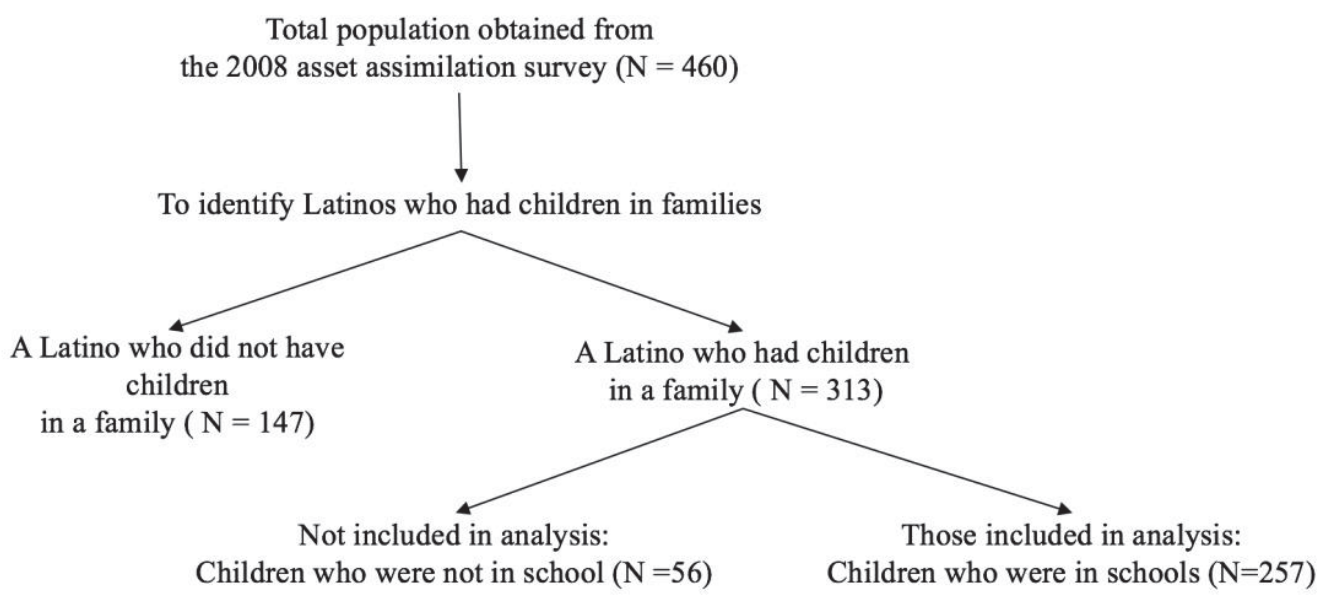

Figure 7. Process of sample selection in the present study 


\section{III.iii. Survey Instrument}

The asset survey used a close-ended questionnaire to collect data from the target population ( $\mathrm{N}=460)$. The survey questionnaire was divided into five sections: 1$)$ socioeconomic data (Q1 to Q7); 2) household, activities, and decision making (Q8 to Q27); 3) acculturation and context of reception (Q28 A-X, Q29 A-B, and Q29a (A-A1); 4) immigration, employment, and remittance (Q30 to Q68); and 5) social capital (Q70 to 95) (Dozi, 2010). The measures used in this study were developed from the questionnaire items.

\section{III.iv. Measurement of Variables}

\section{III.iv.i. Dependent Variables}

Satisfaction in this study was measured by two variables in which respondents were asked to rate their satisfaction with the education and the higher education opportunities of the children of Latino families. These two variables were used as dependent variables for the statistical analysis. The original measurement of two dependent variables of satisfaction used a 10 -point scale $(0=$ completely dissatisfied, $5=$ neither satisfied nor dissatisfied or discontent, $10=$ completely satisfied). These dependent variables were recoded from the original ten ordered categories $(0=$ completely dissatisfied, $5=$ neither satisfied nor dissatisfied or discontent, $10=$ completely satisfied $)$ to five ordered categories $(1=$ very dissatisfied, $3=$ neutral, and $5=$ very satisfied) (See Appendix A for further description of each variable). 


\section{III.iv.ii. Independent Variables}

This analysis in this study included several key independent variables in the models of satisfaction with the education and the higher education opportunities of the children of Latino families (See Appendix A for further description of each variable).

The independent variables in this analysis were divided into three levels: individual, household, and community.

1) The individual level consisted of life satisfaction, ethnic identity, acculturation strategy, and income (See Appendix A for further description of each variable).

Life satisfaction: Life satisfaction is human capital of variable. Life satisfaction was assessed with a 5-items scale with questions on the Satisfaction With Life Scale (SWLS) developed by Diener et al. (1985). The survey respondents rated items on a 7point scale ranging from "strongly disagree" (1) to "strong agree" (5). Cronbach's alpha coefficient for this five-item scale was 0.82 . These responses were averaged to a scale score which an average score $\geq 4.0$ implied that the survey respondents were more likely to be satisfied with their life.

Ethnic identity: Ethnic identity is a measure of cultural capital. Ethnic identity was measured using a 6-items scale that assessed the sense of self as a member of a specific ethnic group (Valdivia \& Flores, 2012). The survey respondents rated items on a 5-point scale ranging from "strongly disagree" (1) to "strong agree" (5). The reliability of the six-item ethnic identity scale was 0.88 , as measured by Cronbach's alpha coefficient. These responses were averaged to a scale score which an average score $>2.5$ would indicate that the survey respondents had fairly strong ties to their ethnicity. 
Acculturation strategies: Acculturation strategies are also a measure of cultural capital. The measure for the acculturation strategy was developed from the Anglo and Latino acculturation based on the Bidimensional Acculturation Scale for Hispanics (Valdivia \& Flores, 2012). Acculturation was categorized into three dimensions language use (6 items), linguistic proficiency (12 items), and media (6 items) - in which there were 12 items for the English language and 12 items for the Spanish language. The survey respondents rated items on a 4-points scale that ranging from "almost never" (1) to "almost always" (4). These responses were averaged to a scale score. Cronbach's alpha coefficient values were 0.95 and 0.81 for Anglo and Latino acculturation respectively.

The average Anglo and Latino acculturation scores were classified into four acculturation strategies by using a cut off at 2.50. The integration strategy was represented by those survey respondents who spoke English and Spanish languages well. With an average scores on Anglo and Latino acculturation of $\geq 2.5$. The separation strategy was represented by those survey respondents who did not speak English well but spoke Spanish well and had an average score on Latino acculturation of $\geq 2.5$, with an average score on Anglo acculturation of $<2.5$. The assimilation strategy was represented by those survey respondents who spoke English well but did not speak Spanish well with an average score on Anglo acculturation of $\geq 2.5$, with an average score on Latino acculturation of $<2.5$. Marginalization was represented by those who did not speak English or Spanish well and had average scores on Anglo and Spanish acculturation of $<2.5$. In this study, the integration strategy was expected to produce the best result for the survey respondents to increase the likelihood of satisfaction with the education and the higher education opportunities of the children of Latino families. 
Income: Income is a measure of financial capital used to assess how wealthy they were. The survey respondents were asked about their last year income. Income was expected to be associated with satisfaction with the education and the higher education of the children.

In addition, survey respondents provided information about marital status that was recoded $(0=$ single, $1=$ otherwise $)$, length of residence was measured in years. Children in the family were measured as the total number of children. Gender was $\operatorname{coded}(0=$ male, $1=$ female $)$, and place of living was recorded $(0=$ community $\mathrm{A}, 1=$ otherwise).

In this study, community A was selected to compare with other communities because community A had the most diversity in population. In the context of education in the three rural communities between 2008 and 2009, Community A in Pettis County had a total enrollment of 4,486 students in 2008 and stood at approximately the same level as in 2009, with 4,441 students. Community B in Sullivan County, the enrollment of students totaled 685 in 2008 and increased to 744 in 2009. Community C in Taney County, the enrollment of students slightly increased from 4,028 in 2008 to 4,154 in 2009 (See Table 3). 
Table 3

School Demographic Data between 2008 and 2009 in Three Rural Community by Race/Ethnicity

\begin{tabular}{lrrrrrr}
\hline & \multicolumn{2}{c}{ Community A } & \multicolumn{2}{c}{ Community B } & \multicolumn{2}{c}{ Community C } \\
\cline { 2 - 7 } & $\mathbf{2 0 0 8}$ & $\mathbf{2 0 0 9}$ & $\mathbf{2 0 0 8}$ & $\mathbf{2 0 0 9}$ & $\mathbf{2 0 0 8}$ & $\mathbf{2 0 0 9}$ \\
\hline Total Enrollment & 4,441 & 4,486 & 685 & 714 & 4,028 & 4,154 \\
Asian Percent & $*$ & $*$ & $*$ & $*$ & $*$ & $*$ \\
Black Percent & 7.2 & 7.1 & $*$ & $*$ & $*$ & $*$ \\
Hispanic Percent & 10.9 & 10.9 & 34.2 & 38.5 & 7.8 & 8.3 \\
Indian Percent & $*$ & $*$ & $*$ & $*$ & $*$ & $*$ \\
Multi-race Percent & $*$ & $*$ & $*$ & $*$ & $*$ & $*$ \\
Pacific Islander Percent & $*$ & $*$ & $*$ & $*$ & $*$ & $*$ \\
White Percent & 80.9 & 81.3 & 64.8 & 60.9 & 87.4 & 86.7 \\
\hline Note: $*$ Indicates the number/percent has been suppressed due to a potential small & &
\end{tabular}

The percentage of students enrolled by race/ethnicity indicated that White student enrollment in the school in community A, increased from $80.9 \%$ in 2008 to $81.3 \%$ in 2009, while the enrollment of Hispanic students did not change between 2008 and 2009, with $10.9 \%$, and Black student enrollment slightly decreased from $7.2 \%$ in 2008 to $7.1 \%$ in 2009 . For community B, the enrollment of White students in the school declined from $64.8 \%$ in 2008 to $60.9 \%$ in 2009 . The number of enrollment in the school among Hispanic students increased from $34.2 \%$ in 2008 to $38.5 \%$ during the same period. For community $\mathrm{C}$, the enrollment of White students in the school increased from $87.4 \%$ in 2008 to $86.7 \%$ in 2009 and the population of Hispanic student enrollment, which increased from $7.8 \%$ in 2008 to $8.3 \%$. There was no information for Indian, Multi-race, and Pacific Islander students.

There are many types of schools in community A, including a childhood school, five elementary schools, one middle school, and one high school. On the other hand, community B has only one school for each type of school: elementary, middle, and high 
school, whereas community $\mathrm{C}$ has a variety of schools, such as one kindergarten center, one primary, one elementary, one junior, one intermediate, and one high school (CityData, 2017)

2) The household level: this included the forms of capital possessed by the Latino household and included variables such as parental employment, parental education, parental English proficiency, recreational/sport associations, informal groups of friends, formal associations, and education expenditure (See Appendix A for further description of each variable).

Parental employment: Parental employment as human capital was measured by the employment status of fathers and mothers. Parental employment status was coded as $(0=$ either parent worked, $1=$ otherwise $)$.

Parental education: Parental education as human capital was estimated to increase the likelihood of satisfaction with the education and the higher education opportunities of the children of Latino families. Education of mothers and fathers was recoded into the number of years of schooling by using a high-point for the response categories indicating an educational attainment level. The numbers of years of schooling of mothers and fathers were averaged as a maximum level of educational achieved by two parents or either parent.

Parental English proficiency: Parental English proficiency was measured with a 3-item scale and also represented human capital. The survey respondents rated English proficiency on a-4-point scale ranging from "not well" (1) to "very well" (4) to indicate how well they were in speaking, writing, and reading in English. They also provided a rating for their spouses. Cronbach's alpha coefficient values were 0.93 and 0.95 for the survey respondents and their spouses respectively. The responses for each subscale were averaged to obtain subscale scores for the survey respondents and their 
spouses. In this study, parental English proficiency would use an average score achieved by two parents or either parent.

Recreational/sport associations: Recreational/sport associations were used as a measure of bridging social capital that used a dichotomous scale $(0=$ not being a member, 1 = otherwise). Survey respondents identified whether or not they or their family members if they were members of recreational/sport associations.

Informal groups of friends: informal groups of friends were included as a measure of bonding social capital assessed using a dichotomous scale $(0=$ not being a member, $1=$ otherwise). Survey respondents identified for themselves or their family members as members of informal groups of friends.

Formal associations: Formal associations as bridging social capital was measured using a dichotomous scale $(0=$ not being a member, $1=$ otherwise $)$. Survey respondents identified for themselves or their family members as members of formal associations.

Education expenditure: education expenditure as financial capital was measured on a continuous scale. Survey respondents provided a total amount of money that their family had allocated resources for the education of their children.

3) Community level: this represented community perceptions including variables that measured perceptions of the context of reception in the areas of community acceptance and discrimination (See Appendix A for further description of each variable).

Community acceptance: community acceptance was measured with five items using a 7-point scale ranging from "strongly disagree" (1) to "strongly agree" (7) with Cronbach's alpha coefficient of 0.81 . These responses were averaged to a scale score. 
If the score average $\geq 4.0$, it indicated that survey respondents were more welcome in the community.

Discrimination: discrimination was measured with a 6-item using a scale ranging from "strongly disagree" (1) to "strongly agree" (7). Cronbach's alpha coefficient was 0.92 . These responses were averaged to a scale score where an average score $\geq 4.0$ indicated that survey respondents were more likely to have experience with discrimination in the community.

Table 4

Lists of Variables Included in Ordinal Logistic Regression Models

\begin{tabular}{|c|c|}
\hline Variables & Description \\
\hline \multicolumn{2}{|l|}{ Dependent variables } \\
\hline $\begin{array}{l}\text { Satisfaction with the education of the } \\
\text { children }\end{array}$ & $\begin{array}{l}\text { "1" for very dissatisfied, " } 2 \text { " for dissatisfied, " } 3 \text { " for neither } \\
\text { dissatisfied nor satisfied, " } 4 \text { " for satisfied, and "5" very } \\
\text { satisfied. }\end{array}$ \\
\hline $\begin{array}{l}\text { Satisfaction with the higher education } \\
\text { opportunities of the children }\end{array}$ & $\begin{array}{l}\text { "1" for very dissatisfied, " } 2 \text { " for dissatisfied, " } 3 \text { " for neither } \\
\text { dissatisfied nor satisfied, " } 4 \text { " for satisfied, and " } 5 \text { " very } \\
\text { satisfied. }\end{array}$ \\
\hline \multicolumn{2}{|l|}{ Independent variables } \\
\hline Individual level & The Latino respondents \\
\hline Life satisfaction index & Life satisfaction score, an average of 5 items \\
\hline Ethnic identity index & Ethic identity score, an average of 6 items \\
\hline Acculturation strategy & If used the integration strategy $=0,1=$ otherwise \\
\hline Income & Total amount of last year income in dollars \\
\hline Gender & Gender of a respondent: $0=$ Male, $1=$ otherwise \\
\hline Marital status & If being a single $=0,1=$ otherwise \\
\hline Residential status & If held a legal status $=0,1=$ otherwise \\
\hline Length of residence & Length of residence in the community in years \\
\hline Place of living & If lived in community $\mathrm{A}=0,1=$ otherwise \\
\hline Children in the family & Number of Children in the family \\
\hline Household level & The Latino household \\
\hline Parental employment status & If either father or mother not working $=0,1=$ otherwise \\
\hline Parental education & Education attainment, average years of schooling \\
\hline Parental English proficiency & English proficiency, average English proficiency \\
\hline Recreational/sport associations & If not being a member $=0,1=$ otherwise \\
\hline Informal groups of friends & If not being a member $=0,1=$ otherwise \\
\hline Formal associations & If not being a member $=0,1=$ otherwise \\
\hline Education expenditure & Total amount of education expenditure \\
\hline Community level & Community perceptions \\
\hline Community acceptance index & Community acceptance, an average of 5 items \\
\hline Discrimination index & Discrimination score, an average of 6 items \\
\hline
\end{tabular}

Note: further description of each variable in Appendix A. 


\section{III.v. Qualitative Data}

In this study, focus group results from the 2008 Asset Accumulation project were used to provide more detailed information about the context of the communities. These results were used in the discussion phase to explore how individuals described or felt about a particular topic and provide context to the quantitative results. In this way, some of the quantitative results could be explained in more detail through the qualitative data (Wisdom \& Creswell, 2013).

The qualitative interviews and discussions with individuals were collected in each of the three rural communities. These discussions focused on perspectives on wellbeing, the context of reception, and the impact of social networks and local institutions in Latinos' daily lives (Dozi, 2010). The focus groups were conducted separately for men and women in each community because of the sensitive nature of the topics being brought up and to acknowledge the cultural capital of Latinos (Dozi, 2010). The focus group sessions were facilitated in Spanish and interviews were transcribed and translated into English.

There were a total of 46 Latino immigrant participants in the focus groups (25 females and 21 males). Most focus group participants were married (63\%) and completed school at least $7^{\text {th }}-9^{\text {th }}$ grade $(47.8 \%)$. The average age of participants was 39.93 years and ranged from 18 through 63 years of age $(S D=12.11)$. Average years in the U.S. was 12.04 years ranging from 1 to 44 years $(\mathrm{SD}=10)$. The average number of children in the family was 2.79 and ranged from 0 through $8(\mathrm{SD}=2.18)$. 


\section{III.vi. Data Analyses}

An ordinal logistic regression was used to answer the specific research questions of this study. Descriptive statistics were used to summarize and describe data in a meaningful way (Agresti \& Finlay, 2014). There were two dependent variables in this analysis (satisfaction with the education and with the higher education opportunities of the children of Latino families) and both were measured on a 10-point scale $(0=$ completely dissatisfied, $5=$ neither satisfied nor dissatisfied or discontent, $10=$ completely satisfied). Since each possessed a natural order ordinal logistic regression was appropriate to use for the subsequent analysis (Kleinbaum \& Klein, 2010). Ordinal logistic regression was geared toward the two dependent variables with ordinal effect since ordinal logistic regression works with the cumulative distribution of the dependent variables. Furthermore, the parameter of the ordinal logistic regression was fitted for each association, representing the general trend across the ordinal values of the two dependent variables (Warner, 2008).

When using ordinal logistic regression, there are four main assumptions that must be considered (Laerd Statistics, 2017): (1) the outcome variable is measured on an ordinal level; (2) the predictor variables can be either continuous, categorical or ordinal; (3) there should be no multicollinearity, with two or more predictor variables highly correlated with each other; and (4) proportional odds (PO) that each predictor variable has identical effect at each cumulative split of the ordinal outcome variable.

These four primary assumptions of the ordinal logistic regression were tested and the results show that all assumptions were not violated:

Assumption 1: two outcome variables with ten ordered categories $(0=$ completely dissatisfied, $5=$ neither satisfied nor dissatisfied or discontent, $10=$ completely satisfied). Since the original ordered categories contained small numbers in 
several individual categories it was necessary to collapse categories of outcome variables. Because of this concern, the two outcome variables included in this analysis were collapsed into five ordered categories $(1=$ very dissatisfied, $3=$ neutral, and $5=$ very satisfied) in order to "increase the number of observations in individual categories and improve the asymptotic approximation used in the standard maximum likelihood analysis" (Murad et al., 2003, p. 155) (See Figure 8).

\section{Collapsing outcome variables from ten ordered categories to five ordered categories}

\begin{tabular}{l|l|l|l|l|l|l|l|l|l|l|}
$\longleftarrow$ & very dissatisfied & neutral & very satisfied $\longrightarrow$ \\
\hline 0 & 1 & 2 & 3 & 4 & 5 & 7 & 8 & 9 \\
\hline
\end{tabular}

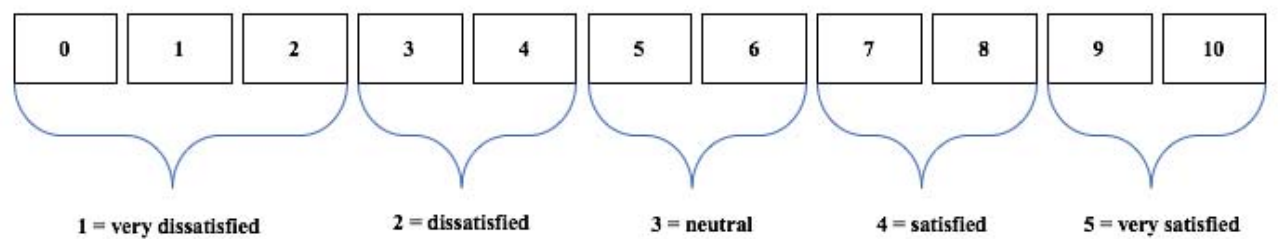

Figure 8. Collapsing outcome variables from ten ordered categories to five ordered categories

Assumption 2: all predictor variables in this analysis consisted of continuous and dichotomous scales (See Table 4).

Assumption 3: there were no multicollinearity issues between independent variables by using variance inflation factors (VIF) to detect multicollinearity. The results of multicollinearity testing with tolerance and variance inflation factors (VIF) are shown in Table 5. 
Table 5

Multicollinearity Testing with Tolerance and Variance Inflation Factors (VIF)

\begin{tabular}{|c|c|c|c|c|}
\hline \multirow[t]{3}{*}{ Independent variables } & \multicolumn{2}{|c|}{$\begin{array}{c}\text { Satisfaction with } \\
\text { children's education }\end{array}$} & \multicolumn{2}{|c|}{$\begin{array}{l}\text { Satisfaction with } \\
\text { children's higher } \\
\text { education opportunities }\end{array}$} \\
\hline & \multicolumn{2}{|c|}{ Collinearity statistics } & \multicolumn{2}{|c|}{ Collinearity statistics } \\
\hline & Tolerance & VIF & Tolerance & VIF \\
\hline \multicolumn{5}{|l|}{ Individual level: } \\
\hline Life satisfaction index & 0.63 & 1.58 & 0.61 & 1.64 \\
\hline Ethnic identity index & 0.74 & 1.36 & 0.71 & 1.42 \\
\hline Acculturation strategy & 0.71 & 1.41 & 0.71 & 1.42 \\
\hline Income & 0.74 & 1.35 & 0.73 & 1.36 \\
\hline Gender & 0.80 & 1.26 & 0.79 & 1.27 \\
\hline Marital status & 0.69 & 1.44 & 0.69 & 1.46 \\
\hline Residential status & 0.85 & 1.18 & 0.85 & 1.17 \\
\hline Length of residence & 0.74 & 1.34 & 0.71 & 1.42 \\
\hline Place of living & 0.75 & 1.33 & 0.71 & 1.40 \\
\hline Children in the family & 0.89 & 1.13 & 0.87 & 1.15 \\
\hline \multicolumn{5}{|l|}{ Household level: } \\
\hline Parental employment status & 0.69 & 1.46 & 0.68 & 1.46 \\
\hline Parental education & 0.69 & 1.45 & 0.68 & 1.47 \\
\hline Parental English proficiency & 0.69 & 1.45 & 0.68 & 1.47 \\
\hline Recreational associations & 0.80 & 1.25 & 0.77 & 1.30 \\
\hline Informal group of friends & 0.82 & 1.21 & 0.81 & 1.23 \\
\hline Formal associations & 0.89 & 1.13 & 0.88 & 1.13 \\
\hline Education expenditure & 0.88 & 1.13 & 0.85 & 1.18 \\
\hline \multicolumn{5}{|l|}{ Community level: } \\
\hline Community acceptance index & 0.57 & 1.75 & 0.57 & 1.74 \\
\hline Discrimination index & 0.71 & 1.41 & 0.69 & 1.45 \\
\hline
\end{tabular}

Note: The total number of samples of the present study $(\mathrm{N}=257)$.

The overall results of multicollinearity testing show that tolerance and variance inflation factors (VIF) were quite satisfactory. Schroeder (1990) asserted that variables with a small tolerance $<0.1$ must be discarded; however, all independent variables in this analysis were $>0.1$ indicating correlation was low so that these variables should be retained in the models. At the same time, VIF among all independent variables were 
$<10$ indicating that there were no multicollinearity issues. In other words, all independent variables were kept in the models.

According to the Pearson correlation (Table 6), the correlation coefficient values ranked from -0.01 to 0.48 which indicated that there were weak relationships between these variables. The Pearson correlation coefficient is measured on a scale with no units and can take a value from -1 through 0 to +1 . A correlation coefficient of zero can indicate that there is no linear association between the two variables, that is, they are uncorrelated (Sedgwick, 2012). 
Table 6

Summary of Pearson's Correlation Coefficient

\begin{tabular}{|c|c|c|c|c|c|c|c|c|c|c|c|c|c|c|c|c|c|c|c|}
\hline Measure & 1 & 2 & 3 & 4 & 5 & 6 & 7 & 8 & 9 & 10 & 11 & 12 & 13 & 14 & 15 & 16 & 17 & 18 & 19 \\
\hline \multicolumn{20}{|l|}{ Individual level: } \\
\hline 1. Life satisfaction index & --- & 0.10 & -0.06 & 0.14 & -0.05 & 0.21 & -0.01 & 0.14 & 0.04 & 0.06 & 0.06 & 0.02 & 0.04 & 0.07 & 0.16 & -0.07 & 0.01 & 0.48 & -0.24 \\
\hline 2. Ethnic identity index & 0.10 & --- & 0.01 & 0.06 & -0.18 & 0.02 & -0.07 & 0.18 & -0.11 & -0.06 & 0.03 & 0.02 & -0.14 & 0.13 & 0.18 & 0.08 & 0.05 & 0.12 & 0.16 \\
\hline 3. Integration strategy & -0.06 & 0.01 & --- & -0.20 & 0.05 & 0.14 & -0.01 & -0.14 & 0.15 & 0.03 & 0.12 & -0.32 & 0.14 & -0.02 & 0.06 & 0.04 & -0.09 & -0.12 & 0.09 \\
\hline 4. Income & 0.14 & 0.06 & -0.20 & --- & -0.20 & 0.03 & -0.05 & 0.22 & 0.05 & 0.04 & 0.01 & 0.13 & 0.07 & 0.02 & -0.06 & 0.09 & -0.06 & 0.21 & -0.17 \\
\hline 5. Gender & -0.05 & -0.18 & 0.05 & -0.20 & --- & -0.19 & -0.01 & 0.00 & 0.01 & 0.02 & -0.16 & 0.09 & 0.00 & -0.16 & -0.16 & -0.04 & 0.04 & -0.05 & 0.03 \\
\hline 6. Marital status & 0.21 & 0.02 & 0.14 & 0.03 & -0.19 & --- & 0.03 & -0.10 & 0.15 & -0.04 & 0.32 & -0.10 & 0.06 & 0.09 & 0.10 & 0.00 & 0.10 & 0.10 & -0.07 \\
\hline 7. Residential status & -0.01 & -0.07 & -0.01 & -0.05 & -0.01 & 0.03 & --- & -0.14 & 0.01 & -0.08 & -0.19 & 0.00 & 0.05 & -0.12 & 0.03 & -0.03 & -0.17 & -0.05 & 0.02 \\
\hline 8. Length of residence & 0.14 & 0.18 & -0.14 & 0.22 & 0.00 & -0.01 & -0.14 & --- & -0.15 & -0.04 & 0.15 & 0.11 & -0.09 & 0.03 & -0.02 & 0.05 & 0.19 & 0.10 & -0.03 \\
\hline 9. Place of living & 0.04 & -0.11 & 0.15 & 0.05 & 0.10 & 0.15 & 0.01 & -0.15 & --- & -0.04 & 0.14 & 0.04 & 0.12 & 0.02 & -0.02 & -0.11 & -0.15 & -0.04 & 0.01 \\
\hline $\begin{array}{l}\text { 10. Children in the family } \\
\text { Household level: }\end{array}$ & 0.06 & -0.06 & 0.03 & 0.04 & 0.02 & -0.04 & -0.08 & -0.04 & -0.04 & --- & -0.05 & -0.13 & 0.01 & -0.08 & -0.01 & 0.05 & 0.07 & 0.12 & -0.15 \\
\hline 11. Parental employment & 0.06 & 0.03 & 0.12 & 0.01 & -0.16 & 0.32 & -0.19 & 0.15 & 0.14 & -0.05 & -- & 0.06 & -0.10 & 0.22 & 0.00 & 0.02 & 0.01 & 0.03 & -0.06 \\
\hline 12. Parental education & 0.02 & 0.02 & -0.32 & 0.13 & 0.09 & -0.10 & 0.00 & 0.11 & 0.04 & -0.13 & 0.06 & --- & -0.27 & 0.01 & -0.05 & 0.12 & 0.09 & -0.02 & 0.02 \\
\hline $\begin{array}{l}\text { 13. Parental English } \\
\text { proficiency }\end{array}$ & 0.04 & -0.14 & 0.14 & 0.07 & 0.00 & 0.06 & 0.05 & -0.09 & 0.12 & 0.01 & -0.10 & -0.27 & --- & -0.07 & -0.02 & -0.09 & -0.08 & 0.01 & -0.11 \\
\hline $\begin{array}{l}\text { 14. Recreational/sport } \\
\text { association }\end{array}$ & 0.07 & 0.13 & -0.02 & 0.02 & -0.16 & 0.09 & -0.12 & 0.03 & 0.02 & -0.08 & 0.22 & 0.01 & -0.07 & --- & 0.33 & 0.15 & 0.08 & 0.01 & 0.05 \\
\hline $\begin{array}{l}\text { 15. Informal group of } \\
\text { friends }\end{array}$ & 0.16 & 0.18 & 0.06 & -0.06 & -0.16 & 0.10 & 0.03 & -0.02 & -0.03 & -0.01 & 0.00 & -0.05 & -0.02 & 0.33 & --- & 0.02 & 0.02 & 0.15 & 0.00 \\
\hline 16. Formal association & -0.07 & 0.08 & 0.04 & 0.09 & -0.04 & 0.00 & -0.03 & 0.05 & -0.11 & 0.05 & 0.02 & 0.12 & -0.09 & 0.15 & 0.02 & --- & 0.08 & 0.02 & -0.04 \\
\hline $\begin{array}{l}\text { 17. Education expenditure } \\
\text { Community level: }\end{array}$ & 0.01 & 0.05 & -0.09 & -0.06 & 0.04 & 0.01 & -0.17 & 0.19 & -0.15 & 0.07 & 0.01 & 0.09 & -0.08 & 0.08 & 0.02 & 0.08 & --- & -0.06 & 0.05 \\
\hline $\begin{array}{l}\text { 18. Community acceptance } \\
\text { index }\end{array}$ & 0.48 & 0.12 & -0.12 & 0.21 & -0.05 & 0.10 & -0.05 & 0.10 & -0.04 & 0.12 & 0.03 & -0.02 & 0.01 & 0.01 & 0.15 & 0.02 & -0.06 & --- & -0.34 \\
\hline 19. Discrimination index & -0.24 & 0.16 & 0.09 & -0.17 & 0.03 & -0.07 & 0.02 & -0.03 & 0.01 & -0.15 & -0.06 & 0.02 & -0.11 & 0.05 & 0.00 & -0.04 & 0.05 & -0.34 & --- \\
\hline
\end{tabular}


Assumption 4: the assumption of proportional odds based on the test of parallel lines was met because the statistically significant value was $>0.05$. By not violating this assumption, we could perform each independent variable as having the same effect for each cumulative logit (Laerd Statistics, 2017) (See Table 7 and Table 8).

\section{Table 7}

Test of Parallel Lines for Satisfaction with the Education of the Children of Latino Families in Three Rural Communities of Missouri in 2008

\begin{tabular}{lcccc}
\hline & $\begin{array}{c}-2 \text { Log } \\
\text { Likelihood }\end{array}$ & Chi-Square & df & Sig. \\
Model & 136.693 & & & \\
\hline Null Hypothesis & 91.839 & 44.857 & 57 & 0.878 \\
General & Note: The ordinal logistic regression, $\mathrm{N}=132$. & &
\end{tabular}

Table 7 shows the results of the test of parallel lines for satisfaction with the education of the children of Latino families. The assumption of proportional odds was assessed through a full likelihood ratio test comparing the fitted model to a model with varying location parameters $X^{2}(57)=44.854, \mathrm{p}=0.878$, but most cells were sparse with zero frequencies in $80.0 \%$ of cells that combined the values of the independent and dependent variables. The final model predicted the dependent variable, $X^{2}(19)=$ $37.185, \mathrm{p}=0.008$ as statistically significant. 
Table 8

Test of Parallel Lines for Satisfaction with the Higher Education Opportunities of the Children of Latino Families in Three Rural Communities of Missouri in 2008

\begin{tabular}{lcccc}
\hline & $\begin{array}{c}-2 \text { Log } \\
\text { Likelihood }\end{array}$ & Chi-Square & df & Sig. \\
Model & 224.907 & & & \\
\hline Null Hypothesis & 173.189 & 51.718 & 57 & 0.673 \\
General & Note. The ordinal logistic regression, $\mathrm{N}=120$. & &
\end{tabular}

Table 8 represents the results of the test of parallel lines for satisfaction with higher education opportunities of the children of Latino families. The assumption of proportional odds was assessed through a full likelihood ratio test comparing the fitted model to a model with varying location parameters $X^{2}(57)=51.718, p=0.673$, but most cells were sparse with zero frequencies in $80.0 \%$ of cells that combined the values of the independent and dependent variables. The final model predicted the dependent variable, $X^{2}(19)=31.239, \mathrm{p}=0.038$ as statistically significant. 


\section{CHAPTER IV}

\section{FINDINGS}

This chapter presents the results of the statistical analysis from an ordinal logistic regression in determining factors affecting satisfaction with the education and the higher education opportunities of the children of Latino families in three rural communities in Missouri. The research questions of this study as follows:

(1) What are the forms of capital of the survey respondents predict satisfaction with the education and the higher education opportunities of the children of Latino families?

(2) What are the forms of capital of the Latino household that predict satisfaction with the education and the higher education opportunities of the children of Latino families?

(3) What are the community perceptions that predict satisfaction with education and the higher education opportunities of the children of Latino families?

(4) How does the gender of the survey respondents relate to satisfaction with the education and the higher education opportunities of the children of Latino families?

The findings in this chapter are divided into two sections: descriptive statistics and analytic statistics. The first section uses descriptive statistics, such as frequency, percentage, and mean, to summarize and describe operational variables. The second section uses ordinal logistic regression to estimate ordinal outcomes of satisfaction with the education and the higher education opportunities of the children of Latino families. 


\section{IV.i. Descriptive Statistics}

The descriptive statistics for the dependent and independent variables used in ordered logistic regression models are shown in Table 9. The two dependent variables were satisfaction with the education and with the higher education opportunities of the children of Latino families. Most survey respondents were very satisfied with the education and the higher education opportunities of their children, $79.6 \%$ and $65.7 \%$ respectively.

The survey responses for the independent variable included being male (49.4\%), with two employed parents (50.6\%), being a single parent (14.7\%), following an integration strategy (21.6\%), living in the community with as proper documentation (24.1\%), being a member of recreation/sport associations (28.8\%), being a member of informal group of friends (38.1\%), being a member of formal associations (5.4\%). The average length of residence in the community was 6.5 years $(\mathrm{SD}=4.08)$, and the average number of children in the family was $1.77(\mathrm{SD}=0.47)$. The life satisfaction index average was $4.87(\mathrm{SD}=1.27)$, the average ethnic identity index was $2.99(\mathrm{SD}=0.60)$, the average income was $\$ 21,113.11(\mathrm{SD}=24657.21)$, and the average education expenditure was $\$ 262.10(\mathrm{SD}=789.38)$. Average parental education was $9.25(\mathrm{SD}=3.50)$, the parental English proficiency average was $3.04(\mathrm{SD}=0.75)$, the average community acceptance index was $4.92(\mathrm{SD}=1.20)$, and the average discrimination index value was $3.39(\mathrm{SD}=$ 1.57). 
Table 9

Descriptive Statistics for Variables Included in Ordered Logistic Regression Models*

\begin{tabular}{|c|c|c|c|c|}
\hline Variables & $\mathbf{N}$ & $\%$ & Mean & SD \\
\hline \multicolumn{5}{|l|}{ Dependent variables } \\
\hline \multicolumn{5}{|l|}{ Satisfaction with the education of the children } \\
\hline $1=$ very dissatisfied & 2 & 0.9 & & \\
\hline $2=$ dissatisfied & 1 & 0.4 & & \\
\hline $3=$ neutral & 13 & 5.5 & & \\
\hline $4=$ satisfied & 32 & 13.6 & & \\
\hline $5=$ very satisfied & 187 & 79.6 & & \\
\hline \multicolumn{5}{|l|}{$\begin{array}{l}\text { Satisfaction with the higher education opportunities of the } \\
\text { children }\end{array}$} \\
\hline $1=$ very dissatisfied & 12 & 5.6 & & \\
\hline $2=$ dissatisfied & 4 & 1.9 & & \\
\hline $3=$ neutral & 27 & 12.5 & & \\
\hline $4=$ satisfied & 31 & 14.4 & & \\
\hline $5=$ very satisfied & 142 & 65.7 & & \\
\hline \multicolumn{5}{|l|}{ Independent variables } \\
\hline \multicolumn{5}{|l|}{ Individual level: as Latino respondent } \\
\hline Life satisfaction index & 257 & & 4.87 & 1.27 \\
\hline Ethnic identity index & 252 & & 2.99 & 0.60 \\
\hline Acculturation strategy as integration strategy & 55 & 21.6 & & \\
\hline Income (in dollars) $* *$ & 206 & & 21113.11 & 24657.21 \\
\hline Gender as male & 127 & 49.4 & & \\
\hline Marital status as single & 37 & 14.7 & & \\
\hline $\begin{array}{l}\text { Residential status as holding a legal status (a properly } \\
\text { documented }\end{array}$ & 62 & 24.1 & & \\
\hline Place where they live as community $\mathrm{A}^{* *}$ & 76 & 29.6 & & \\
\hline Length of residence (in years) & 257 & & 6.50 & 4.08 \\
\hline Children in the family & 257 & & 1.77 & 0.47 \\
\hline \multicolumn{5}{|l|}{ Household level: as Latino Household } \\
\hline Parental employment status as two employed parents & 128 & 50.6 & & \\
\hline Parental education** & 255 & & 9.25 & 3.50 \\
\hline Parental English proficiency & 252 & & 3.04 & 0.75 \\
\hline Recreational association as being a member & 74 & 28.8 & & \\
\hline Informal group of friends as being a member & 98 & 38.1 & & \\
\hline Formal association as being a member & 14 & 5.4 & & \\
\hline \multicolumn{5}{|l|}{ Community level: as community perceptions } \\
\hline Community acceptance index & 257 & & 4.92 & 1.20 \\
\hline Discrimination index & 257 & & 3.39 & 1.57 \\
\hline
\end{tabular}

Note: *The descriptive statistics for variables used in ordered logistic regression models were drawn from the 2008 Asset Accumulation Survey. The total number in this samples included $(\mathrm{N}=257)$.

** Variables included as a control variable in the models. 


\section{IV.ii. Analytic Statistics}

This section presents the ordinal logistic regression results of satisfaction with the education and the higher education opportunities of the children of Latino families with respect to the four research questions of this study:

(1) What are the forms of capital of the survey respondents predict satisfaction with the education and the higher education opportunities of the children of Latino families?

(2) What are the forms of capital of the Latino household that predict satisfaction with the education and the higher education opportunities of the children of Latino families?

(3) What are the community perceptions that predict satisfaction with education and the higher education opportunities of the children of Latino families?

(4) How does the gender of the survey respondents relate to satisfaction with the education and the higher education opportunities of the children of Latino families?

The ordinal logistic regression results for satisfaction with the education and the higher education opportunities of their children are shown in Table 10 and Table 11, respectively. 
Table 10

Satisfaction with the Education of the Children of Latino Families in Three Rural

Communities of Missouri in 2008

\begin{tabular}{|c|c|c|c|c|c|c|c|}
\hline & \multirow[t]{2}{*}{ Estimate } & \multirow{2}{*}{$\begin{array}{l}\text { Std. } \\
\text { Error }\end{array}$} & \multirow[t]{2}{*}{ Wald } & \multirow[t]{2}{*}{ Sig. } & \multirow{2}{*}{$\begin{array}{l}\text { Odds } \\
\text { ratio }\end{array}$} & \multicolumn{2}{|c|}{$90 \% \mathrm{CI}$} \\
\hline & & & & & & Lower & Upper \\
\hline \multicolumn{8}{|l|}{ Individual level: } \\
\hline Life satisfaction index & 0.609 & .265 & 5.285 & $0.022 *$ & 1.84 & 1.19 & 2.84 \\
\hline Ethnic identity index & 0.951 & 0.528 & 3.239 & $0.072 *$ & 2.59 & 1.09 & 6.17 \\
\hline Acculturation (as integration strategy) & 3.292 & 1.233 & 7.125 & $0.008 *$ & 26.88 & 3.54 & 204.37 \\
\hline Otherwise & Ref & & & & & & \\
\hline Income $* *$ & 0.070 & 0.230 & 0.092 & 0.762 & 1.07 & 0.73 & 1.57 \\
\hline Gender (as male) & -0.695 & 0.613 & 1.285 & 0.257 & 0.50 & 0.18 & 1.37 \\
\hline Otherwise & Ref & & & & & & \\
\hline Marital status (as a single parent) & -0.411 & 0.919 & 0.200 & 0.655 & 0.66 & 0.15 & 3.00 \\
\hline Otherwise & Ref & & & & & & \\
\hline $\begin{array}{l}\text { Residential status (as properly } \\
\text { documented) }\end{array}$ & -0.606 & 0.597 & 1.030 & 0.310 & 0.55 & 0.20 & 1.46 \\
\hline Otherwise & Ref & & & & & & \\
\hline Place of living (as community A) ** & -1.151 & 0.638 & 3.252 & $0.071 *$ & 0.32 & 0.11 & 0.90 \\
\hline Otherwise & Ref & & & & & & \\
\hline Length of residence & 0.041 & 0.070 & 0.348 & 0.762 & 1.04 & 0.93 & 1.17 \\
\hline Children in the family & -1.023 & 0.695 & 2.168 & 0.141 & 0.36 & 0.11 & 1.13 \\
\hline \multicolumn{8}{|l|}{ Household level: } \\
\hline $\begin{array}{l}\text { Parental employment (either father or } \\
\text { mother not working) }\end{array}$ & 0.261 & 0.607 & 0.185 & 0.667 & 1.30 & 0.48 & 3.52 \\
\hline Otherwise & Ref & & & & & & \\
\hline Parental education ${ }^{* *}$ & -0.136 & 0.109 & 1.538 & 0.215 & 0.87 & 0.73 & 1.05 \\
\hline Parental English proficiency & -0.309 & 0.431 & 0.512 & 0.474 & 0.73 & 0.36 & 1.49 \\
\hline $\begin{array}{l}\text { Recreational/sport associations (as not } \\
\text { a member) }\end{array}$ & -1.940 & 0.945 & 4.216 & $0.040^{*}$ & 0.14 & 0.3 & 0.68 \\
\hline Otherwise & Ref & & & & & & \\
\hline $\begin{array}{l}\text { Informal groups of friends (as not a } \\
\text { member) }\end{array}$ & 0.535 & 0.584 & 0.841 & 0.359 & 1.71 & 0.65 & 4.46 \\
\hline Otherwise & Ref & & & & & & \\
\hline $\begin{array}{l}\text { Formal associations (as not a } \\
\text { member) }\end{array}$ & 1.869 & 1.086 & 2.965 & $0.085^{*}$ & 6.48 & 1.09 & 38.66 \\
\hline Otherwise & Ref & & & & & & \\
\hline Education expenditure & -0.103 & 0.125 & 0.669 & 0.413 & 0.90 & 0.73 & 1.11 \\
\hline \multicolumn{8}{|l|}{ Community level: } \\
\hline Community acceptance index & -0.254 & 0.276 & 0.847 & 0.357 & 0.78 & 0.49 & 1.22 \\
\hline Discrimination index & 0.264 & 0.242 & 1.190 & 0.275 & 1.30 & 0.87 & 1.94 \\
\hline
\end{tabular}

Note: $\mathrm{N}=132, \mathrm{CI}=$ confidence interval

* Statistically significant was set at $90 \%$ confidential level $(\mathrm{p}<0.10)$

** The parental education, income, and place of living included as control variables in the model 


\section{Table 11}

\section{Satisfaction with the Higher Education Opportunities of the Children of Latino Families}

in Three Rural Communities in Missouri in 2008

\begin{tabular}{|c|c|c|c|c|c|c|c|}
\hline & \multirow{2}{*}{ Estimate } & \multirow{2}{*}{$\begin{array}{l}\text { Std. } \\
\text { Error }\end{array}$} & \multirow{2}{*}{ Wald } & \multirow{2}{*}{ Sig. } & \multirow{2}{*}{$\begin{array}{l}\text { Odds } \\
\text { ratio }\end{array}$} & \multicolumn{2}{|c|}{$90 \%$ CI } \\
\hline & & & & & & Lower & Upper \\
\hline \multicolumn{8}{|l|}{ Individual level: } \\
\hline Life satisfaction index & 0.101 & 0.190 & 0.284 & $0.594 *$ & 1.11 & 0.81 & 1.51 \\
\hline Ethnic identity index & -0.387 & 0.456 & 0.719 & 0.396 & 0.68 & 0.32 & 1.44 \\
\hline Acculturation (as integration strategy) & 1.608 & 0.712 & 5.103 & $0.024 *$ & 4.99 & 1.55 & 16.11 \\
\hline Otherwise & Ref & & & & & & \\
\hline Income** & -0.110 & 0.105 & 1.105 & 0.293 & 0.90 & 0.75 & 1.06 \\
\hline Gender (as male) & 1.019 & 00.485 & 4.410 & $0.036^{*}$ & 2.77 & 1.25 & 6.16 \\
\hline Otherwise & Ref & & & & & & \\
\hline Marital status (as a single parent) & -0.160 & 0.668 & 0.057 & 0.811 & 0.85 & 0.28 & 2.56 \\
\hline Otherwise & Ref & & & & & & \\
\hline $\begin{array}{l}\text { Residential status (as properly } \\
\text { documented) }\end{array}$ & 0.300 & 0.481 & 0.389 & 0.533 & 1.35 & 0.61 & 2.98 \\
\hline Otherwise & Ref & & & & & & \\
\hline Length of residence & 0.074 & 0.059 & 1.563 & 0.211 & 1.08 & 0.98 & 1.19 \\
\hline Place of living (as community A) $* *$ & -0.417 & 0.519 & 0.645 & 0.422 & 0.66 & 0.28 & 1.55 \\
\hline Otherwise & Ref & & & & & & \\
\hline Children in the family & -0.217 & 0.439 & 0.245 & 0.621 & 0.800 & 0.39 & 1.66 \\
\hline \multicolumn{8}{|l|}{ Household level: } \\
\hline $\begin{array}{l}\text { Parental employment (either father or } \\
\text { mother not working) }\end{array}$ & 0.233 & 0.491 & 0.225 & 0.636 & 1.26 & 0.56 & 2.83 \\
\hline Otherwise & Ref & & & & & & \\
\hline Parental education** & 0.031 & 0.083 & 0.137 & 0.711 & 1.03 & 0.90 & 1.18 \\
\hline Parental English proficiency & 0.619 & 0.316 & 3.841 & $0.050 *$ & 1.86 & 1.10 & 3.12 \\
\hline $\begin{array}{l}\text { Recreational/sport associations (as not } \\
\text { a member) }\end{array}$ & -0.704 & 0.547 & 1.657 & 0.198 & 0.49 & 0.20 & 1.22 \\
\hline Otherwise & Ref & & & & & & \\
\hline \multicolumn{8}{|l|}{ Informal groups of friends (as not a } \\
\hline Otherwise & Ref & & & & & & \\
\hline $\begin{array}{l}\text { Formal associations (as not a } \\
\text { member) }\end{array}$ & -1.527 & 1.299 & 1.383 & 0.240 & 0.22 & 0.03 & 1.84 \\
\hline Otherwise & Ref & & & & & & \\
\hline Education expenditure & -0.057 & 0.099 & 0.329 & 0.566 & 0.94 & 0.80 & 1.11 \\
\hline \multicolumn{8}{|l|}{ Community level: } \\
\hline Community acceptance index & 0.464 & 0.205 & 5.106 & $0.024 *$ & 1.59 & 1.13 & 2.23 \\
\hline Discrimination index & -0.053 & 0.158 & 0.112 & 0.738 & 0.95 & 0.73 & 1.23 \\
\hline
\end{tabular}




\section{IV.ii.i. Forms of Capital of the Survey Respondents (Individual Level)}

The ordinal logistic regression results illustrate that forms of capital which possessed by the survey respondents (individual level factors) were found to be significantly associated with both satisfaction with the education and the higher education opportunities of the children of Latino families when controlling for parental education, income, and place of living (See Table 10 and Table 11). The ordinal logistic regression results show that life satisfaction, ethnic identity, and the integration strategy of the survey respondents were significantly correlated to satisfaction with the education of the children at the individual level (See Table 10). The ordinal logistic regression results show that the only individual level measure for satisfaction with the higher education opportunities of the children of Latinos was the acculturation path of integration (See Table 11).

\section{IV.ii.i.i. Satisfaction with the Education of the Children}

Life satisfaction, ethnic identity, and the integration strategy of the survey respondents were the variables that significantly correlated to satisfaction with the education of the children at the individual level (See Table 10).

There was an association between life satisfaction and satisfaction with the education of the children, Wald $X^{2}(1)=5.285, \mathrm{p}=0.002$, while the other variables in the model were held constant. Indicating that an increase in life satisfaction of the survey respondents was associated with an increase in the ordered log-odds of being at higher levels of satisfaction with the education of the children, with the odds ratio of $e^{0.609}=$ $1.84,90 \%$ CI [1.19-2.84]. A one-unit increase in life satisfaction would result in a 0.609- 
unit increase in the ordered log-odds of being at a higher level of satisfaction with the education of the children.

Ethnic identity of the survey respondents was significantly associated with an increase in the ordered log-odds of being at higher levels of satisfaction with the education of the children, with the odds ratio of $e^{0.951}=2.59,90 \%$ CI [1.09-6.17], Wald $X^{2}(1)=3.239, p=0.072$, while the other variables in the model were held constant. In other words, if the ethnic identity of the survey respondents were increased by one unit, their ordered log-odds of being at a higher level of satisfaction would increase by 0.951 .

The integration strategy of the survey respondents had a statistically significant effect on satisfaction with the education of the children, Wald $X^{2}(1)=7.125, p$ $=0.008$. It indicated that the survey respondents who used the integration strategy (as oppose to the other strategies of separation, assimilation and marginalization) were associated with an increase in the ordered log-odds of being at higher levels of satisfaction with the education of the children, with the odds ratio of $e^{3.292}=26.88,90 \%$ CI [3.54204.37] times than for the survey respondents who used other acculturation strategies, while the other variables in the model were held constant. This means the survey respondents who used the integration strategy were more likely to be satisfied with the education of the children than those respondents who used other acculturation strategies (e.g. separation, assimilation, or marginalization).

Several demographic characteristics of the survey respondents as follows: income $(\mathrm{p}=0.895)$, being a single parent $(\mathrm{p}=0.381)$, holding a legal status (as properly documented $)(p=0.301)$, length of residence $(p=0.762)$, and children in the family $(p=$ 0.141) were not significantly associated with satisfaction with the education of the children 
(See Table 10). However, the survey respondents who lived in community A were associated with a decrease in the ordered log-odds of being at higher levels of satisfaction with the education of the children, with the odds ratio of $e^{-1.151}=0.32,90 \%$ CI $[0.11$ 0.90 ] times than for those who lived in other communities, Wald $X^{2}(1)=3.252, p=0.071$, while the other variables in the model were held constant. The survey respondents who lived in community A were less likely to be satisfied with the education of the children than those survey respondents who lived in other communities.

\section{IV.ii.i.ii. Satisfaction with the Higher Education Opportunities of the Children}

The only individual level measure for satisfaction with the higher education opportunities of the children of Latinos was the acculturation path of integration (See Table 11). The integration strategy of the survey respondents was significantly associated with satisfaction with the higher education opportunities of the children, Wald $X^{2}(1)=5.103$, p $=0.024$. Indicating that the survey respondents who used the integration strategy were associated with an increase in the ordered log-odds of being at higher levels of satisfaction with the higher education opportunities of the children, with the odds ratio of $e^{1.608}=4.99$, 90\% CI [1.55-16.11] times than for those who used other acculturation strategies, while the other variables in the model were held constant. Survey respondents who used the integration strategy were more likely to be satisfied with the higher education opportunities of the children than those survey respondents who used other acculturation strategies (i.e. separation, assimilation, or marginalization). 
The results show that the demographic characteristics of the survey respondents were not associated with satisfaction with the higher education opportunities of the children: income $(\mathrm{p}=0.293)$, being a single parent $(\mathrm{p}=0.811)$, holding a legal status (as proper documentation) $(\mathrm{p}=0.533)$, length of residence $(\mathrm{p}=0.211)$, and the number of children in the family $(\mathrm{p}=0.621)($ See Table 11$)$.

\section{IV.ii.ii. Forms of Capital of the Latino Household (Household Level)}

The ordinal logistic regression results show that forms of capital possessed by the Latino household were significantly associated with both satisfaction with the education and with the higher education opportunities of the children when controlling for parental education, income, and place of living (See Table 10 and Table 11). The variables significantly affecting satisfaction with the education of the children included not being a member of a recreation/sports association and not being a member of a formal association. Parental English proficiency and not being a member of an informal group were the variables that significantly affected the satisfaction with higher education opportunities of the children.

\section{IV.ii.ii.i. Satisfaction with the Education of the Children}

Not being a member of a recreation/sports association and not being a member of a formal association were the two significant variables affecting satisfaction with the education of the children (See table 10). The ordinal logistic regression results show that the Latino households whose family members were not members of recreational/sport associations were associated with a decrease in the ordered log-odds of 
being at higher levels of satisfaction with the education of the children, with the odds ratio of $e^{-1.940}=0.14,90 \%$ CI $[0.3-0.65]$ times than for those who were members of recreational/sport associations, Wald $X^{2}(1)=4.216, \mathrm{p}=0.040$, while the other variables in the model were held constant. Thus, the Latino households whose family members were not involved in recreational/sport associations were less likely to be satisfied with the education of the children than those whose family members were involved in recreational/sport associations (See Table 10).

Additionally, the Latino households whose family members were not members of formal associations were correlated with an increase in the ordered log-odds of being at higher levels of satisfaction with the education of the children, with the odds ratio of $e^{1.869}=6.48,90 \% \mathrm{CI}[1.09-38.66]$ times than for those family members were members of formal associations, Wald $X^{2}(1)=2.965, p=0.085$, while the other variables in the model were held constant. This means the Latino households whose family members were not involved in formal associations were more likely to be satisfied with the education of the children than those family members were involved in formal associations.

Other forms of capital possessed by the Latino household were not found to have a statistically significant effect on satisfaction with the education of the children: parental employment $(\mathrm{p}=0.667)$, parental education $(\mathrm{p}=0.215)$, parental English proficiency $(\mathrm{p}=0.474)$, education expenditure $(\mathrm{p}=0.413)$, and not being a member of an informal group of friends $(\mathrm{p}=0.359)($ See Table 10). 


\section{IV.ii.ii.ii. Satisfaction with the Higher Education Opportunities of the Children}

Parental English proficiency and not being a member of an informal group of friends were the variables that significantly affected satisfaction with the higher education opportunities of the children (See Table 11).

An increase in parental English proficiency of the Latino households corresponded to an increase in the ordered log-odds of being at higher levels of satisfaction with the higher education opportunities of the children, with the odds ratio of $e^{0.619}=1.86$, 90\% CI [1.10-3.12], Wald $X^{2}(1)=3.841, \mathrm{p}=0.050$, while the other variables in the model were held constant. Indicating that a one-unit increase in parental English proficiency would result in a 0.619 -unit increase in the ordered log-odds of being at a higher level of satisfaction with the higher education opportunities of the children. Thus, parents with higher levels of English proficiency have a higher level of satisfaction with the higher education opportunities of the children.

The Latino households whose family members were not members of informal groups of friends were also associated with an increase in the ordered log-odds of being at higher levels of satisfaction with the higher education opportunities of the children, with the odds ratio of $e^{1.199}=3.32,90 \%$ CI [1.52-7.25] times than for the Latino households whose family members were members of informal groups of friends, Wald $X^{2}(1)=6.343, p=0.012$, while the other variables in the model held constant. In other words, the Latino households whose family member were not involved in informal groups of friends were more likely to be satisfied with the higher education opportunities of the children than those family members were involved in informal groups of friends. 
Several variable representatives of the Latino household were not significantly associated with satisfaction with higher education opportunities of the children: parental employment $(p=0.636)$, parental education $(p=0.711)$, education expenditure $(p=0.566)$, not being a member of a recreational/sport association $(p=0.198)$, and not being a member of a formal association $(\mathrm{p}=0.240)($ See Table 11).

\section{IV.ii.iii. Community Perceptions (Community Level)}

The ordinal logistic regression results show that only community acceptance was associated with satisfaction with the higher education opportunities of the children of Latino families, while discrimination and community acceptance variables were not associated with satisfaction with the education of the children after controlling for parental education, income, and place of living (See Table 10 and Table 11)

\section{IV.ii.iii.i. Satisfaction with the Education of the Children}

The ordinal logistic regression results show that with regards to community perceptions, community acceptance $(\mathrm{p}=0.357)$ and discrimination $(\mathrm{p}=0.275)$ were not significantly associated with satisfaction with the education of the children (See Table 10).

\section{IV.ii.iii.ii. Satisfaction with the Higher Education Opportunities of the Children}

The ordinal logistic regression results show that community acceptance was significantly associated with satisfaction with the higher education opportunities of the children, Wald $X^{2}(1)=5.106, p=0.024$. Indicating that an increase in community 
acceptance was associated with an increase in the ordered log-odds of being at higher levels of satisfaction with the higher education opportunities of the children, with the odds ratio $e^{0.464}=1.59,90 \%$ CI [1.13-2.23], while the other variables in the model were held constant. A one-unit increase in community acceptance would result in a 0.464-unit increase in the ordered log-odds of being at a higher level of satisfaction with the higher education opportunities of the children. However, discrimination $(\mathrm{p}=0.738)$ was not related to satisfaction with the higher education opportunities of the children (See Table $11)$.

\section{IV.ii.iv. Gender of the Survey Respondents}

The fourth research question focused on the relationship between gender of the survey respondents and satisfaction with the education and the higher education opportunities of the children. The ordinal logistic regression results show that being male was not related to satisfaction with the education of the children $(p=0.257)$. However, being male was significantly associated with satisfaction with the higher education opportunities of the children, Wald $X^{2}(1)=4.410, p=0.036$. Indicating that that being male was associated with an increase in the ordered log-odds of being at higher levels of satisfaction with the higher education opportunities of the children, with the odds ratio of $e^{1.019}=2.77,90 \% \mathrm{CI}[1.25-6.16]$ times than for being female, while the other variables in the model were held constant. Male respondents were more likely to be satisfied with the higher education opportunities of the children than female respondents (See Table 10 and Table 11). 
In conclusion, after controlling for parental education, income, and place of living, the findings for the first research question illustrate the forms of capital possessed by the survey respondents that were positively associated with how satisfied they were with the education of the children included; (1) life satisfaction as human capital; and (2) ethnic identity and the integration strategy as cultural capital. The integration strategy of the survey respondents was the only factor related to satisfaction with the higher education opportunities of the children.

Findings for the second research question indicate that forms of capital possessed by the Latino household related to satisfaction with the education and the higher education opportunities of their children included: parental English proficiency, as a measure of family human capital, was positively correlated with satisfaction with the higher education opportunities of the children. The Latino households whose family members were not members of recreational/sport associations, as a measure of family bonding social capital, were negatively associated with satisfaction with the education of the children. Additionally, the Latino households whose family members were not members of formal associations, as a measure of family bridging social capital, were positively associated with satisfaction with the education of the children. The Latino households whose family members were not members of informal groups of friends, as a measure of family bridging social capital, were positively associated with satisfaction with the higher education opportunities of the children.

The finding for the third research question illustrates that regarding community perceptions, community acceptance was positively related to satisfaction with the higher education opportunities of the children, while community acceptance and discrimination 
were not associated with satisfaction with the education of the children after controlling parental education, income, and place of living.

The findings for the fourth research question show that the male respondents were positively associated with satisfaction with the higher education opportunities; however, there was no relationship between the male respondents and satisfaction with the education of the children.

Additionally, the findings for the demographic variables illustrate that the survey respondents who lived in the community A were negatively related to satisfaction with the education of the children. 


\section{CHAPTER V}

\section{DISCUSSION}

This study set out to examine forms of capital affecting satisfaction with the education and the higher education opportunities of the children of Latino families in three rural communities in Missouri. The four research questions of this study included:

(1) What are the forms of capital of the survey respondents predict satisfaction with the education and the higher education opportunities of the children of Latino families?

(2) What are the forms of capital of the Latino household that predict satisfaction with the education and the higher education opportunities of the children of Latino families?

(3) What are the community perceptions that predict satisfaction with education and the higher education opportunities of the children of Latino families?

(4) How does the gender of the survey respondents relate to satisfaction with the education and the higher education opportunities of the children of Latino families?

The main findings illustrate that the forms of capital possessed by the survey respondents (individual level) and by the Latino household (household level) were associated with both satisfaction with the education and the higher education opportunities of the children of Latino families. In addition, community acceptance, as community level, and being male were positively associated with satisfaction with the higher education opportunities of the children. Furthermore, living in community A was negatively associated with satisfaction with the education of the children. 
After controlling for parental education, income, and place of living, the findings illustrate that the forms of capital possessed by the survey respondents and by the Latino household were significantly associated with satisfaction with the education and the higher education opportunities of the children. These findings were broadly consistent with existing research findings related to the education of the children. Forms of capital in this study included human, social, cultural, and financial capital, were associated with Bebbington's explanation on forms of capital facilitating families to access to resources in building livelihoods (Bebbington, 1999). Cultural and financial elements of families are reflected in the human capital of their children in terms of skills, knowledge, and qualifications (Field, 2003). Therefore, forms of capital are valuable resources for Latino families and are expected to improve the well-being and development of their children (Martin, 2013).

\section{V.i. Forms of Capital of the Survey Respondents (Individual Level): Satisfaction with the Education and with the Higher Education Opportunities of the Children}

In this study, life satisfaction of a Latino respondent was a measure of human capital because it is an ultimate goal of human development (Chang et al., 2003). There was also a cognitive element of subjective well-being (Park, 2004). In general, if an individual encounter psychological or physical harm regarding his/her ethnicity when interacting with social environments, the individual may experience ethnic-related stress; for example, perceived ethnic harassment would decrease life satisfaction of Latinos (Ojeda et al., 2012). The findings of this study indicated that life satisfaction of the survey respondents was positively correlated with satisfaction with the education of the children. In other words, an increase in life satisfaction of the survey respondents 
would increase satisfaction with the education of the children. These findings were consistent with Nikolaou's life satisfaction review (2012) which showed that martial satisfaction may affect the development of children. For example, happier mothers were more likely to be productive in the labor market, which allowed these mothers to increase the amount of monetary investment they could make for their children. In addition, happier mothers were more likely to be responsive and sensitive towards the needs of their children (Nikolaou, 2012).

Acculturation was a measure of cultural capital of the survey respondents consisting of four paths: integration, separation, assimilation, and marginalization. The findings indicated that the survey respondents who used the integration strategy were more satisfied with the education and the higher education opportunities of the children than those who used other strategies, such as separation, assimilation, or marginalization. The integration acculturation strategy is expected to produce the best result for Latino individuals in their host country because the integration strategy is the acculturation path whereby Latino individuals maintain their original cultural identity; and at the same time, they adapt to their new culture and interact with host community members (Zagefka \& Brown, 2002). Longer-term adaptation to life in the host country takes place in various forms, such as learning each other's language, sharing each other's food preferences, and adopting forms of dress (Berry, 2005). For example, the literature has shown that language competence had a positive impact on adjustment and was measured by language use and proficiency (Kang, 2006). Likewise, Schwartz et al. (2014) indicated that immigrants who were fluent in English and familiar with U.S. culture were more likely to have positive experience in the local receiving context rather than those with poor English proficiency and unfamiliarity with U.S. culture. Furthermore, the use of language between English and Spanish in daily life in the 
homes of Latino individuals was expected to result in acculturation paths that lead to better adaptation results in the host country.

The survey respondents who were proficient in English and Spanish language were more likely to have higher levels of satisfaction with the education and the higher education opportunities of the children. These findings were consistent with prior research; for example, Plunkett and Bámaca-Gómez (2003) indicated that acculturation was associated with academic outcomes of children. The language spoken in the home has been found to be correlated with the school performance of Latino children. Mexican adolescents from families that spoke less English at home may have parents with little or no English ability. In addition, children whose families spoke Spanish at home were less likely to be enrolled in preschool when holding family income and maternal education constant (Magnuson, Lahaie, \& Waldfogel, 2006). In addition, the focus group results from the 2008 Asset Accumulation project indicated that the children of Latino families were comfortable using English with their friends and teachers at the school; at the same time, they were more likely to speak Spanish than English with their parents at home. As a result, the children of Latino families were more connected and integrated to the community than their parents. It seemed that the children of Latino families were generally obtaining English and slowly losing Spanish (National Academy of Sciences, 2015). However, Latino parents prefer that their children maintain the language and cultural identity of their country of origin.

Ethnic identity was a measure of cultural capital of the survey respondents. Having Latino parents, the children were generally exposed to more information about and attitudes toward their parents' cultural background, specifically engagement in cultural practices (Miller, 2013). Latino community members have strengthened culture values and traditions in first and second-generation immigrant children and 
promoted a strong ethnic identity (Grindal \& Nieri, 2015). Cultural integration has been a way for immigrant parents to influence the education of their children (Schüller, 2015). Ethnic identity of the survey respondents was positively associated with satisfaction with the higher education opportunities of the children. These findings were consistent with other empirical studies that have shown that ethnic identity influenced youth academic performance (Estela-Zarate, Bhimji \& Reese, 2005; Grindal \& Nieri, 2015). Characteristics and actions of Latino parents also helped to facilitate or obstruct the academic performance of their children (Grindal \& Nieri, 2015). For example, immigrant parents who are deeply rooted in their culture of origin tended to focus on development of the ethnic skills within their children which was affected by the cultural tension between immigrant and dominant culture (Chiswick, 2009; Schüller, 2015). Furthermore, there are several manners in which immigrant parental ethnic identity may influence their children. For example, the parental ethnic identity helps to shape the social environment of their children through the choice of school or social clubs. Specifically, the parental ethnic identity may foster the amount of support available via their ethnic social networks that they belong to (Campbell et al., 2017). Latino parents promote the ethnic identity of their children by using their native language. Latino parents who were better in English and Spanish tended to access diverse social groups and have access to better information and resources that could expand the life chances of their children as well as their well-being (Kim \& Schneider, 2005).

Furthermore, the findings indicated that there was an association between place of living and satisfaction with the education of the children. Place of living in this present study referred to the place where people live together and meet their daily needs for interaction with a common physical and social environment (Wilkinson, 1986). In this sense, places could be very important for Latino parents and their children. For 
example, people lived, worked, worshipped, shopped, sent their children to school, and socialized all in the same place (Flora \& Flora, 2013). People relied on their environments to satisfy needs and desires (Bubolz et al., 1980). When people had their needs met, they were less likely to leave the community and more likely to establish community attachment. Therefore, people evaluate their community characteristics based on subjective standards that are provided by the physical and social environment of the community, including the degree to which the community qualities fit their needs and desires (Mesch \& Namor, 1998).

In addition, focus group information from the 2008 Asset Accumulation project indicated that one of the main reasons the survey respondents moved to these rural areas was out of safety concerns regarding the places they migrated from. They wanted to live in neighborhoods with less crime and violence. They were seeking a shared sense of place that involved relationships with people, cultures, and environments (Flora \& Flora, 2013). Likewise, Perreira, Chapman, and Stein (2006) stated that without a sense of community and without knowing other children's parents, parents did not feel safe allowing their children to attend other children's parties or to go to the movies with their peers. For most Latino immigrant families and their children, the school was the first institutional contract in the host country (Perreira, Chapman \& Stein, 2006). It is also likely to be the primary social environment for the youth that the parents are not directly involved in with their children. In this sense, school climate is an important factor that influences academic performance, behaviors, and mental health outcomes for children (O’Brennan \& Bradshaw, 2013). School climate is based on "patterns of people's experiences of school life and reflects norms, goals, values, interpersonal relationships, teaching and learning, and organizational structure" (Cohen, Mccabe, Michelli \& Pickeral, 2009, p.182). School climate includes norms, values, and 
expectations that enhanced people feeling socially, emotionally, and physically safe (Cohen, Mccabe, Michelli \& Pickeral, 2009).

\section{V.ii. Forms of Capital of the Latino Household (Household Level): Satisfaction with the Education and with the Higher Education \\ Opportunities of the Children}

The findings indicated that parental English proficiency as human capital was related to satisfaction with the higher education opportunities of the children. Parental English proficiency was related to understanding and communicating in English which included the ability to speak, read, and write in English. If immigrant parents are not comfortable with their English proficiency, they may be less involved in the education of their children and have limited in school participation (Jung \& Zhang, 2016). In addition, if no one in the family communicates well in English, the family will tend to face limitations such as findings higher wage employment, interacting with the teachers of their children, and accessing health care and other social services (Shields \& Behrman, 2004).

Latino families in the three communities of this study were limited in their human capital because of their lower level of English proficiency making it difficult to support their children with activities related to their literacy, such as doing homework and reading books. These findings were consistent with other previous studies. For example, a study of the preschool children of immigrants by Maguson, Lahaie, and Waldfogel (2006) illustrated that the use of the English language by immigrant mothers was associated with the English proficiency of the children at the time they start school. Much of the work on acculturation points to associations between language proficiency and the education of children (Kang, 2006; Hurtado-Ortiz \& Gauvain, 2007; Bobonis, 
2009). Families with low English proficiency had limited in their access to resources and also decreased the likelihood of the academic achievement of their children (Farver, Eppe, \& Lonigan, 2006). Furthermore, immigrant parents with low levels of English proficiency were more likely to be dissatisfied with and distressed regarding the goals of education of their children (Jung \& Zhang, 2016).

Although the Latino families in this study were limited by their human capital, they were able to utilize their social networks as social capital to help them successfully navigate the American educational system for their children. The findings of this study suggested that the social groups that Latino families were involved in may influence satisfaction with the education and the higher education opportunities of the children. Social groups represent the social networks that Latino families may utilize to support their family as they attempt to address issues, particularly in the context of the education of their children. In this study, the social groups constructed by Latino families were based on two types of social networks - bonding and bridging networks.

Results regarding the social capital of the Latino household illustrated that when members of the Latino household were not members of recreational/sport associations, they were less likely to be satisfied with the education of their children. On the other hands, when members of the Latino household were not members of formal associations, they were more likely to be satisfied with the education of their children. In this study, these two social groups were expected to create bridging networks which may connect Latino families with people outside of their ethic networks. These bridging networks can be beneficial to Latino families by connecting them to external assets and information diffusion (Putnam, 2001). Thus, the findings suggested that Latino families should be involved in recreational/sport associations in order to connect with different group networks to access to information and resources that may benefit the education 
of their children. In addition, Latino children depend on the networks of their parents or other adults to access to information and resources that enhanced their future life chances, particularly Latino children in families with limited English proficiency parents who may need to access information from a wide range of network diversity of their parents (Kim \& Schneider, 2005). Furthermore, although formal associations could help Latino families to access information and resources for education, formal associations have formal structures and mandatory elements, such as by law or through regular group meetings to help their members join activities (The Saguaro Seminar, 2012). Additionally, these formal associations may include activities that individuals are prohibited from doing, and at the same time, permission to participate in them under certain conditions (North, 2011). These characteristics of formal associations could serve as important constrains limiting the ability of Latino families from connecting to people within these formal networks that can help them gain access to information and resources. The formal networks can serve as an integrative setting but also can be a barrier to integration between Latino families and native community members since these formal associations may have high expectations of the members that are not able to be met by Latino families.

In addition, the findings show that Latino families whose family members were not members of informal groups of friends tended to be satisfied with the higher education opportunities of the children, compared to those whose family members were. This is because informal groups of friends represent bonding networks that are based on the shared social identity of close friends (Murayama, Fujiwara, \& Kawachi, 2012; Rouxel et al., 2015). Informal groups of friends are also related to ethnic networks. Research on ethnic identity has shown that ethnic networks tend to transfer job information to their members within the networks (Campbell et al., 2017). 
Likewise, the focus group information from the 2008 Asset Accumulation project showed that Latino immigrants in three communities were more likely to use their ethnic networks, specially friends and family members to seek job information rather than educational information. In addition, a previous study indicated that two-thirds of the sample participants reported they found their job through family contacts (Dozi, 2010). Therefore, this becomes a primary reason that Latino families need to seek information and resources outside of their ethnic networks to improve opportunities for their children. For example, Latino parents may contact a school counselor about a college program and ask about how to apply for financial aid (Kim \& Schneider, 2005). Most Latino families in the three rural communities were more likely to contact school teachers $(98.7 \%)$ and counselors $(92.3 \%)$ to help their children to do well in the school. Hence, the findings of this present study suggest that Latino families who are able to access a diverse set of social groups beyond their informal groups of friends may enhance their ability to be more connected outside their ethnic networks and increase their potential ability to gain access to better resources that help the education of their children.

\section{V.ii. Community Perceptions (Community Level): \\ Satisfaction with the Education of the Children and with the Higher Education Opportunities of the Children}

Community perceptions in this study included community acceptance and discrimination. When immigrant families arrived in the U.S., they often settled in communities with others with the same ethnic identity or country of origin (Shields \& Behrman, 2004). Friends and family members facilitated newly arrived immigrants and helped them to navigate new systems and institutions, in particular helping them to find 
jobs (Shields \& Behrman, 2004). Latino immigrants need support from their host communities to settle down and enhance the education of their children and their wellbeing; however, not all the host communities are equally friendly or unfriendly to Latino immigrants (Schwartz et al., 2014). This is due to language and cultural barriers can exist which may contribute to an unwelcoming environment in which both Latino immigrants and receiving members feel uncomfortable with each other (DownsKarkos, 2011).

The findings of the present study indicated that community acceptance was positively associated with satisfaction with the higher children opportunities of the children, while community acceptance and discrimination were not associated with satisfaction with the education of the children. In other words, the more members of the host community from the dominant culture welcomed Latino families and their children, the more Latino families were likely to be satisfied with the education of their children. These findings were consistent with Perreira, Fuligni, and Potochnick (2010) indicating that social acceptance was positively associated with academic motivations of Latino students. Latino students who experienced social acceptance in four primary dimensions: (1) positive school climate; (2) adult school encouragement; (3) daily positive school experiences; and (4) positive ethnic treatment were able to influence in terms of academic achievement directly and academic motivations indirectly. 


\section{V.iv. Gender of the Survey Respondents: Satisfaction with the Education of the Children and with the Higher Education Opportunities of the Children}

The findings illustrate that male respondents were more likely to be satisfied with the higher education opportunities of the children than female respondents. Fathers play an important role in their children's lives (Karberg et al., 2017). The current view on Latino fathers has indicated that many Latino fathers value their role as teachers and teach their children to respect themselves and others. Additionally, Latino fathers view themselves as egalitarian with high educational aspirations for their children (Cabrera \&Bradley, 2012). Cabrera and Bradley (2012) indicated that within a Latino family, cultural values, such as familism and machismo, remained important for Latino fathers because these cultural values were linked to behaviors that encouraged the satisfaction of family roles. Men who strongly identified with this parenting role tended to be motivated by their beliefs about what fathers should do and were more involved in their children's lives, compared to those fathers who did not strongly identify with being a father (Cabrera \&Bradley, 2012). For many immigrant Latino fathers, acculturation was also an important factor which influenced how Latino men were involved with their children.

In this study, the majority of Latino fathers were immigrants with low levels of formal education and low income, these characteristics impacted the education and development of their children. For example, Karberge et al. (2017) noted that lowincome Latino fathers may be less engaged in daily activities with their children because they work for many hours and with limited access to their children during key

times of the day, such as during meals. In this case, the literature on the division of household labor has showed that the importance of time constraints, socioeconomic resources, and cultural orientations in helping understand the gendered practices and 
beliefs between mothers and fathers (Lam, McHale \& Updegraff, 2013). Karberge et al. (2017) suggested that Latino low-income immigrant families may believe in gender roles that focus on the roles of the economic provider among males and caregiver among females. Lloyd and Blance's study on the role of fathers, mothers, and others on the education of children, indicating that children who lived in female-headed households were more likely to perform better in school than children who lived in male-headed households. In addition, female-headed households were more likely to invest resources, such as time, money, and emotional support for their children (Lloyd \& Blanc, 1996).

In conclusion, the forms of capital, possessed by the individual respondents and the Latino household, played an important role in helping support satisfaction of Latino families with the education and the higher education opportunities of their children. Community acceptance also shaped experiences of Latino families and their children in the host country. In addition, Latino fathers were more likely to be satisfied with the higher education opportunities of the children than female respondents. 


\section{CHAPTER VI}

\section{CONCLUSION}

This study aimed to investigate how forms of capital related to satisfaction with the education and the higher education opportunities of the children of Latino families in three rural communities in Missouri. After controlling for parental education, income, and place of living, the ordinal logistic regression results illustrated that the forms of capital which were possessed by the survey respondents and by the Latino household were significantly associated with satisfaction with the education and the higher education opportunities of the children of Latino families. In addition, the findings showed that having community acceptance and being male made the parents more likely to be satisfied with the higher education opportunities of the children. Furthermore, place of living, as a demographic characteristic, was significantly related to the satisfaction with the education of the children of Latino families.

Future research is necessary in order to explore these findings further and to situate them in both community development and practice. This chapter consists of three sections: (1) implication for community development and practice; (2) limitations of the study; and (3) future research. 


\section{VI.i. Implication for Community Development and Practice}

The American education system is viewed as an important pathway for Latino immigrant children who aspire for better life opportunities. Many empirical studies have shown that Latino parents have placed high expectations for the education of their children and want to get involved in the academic achievement of their children (Quiocho \& Daound, 2006). However, as a matter of fact, Latino immigrants in the U.S. are mostly foreign-born Mexicans and Central Americans whose average educational levels is less than 10 years with low income and language ability. These disadvantaged outcomes are reflected on the forms of human and financial capital which Latino immigrants bring to the U.S. and influence the educational progress of their children (National Academy of Sciences, 2015). On the other hand, Latino immigrants with more knowledge and skill have more opportunities to improve their occupational position and receive earnings that help support their family situation over the time. Children of Latino families in this study were often from low-income families that lacked the resources and English proficiency to effectively support the education of their children.

This study has important implications for community development and practice because knowledge about the forms of capital and satisfaction with the education and the higher education opportunities may be useful disadvantaged Latino families in these three rural communities achieve their goals in regard to the education of their children. For example, the results could be useful in improving the quality of the schools within the community and reduce the number of limitations Latino families face and help Latino parents understand their roles in supporting the education of their children and Latino families need help to more actively participate in school activities, such as 
joining the school's parent organizations, volunteering in classrooms, or attending school meetings.

The main findings suggest that most Latino families are more likely to be proficient in Spanish, but are less likely to be proficient in English. However, Latino families viewed English as important as Spanish in the three rural communities where they lived so that it is important for Latino families to learn English in order to effectively assist their children with literacy related activities, such as doing homework, reading books, or having a conversation in English. Latino families who were proficient in English were more likely to support the education of their children and enhance the relationships between parent and child. This is a challenge in many rural communities including the three communities in this study because there are few resources in these communities to help adults learn English. Most of the resources that do exist are informal and are not necessarily accessible to many Latino adults who tend to work long hour days. Introducing English programs for adults in the workplace, at church and through the schools can make a big difference.

Learning English may provide opportunities for some Latino families to connect to school representatives and community receiving members as well as decrease potential experiences with discrimination regardless of race/ethnicity or socioeconomic status. Although schools in the three communities do provide interpreters to assist Latino families with their contact with school representatives and associations, Latino families need to learn English to improve their economic prospects and access other resources in the community which may not have the same access to translation services. Therefore, community organizations may provide resources and programs for Latino families to engage and support Latino families learning English and help them to access useful information to benefits the education of their children. 
In particular, improving the English proficiency the Latino families may help them engage more with community receiving members and create more welcoming environments for Latino families in the receiving community.

Since most Latino families in the three communities included in this study are more fluent in Spanish rather than English so that they often use Spanish at home with their children. In fact, they often prefer to speak in Spanish with their children. Generally, Latino parents want their children to English; nevertheless, they also have a desire for that their children to preserve their native language and culture as a way of supporting and sustaining family ties (Quiocho \& Daound, 2006). Likewise, information from the focus groups of the 2008 Assert Accumulation project indicated that within Latino families, children who tended to use English with their parents could have created tensions between parents and child. As a result, the most stress that Latino children experience is from their parents and members of their ethnic group (Ojeda et al., 2012). However, Latino parents are comfortable when their children use English outside their home, such as at school, the hospital, or other public areas because children help their parents communicate with English speakers and access useful information which could provide benefits for the family. These behavioral changes in cultural identity, particularly in the manner of speaking, could produce acculturative stress for Latino parents; for example, uncertainty or anxiety (Berry 2005; Quiocho \& Daoud, 2006). Therefore, Latino parents and their children needed to adapt themselves to the receiving communities by using the integration acculturation strategy that may help Latino parents and their children construct a strong attachment to the host community; simultaneously, this acculturation strategy may promote a sense of wellbeing (Berry, 2005; Campbell et al., 2017). 
In a cultural context, these findings suggest that the integration acculturation strategy influenced both satisfaction with education and the higher education opportunities for the children of Latino families. Latino parents who chose to use the integration strategy wished to have their families maintain their own culture of origin and adopt U.S. culture. The more Latino families and their children become familiar with the receiving community members of the places they move to, the more they will improve their well-being over the time. If Latino families and their children are more acculturated, they may be less likely to perceive discrimination and more likely to connect with the dominant culture of the community (Ojeda et al., 2012). Specifically, Latino parents who tend to keep alive both the dominant culture and their own culture within their household are better able to help support the education of their children. For instance, they are better equipped to offer support for reading and homework, or attending parent conferences and workshops (Quiocho \& Daoud, 2006). Moreover, the integration acculturation path enhances the way that Latino parents communicate effectively using bilingual language resources for communicating with school teachers, counselors, or administers about the education and the higher education opportunities available for their children.

As mentioned earlier, one implication for practitioners is to use community integration strategies to promote cultural diversity within the community and to help people learn how to respect each other's cultural differences. Within a diverse cultural community, Latino families may experience discrimination due to the limitation of their English proficiency and their ethnicity. These barriers can create tension between Latino families as newcomers and receiving members in various ways. For example, receiving community members may treat Latino families negatively because they don't speak English and have a negative attitude toward Latino families in the community. 
For example, in the context of education, school teachers or administrators with negative perceptions about Latino families were less likely to care about the education of Latino children (Quiocho \& Daoud, 2006). As a result, Latino immigrants who were culturally different and were not fluent in English were sometimes not positively received by the members of the dominant culture. Within these hostile environments, it may be difficult for practitioners to create effective strategies that integrate newcomers and long-term community members as well as promote a welcoming community that minimizes tensions across ethnic and racial divides. There are things that can be done to move people in that direction. For example, community development practitioners may work with both newcomers and long-term community members to build stronger connections by facilitating community activities and programs that foster communication between the newcomers and help the receiving communities to break down stereotypes around what the "other" represents. These kinds of programs may include simple things, such as a multi-cultural festival as well as more complicated activities such as a cross-cultural leadership development program. In this sense, social capital may be central to creating strong connections between newcomers and receiving members. The strong connections of Latino families may help them access to information and resources for the education of their children.

Latino families who are arrivals depended on their ethnic network as bonding social capital to get basic help assistance and support while they are settling in their new community. This means that Latino newcomers rely on connections with their closet networks. For instance, friends and family members who may already been living in the community rather than link to members of the receiving. Analysis of the 2008 Asset Accumulation Focus Groups data indicates that Latino families mostly relied on their networks of friends and family members to obtain information regarding 
employment. Friends and family members were the primary support systems for newcomers when they arrived in their new places. In addition, newly arrived Latino families tended to take the separation acculturation path when they moved to the new community to maintain their native language and sociocultural norms. However, the quality of information that these newcomers sometimes received from friends and family networks was not as reliable as it needed be. In this study, there is evidence bonding networks of Latino families may not provide good information and resources to help support the education of their children. In this sense, Latino families may need to develop relationships with people from outside their friend and family networks, such as social workers, school teachers, or priests as a means of developing the bridging social capital they need for support and help. Latino families need a broad network which includes outside members to facilitate and access beneficial information and resources that would otherwise be difficult to access. Bridging social capital is important for Latino families because they get connected outside of their ethic network to open themselves to a wider network containing even more resources (Lancee, 2012). Latino families who build connections with receiving members may receive access to host community-specific resources, such as school information or government welfare which can be hard to access through friends and family (Lancee, 2012). These bridging networks may also contribute to the attachment of Latino families and their children to the community. In this sense, communities may need to learn how to strengthen relations and communication through interactions among both Latino newcomers and members of the receiving community regardless of the ethnicity, language, and socioeconomic backgrounds of Latino families. For example, community projects (i.e. gardening or sports) may promote the involvement of Latino immigrants in various ways, such as making contributions of time, money, or active participation as 
volunteers. These community projects and activities may also provide a concrete opportunity to bring people together from culturally different backgrounds to develop connections with each other, and specifically to help Latino immigrants integrate into the mainstream culture (Downs-Karkos, 2011).

In addition, local governments should consider developing public policies that promote newcomer integration and leadership as well as foster a diverse and inclusive environment in the community. By promoting diversity, equality, and inclusion, communities may create even greater opportunities for bringing newcomers and receiving community members together. Community development practitioners and local government leaders may work on actively engaging diverse community members to work on issues of common concern, such as community safety or improving education. Furthermore, Latino families with a culture different from the mainstream one should be included whenever the community make important decisions about local policies or programs to ensure that services are available for Latino families in these communities.

In regard to the gender perspective, although Latino fathers were more likely to be satisfied with the higher education opportunities of their children than Latino mothers, in particular tend to be more involved in their children's development and education. For example, Latino mothers tend to invest resources, such as time, money, and emotional support to their children (Lloyd \& Blanc, 1996). However, these Latino mothers may also have a limited command of English, low-income, and low educational attainment. Community development practitioners may consider providing program services that help low-income women obtain higher levels of education, so that they can improve their family's well-being and actively support and participate in the education of their children. For example, Latino mothers should able to monitor 
their children's academic performance and report to teachers. Likewise, they should access to all information (newsletters or the annual report) that the school sends to their home. Community development practitioners may provide program services in terms of financial assistance or academic guidance. In addition, community development practitioners and schools may collaborate to promote parent support groups to assist Latino families with low level of English proficiency in order to help them communicate more effectively with teachers, counselors, or administrators to access to useful information for the education of their children.

\section{VI.ii. Limitations of the Study}

Since this study used secondary data that was drawn from the 2008 Asset Accumulation Survey, there were indeed some limitations to measuring satisfaction with the education and the higher education opportunities of the children of Latino families in the three rural communities.

One limitation of this study is that the survey data was not collected to specifically answer the four research questions in this study. Therefore, specific information that could have been useful in the analysis was not included in this survey data. For example, this study aimed to examine family capital and the satisfaction with the education and the higher education opportunities of the children. Other variables of family capital not included in the Asset Accumulation Survey but would have been useful include more information about the spouse such as ethnicity, life satisfaction, income, length of residence in the community, and residential status. If the information had been measured separately, we would be able to see how much each parent independently affected satisfaction with the education and higher education opportunities of their children. However, the 2008 Asset Accumulation Survey relies on respondents' self- 
assessment such that specific information of the spouse was not included in the 2008 survey.

Related to this limitation, the wording of some of the questions on the survey may have caused a failure to interpret answers correctly. For instance, the question asked respondents how long they have been living in their present community is an example. Respondents were asked to answer how many years and months if possible they lived in the community. However, all the answers in the raw dataset were difficult to identify as either years or months. In this sense, it was important to clarify this limitation with the primary research team before performing new analyses.

In addition, some of the variables which were interesting to explore in regard to their impact on satisfaction with the education and the higher education opportunities of the children included a lot of missing information. This limitation decreased a large sample size into a smaller size for analyses. Making it difficult to produce more extensive analyses to determine the relationship between forms of capital and the satisfaction of Latino families because of the small sample size of some the variables.

Furthermore, the small sample size led to constraints in the data analysis because the small sample size influenced producing complex models we need to predict the outcome variables, it also violated the assumptions of ordinal logistic regression. Additionally, the large set of independent variables included in the model influenced the outcome variables; therefore, the number of independent variables should be limited to an appropriate number in order to produce the best explanations of the outcome variables (Stoltzfus, 2011). Generally speaking, when there is a small sample size and there are many independent variables, it produces an overfit model that has estimated beta coefficients for exploratory variables. These beta coefficients are much larger than they should have been as well as being higher than expected standard errors. These 
situations can cause model instability due to the fact that the logistic regression focuses on outcome variables rather than independent variables to iteratively cycle through different explanations in examining of the best model fit for the data through the process of maximum likelihood estimation (Stoltzfus, 2011).

Lastly, the findings here cannot be generalized to a larger population; therefore, they can only be used to draw conclusions concerning the communities involved in the present study. However, this study may be replicated in other communities which may deal with similar demographic circumstances. It is also relevant to note here that the positive and negative impacts that appeared from the different forms of capital could vary by locality.

\section{VI.iii. Future Research}

This study did not examine the relationship between the age of the children and satisfaction with the education and the higher education opportunities of the children of Latino families. Therefore, future research should compare satisfaction of Latino families across the age groups of their children in order to see how levels of satisfaction differ for Latino families based on the different ages of their children. For example, four age groups: preschool (ages 0 to 4), elementary school (ages 5 to 12), secondary school (ages 13-18), and post-secondary school (ages 19 year and older).

In addition, future research should investigate family patterns, especially the single-parent household, to get a clear picture on how a family pattern influences satisfaction of Latino families with the education of their children. Other issues related to family pattern, such as the aggregation of vulnerability in Latino families with respect to ethnicity and socioeconomic status (SES), such as difficulty in paying bills, poor housing, or food insecurity- should be investigated in regard to the impact they 
have on satisfaction of Latino families for the future research. Future research should also examine satisfaction of Latino parents with the education and the higher education opportunities of their children across country of origin. Each country of origin reflects how Latino families take care of their children, their attitudes toward their children's education, and the role of household roles regarding gender.

Furthermore, future study should investigate the interaction of the four forms of capital with each other, which may require larger sample sizes to predict the levels of satisfaction with the education and the higher education opportunities of the children of Latino families. 


\section{Appendix A}

\section{Description of Variables and Coding Scheme Used in the Ordinal Logistic Regression}

\begin{tabular}{|c|c|c|c|}
\hline Variable & Question & Original measurement & New measurement \\
\hline Dependent variables: & & & \\
\hline Satisfied with children's education & $\begin{array}{l}\text { [If you have children] how satisfied are you } \\
\text { with your children's education? }\end{array}$ & $\begin{array}{l}\text { a } 10 \text {-point scale } 0=\text { completely dissatisfied, } 5 \\
=\text { neither satisfied nor dissatisfied or } \\
\text { discontent, } 10=\text { completely satisfied. }\end{array}$ & $\begin{array}{l}\text { Recoded into five categories as ordinal scale: } \\
\text { " } 1 \text { " for very dissatisfied, " } 2 \text { " for dissatisfied, } \\
\text { " } 3 \text { " for neither dissatisfied nor satisfied, "4" } \\
\text { for satisfied, and " } 5 \text { " very satisfied. }\end{array}$ \\
\hline $\begin{array}{l}\text { Satisfied with children's higher education } \\
\text { opportunities }\end{array}$ & $\begin{array}{l}\text { [If you have children] how satisfied are you } \\
\text { with your children's education opportunities } \\
\text { after high school? }\end{array}$ & $\begin{array}{l}\text { a } 10 \text {-point scale } 0=\text { completely dissatisfied, } 5 \\
=\text { neither satisfied nor dissatisfied or } \\
\text { discontent, } 10=\text { completely satisfied. }\end{array}$ & $\begin{array}{l}\text { Recoded into five categories as ordinal } \\
\text { scale: "1" for very dissatisfied, "2" for } \\
\text { dissatisfied, "3" for neither dissatisfied nor } \\
\text { satisfied, "4" for satisfied, and "5" very } \\
\text { satisfied. }\end{array}$ \\
\hline Independent variables: & & & \\
\hline Individual level: (Latino respondent) & & & \\
\hline $\begin{array}{l}\text { Life satisfaction } \\
\text { (as human capital) }\end{array}$ & $\begin{array}{l}\text { 1. In most ways my life is close to my local } \\
\text { ideal. } \\
\text { 2. The conditions of my life are excellent. } \\
\text { 3. I am satisfied with my life. }\end{array}$ & $\begin{array}{l}\text { A 4-ponit scale: } 1=\text { strongly disagree, } 2= \\
\text { disagree, } 3 \text { = agree, } 4=\text { strongly agree. }\end{array}$ & $\begin{array}{l}\text { Created a new index as continuous scale by } \\
\text { averaging the responses for all five items. }\end{array}$ \\
\hline
\end{tabular}




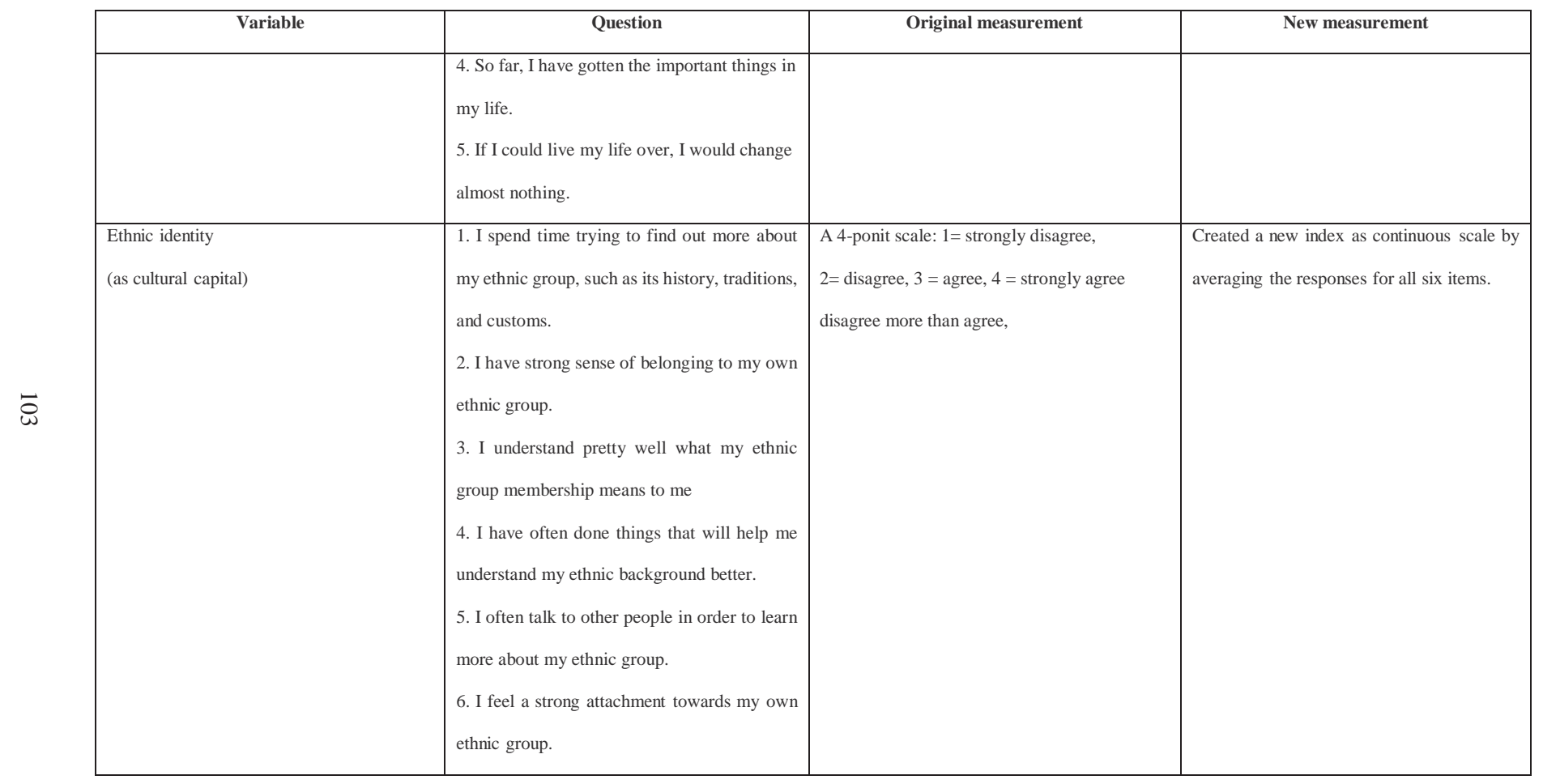




\begin{tabular}{|c|c|c|c|}
\hline Variable & Question & Original measurement & New measurement \\
\hline $\begin{array}{l}\text { Acculturation strategies } \\
\text { (as cultural capital) }\end{array}$ & $\begin{array}{l}\text { Latino-acculturation: } \\
\text { Dimension: language use ( } 3 \text { items) } \\
\text { 1. How often do you speak Spanish? } \\
\text { 2. How often do you speak Spanish with you } \\
\text { friend? } \\
\text { 3. How often do you think in Spanish? } \\
\text { Dimension: linguistic proficiency (6 items) } \\
\text { 1. How well do you speak Spanish? } \\
\text { 2. How well do you read in Spanish? } \\
\text { 3. How well do you understand television } \\
\text { programs in Spanish? } \\
\text { 4. How well do you understand radio } \\
\text { programs in Spanish? } \\
\text { 5. How well do you write in Spanish? } \\
\text { 6. How well do you understand in Spanish? } \\
\text { Dimension: media (3 items) } \\
\text { 1. How often do you watch television } \\
\text { programs in Spanish? }\end{array}$ & $\begin{array}{l}\text { A 4-ponit scale: } 1=\text { almost never, } 2=\text { sometimes, } \\
3=\text { often, } 4=\text { almost always }\end{array}$ & $\begin{array}{l}\text { Using a cut-off at } 2.5 \text { to create new four } \\
\text { categories of acculturation strategies: } \\
1=\text { integration (English and Spanish } \geq 2.5 \text { ) } \\
2=\text { separation (English }<2.5 \text { and Spanish } \\
\geq 2.5 \text { ) } \\
3=\text { assimilation (English } \geq 2.5 \text { and Spanish } \\
<2.5 \text { ) } \\
4=\text { marginalization (English and Spanish } \\
<2.5 \text { ) } \\
\text { Recoded into dichotomous scale: "0" for } \\
\text { integration strategy and "1" other strategies. }\end{array}$ \\
\hline
\end{tabular}




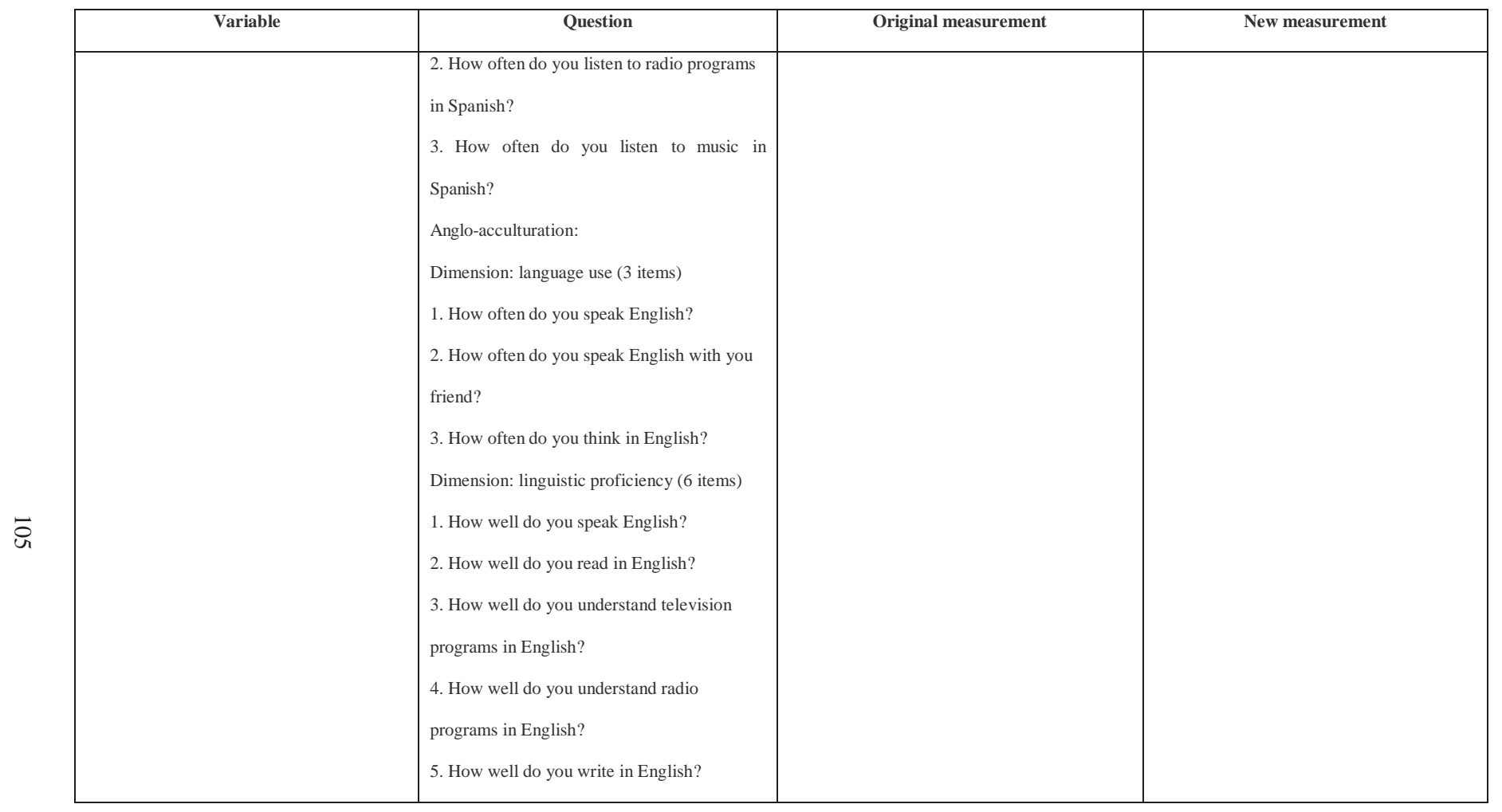




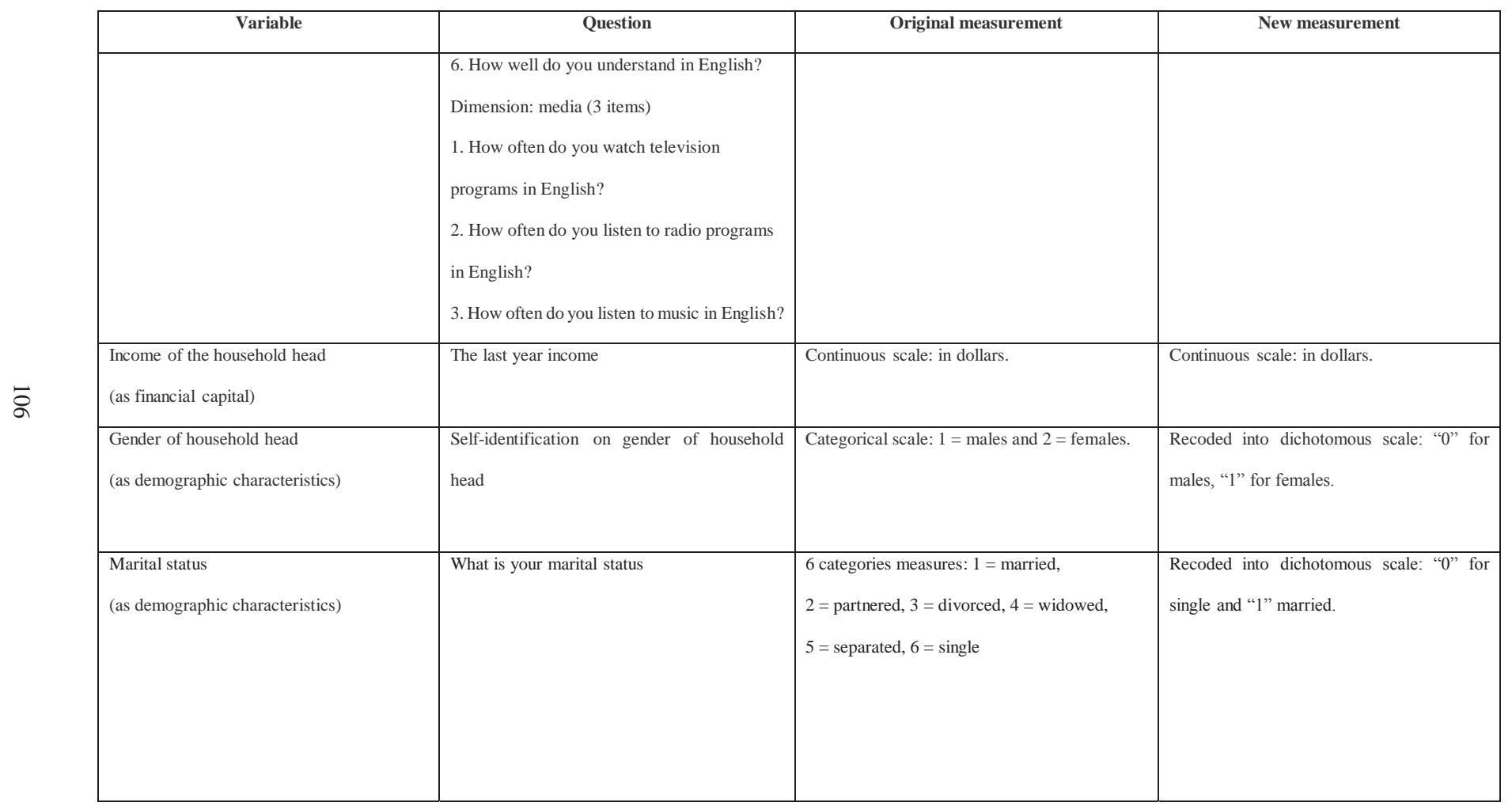




\begin{tabular}{|c|c|c|c|}
\hline Variable & Question & Original measurement & New measurement \\
\hline $\begin{array}{l}\text { Length of residence } \\
\text { (as demographic characteristics) }\end{array}$ & How long have you lived in the community? & Continuous scale: in years. & Continuous scale: in years. \\
\hline $\begin{array}{l}\text { Children in the family } \\
\text { (as demographic characteristics) }\end{array}$ & Total number of children in the family & Continuous scale & Continuous scale \\
\hline $\begin{array}{l}\text { Residential status } \\
\text { (as demographic characteristics) }\end{array}$ & What is your residential status? & $\begin{array}{l}\text { A categorical scale: } 1=\text { citizen, } \\
2=\text { legal resident, } 3=\text { not applicable }\end{array}$ & $\begin{array}{l}\text { Recoded into dichotomous scale: "0" for } \\
\text { legal status, "1" for others. }\end{array}$ \\
\hline $\begin{array}{l}\text { Place of living } \\
\text { (as demographic characteristics) }\end{array}$ & Place of living & $\begin{array}{l}\text { A categorical scale: } 1=\text { community A, } \\
2=\text { community } \mathrm{B}, \text { and } 3=\text { community } \mathrm{C}\end{array}$ & $\begin{array}{l}\text { Recoded into dichotomous scale: "0" for } \\
\text { community A, "1" for community B and C }\end{array}$ \\
\hline Household level: (Latino household) & & & \\
\hline $\begin{array}{l}\text { Parental education } \\
\text { (as human capital) }\end{array}$ & $\begin{array}{l}\text { The level of educational attainment of each } \\
\text { parent }\end{array}$ & $\begin{array}{l}15 \text { categorical measures: } 1=\text { no formal } \\
\text { education, } 2=4^{\text {th }} \text { grade or below, } 3=5^{\text {th }} \text { grade } \\
\text { or } 6^{\text {th }} \text { grade below, } 4=7^{\text {th }} \text { grade or } 8^{\text {th }} \text { grade, } 5 \\
=9^{\text {th }} \text { grade, } 6=10^{\text {th }} \text { grade, } 7=11^{\text {th }} \text { grade, } 8= \\
12^{\text {th }} \text { grade or no diploma, } \\
9=\text { high school graduate or equivalent, } \\
10=\text { attended college for more than one year, } \\
\text { no degree, } 11=\text { associate degree, }\end{array}$ & $\begin{array}{l}\text { Recoded into continuous scale: the number } \\
\text { of years of schooling using high point of } \\
\text { response categories. } \\
0=\text { no formal education, } 4=4^{\text {th }} \text { grade or } \\
\text { below, } 6=5^{\text {th }} \text { grade or } 6^{\text {th }} \text { grade below, } 8= \\
7^{\text {th }} \text { grade or } 8^{\text {th }} \text { grade, } 9=9^{\text {th }} \text { grade, } 10= \\
10^{\text {th }} \text { grade, } 11=11^{\text {th }} \text { grade, } 12=12^{\text {th }} \text { grade }\end{array}$ \\
\hline
\end{tabular}




\begin{tabular}{|c|c|c|c|}
\hline Variable & Question & Original measurement & New measurement \\
\hline & & $\begin{array}{l}12=\text { bachelor's degree, } 13 \text { master's degree, } \\
14=\text { professional degree, and } 15=\text { doctoral } \\
\text { degree. }\end{array}$ & $\begin{array}{l}\text { or no diploma/ high school graduate or } \\
\text { equivalent } \\
13 \text { = attended college for more than one } \\
\text { year, no degree, } 14 \text { = associate degree, } 16 \text { = } \\
\text { bachelor's degree, } 18 \text { = master's degree, } 20 \\
=\text { professional degree/doctoral degree. } \\
\text { Created a new index as continuous scale by } \\
\text { averaging year of schooling of father and } \\
\text { mother }\end{array}$ \\
\hline $\begin{array}{l}\text { Parental English proficiency } \\
\text { (as human capital) }\end{array}$ & $\begin{array}{l}\text { 1. How well do you speak in English? } \\
\text { 2. How well do you read in English? } \\
\text { 3. How well do you write in English? }\end{array}$ & $\begin{array}{l}\text { A 4- point scale: } 1=\text { very well, } 2=\text { well, } \\
3=\text { not well, } 4-\text { not at all }\end{array}$ & $\begin{array}{l}\text { Created a new index as continuous scale by } \\
\text { averaging English proficiency scores of } \\
\text { father and mother }\end{array}$ \\
\hline $\begin{array}{l}\text { Parental employment status } \\
\text { (as human capital) }\end{array}$ & Self-identification on occupation & $\begin{array}{l}\text { Coded into six categories: } 1=\text { professionals, } \\
2=\text { skilled workers, } 3=\text { semi-skilled workers, } \\
4=\text { unskilled workers, } 5=\text { housewife, and } \\
6=\text { unemployed. }\end{array}$ & $\begin{array}{l}\text { Recoded into dichotomous scale: "0" for } \\
\text { both parent employed and " } 1 \text { " otherwise }\end{array}$ \\
\hline
\end{tabular}




\begin{tabular}{|c|c|c|c|}
\hline Variable & Question & Original measurement & New measurement \\
\hline $\begin{array}{l}\text { A recreational/sport association } \\
\text { (as bridging social capital) }\end{array}$ & $\begin{array}{l}\text { Are you or anyone in your household a } \\
\text { member of any recreational/sport } \\
\text { associations? }\end{array}$ & Dichotomous scale: $0=$ no, $1=$ yes & Dichotomous scale: $0=$ no, $1=$ yes \\
\hline $\begin{array}{l}\text { An informal group of friends } \\
\text { (as bonding social capital) }\end{array}$ & $\begin{array}{l}\text { Are you or anyone in your household a } \\
\text { member of any informal group of friends that } \\
\text { meet occasionally to talk? }\end{array}$ & Dichotomous scale: $0=$ no, $1=$ yes & Dichotomous scale: $0=$ no, $1=$ yes \\
\hline $\begin{array}{l}\text { A formal association } \\
\text { (as bridging social capital) }\end{array}$ & $\begin{array}{l}\text { Are you or any one in your household a } \\
\text { member of a group of a formal association } \\
\text { such as clubs or a group organized of people } \\
\text { who get together regularly? }\end{array}$ & Dichotomous scale: $0=$ no, $1=$ yes & Dichotomous scale: $0=$ no, $1=$ yes \\
\hline Education expenditure (as financial capital) & The total amount of education expenditure & Continuous scale: in dollars. & Continuous scale: in dollars. \\
\hline Community level: & & & \\
\hline $\begin{array}{l}\text { Community acceptance } \\
\text { (as community perceptions) }\end{array}$ & $\begin{array}{l}\text { 1. I feel valued as a member of this } \\
\text { community. } \\
\text { 2. People in this community have been } \\
\text { willing to help me. } \\
\text { 3. There are services available for me in the } \\
\text { community. }\end{array}$ & $\begin{array}{l}\text { A 7-ponit scale: } 1=\text { strongly disagree, } \\
2=\text { disagree, } 3=\text { disagree more than agree, } \\
4=\text { neither agree or disagree, } 5=\text { slightly agree, } \\
6=\text { agree, } 7 \text { = strongly agree. }\end{array}$ & $\begin{array}{l}\text { Created a new index as continuous scale by } \\
\text { averaging the responses for all five items. }\end{array}$ \\
\hline
\end{tabular}




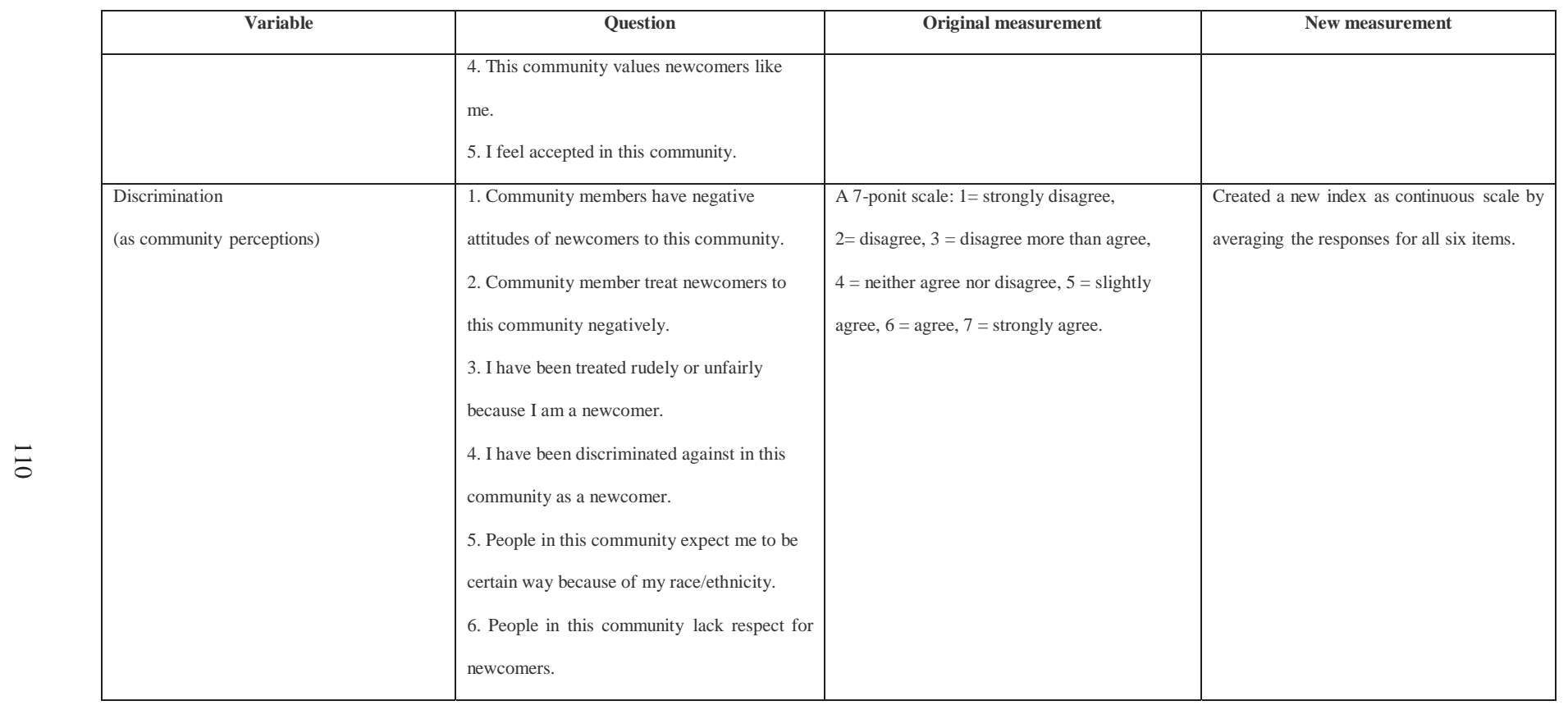




\section{BIBLIOGRAPHY}

Adair, J. K. (2015). The impact of discrimination on the early schooling experiences of children from immigrant families. Migration Policy Institute.

Agresti, A., \& Finlay, B. (2014). Statistical methods for the social Sciences (4 ${ }^{\text {th }}$ ed.). Peason. USA.

Altschul, I. (2011). Parental involvement and the academic achievement of Mexican American youths: what kinds of involvement in youths' education matter most?. Social Work Research, 35(3), 159-170.

Angeles, L. (2010). Children and life satisfaction. Journal of happiness Studies, 11(4), $523-538$.

Atkinson, R., \& Flint, J. (2001). Accessing hidden and hard-to-reach populations: Snowball research strategies. Social research update, 33(1), 1-4.

Bangkok, Thailand: UNESCO; 1992. UNESCO Principal Regional Office for Asia and Pacific. The changing family in Asia: Bangladesh, India, Japan, Philippines and Thailand.

Bámaca-Colbert, M. Y., \& Gayles, J. G. (2010). Variable-centered and personcentered approaches to studying Mexican-origin mother-daughter cultural orientation dissonance. Journal of youth and adolescence, 39(11), 1274-1292.

Baum, S., \& Flores, S. M. (2011). Higher education and children in immigrant families. The future of children, 21(1), 171-193.

Beaulieu, L. J. (1992). Effects of human capital and social capital on dropping out of high school in the South. Journal of Research in Rural Education, 8(1), 75-87. 
Bebbington, A. (1999). Capitals and capabilities: a framework for analyzing peasant viability, rural livelihoods and poverty. World development, 27(12), 20212044.

Belcher, J. R., Peckuonis, E. V., \& Deforge, B. R. (2011). Family capital: Implications for interventions with families. Journal of Family Social Work, 14(1), 68-85.

Berry, J. W. (1997). Immigration, acculturation, and adaptation. Applied psychology, 46(1), 5-34.

Berry, J. W. (2003). Conceptual approaches to acculturation. American Psychological Association.

Berry, J. W. (2005). Acculturation: Living successfully in two cultures. International journal of intercultural relations, 29(6), 697-712.

Beutell, N. (2006). Life satisfaction: a Sloan network encyclopedia entry. Journal of Sloan Work and Family, 2(3), 1125-7.

Bobonis, G. J. (2009). Is the allocation of resources within the household efficient? New evidence from a randomized experiment. Journal of political Economy, 117(3), 453-503.

Bourhis, R. Y., Barrette, G., El-Geledi, S., \& Schmidt Sr, R. (2009). Acculturation orientations and social relations between immigrant and host community members in California. Journal of Cross-Cultural Psychology, 40(3), 443-467.

Brian, K. (2007). OECD Insights Human Capital How what you know shapes your life: How what you know shapes your life. OECD publishing.

Bronfenbrenner, U. (1977). Toward an experimental ecology of human development. American Psychologist, 32(7), 513-531. 
Bronfenbrenner, U. (1986). Ecology of the family as a context for human development: research perspectives. Developmental Psychology, 22(6), 723742.

Bronfenbrenner, U. (2009). The ecology of human development. Harvard university press.

Brouillard, P., \& Hartlaub, M. G. (2006). Ethnic identity, academic achievement, and self-esteem among Mexican-American university students. Review of Psychology, 12(2), 155-160.

Bubolz, M. M., Eicher, J. B., Evers, S. J., \& Sontag, M. S. (1980). A human ecological approach to quality of life: Conceptual framework and results of a preliminary study. Social Indicators Research, 7(1-4), 103-136.

Cabrera, N. J., \& Bradley, R. H. (2012). Latino fathers and their children. Child Development Perspectives, 6(3), 232-238.

Campbell, S., Nuevo-Chiquero, A., Popli, G. and Ratcliffe, A. (2017). Parental ethnic identity and child development. [online] Editorialexpress.com. Available at: https://editorialexpress.com/cgibin/conference/download.cgi?db_name=espe2 017\&paper_id=417 [Accessed 2 Oct. 2017].

Ceballo, R. (2004). From barrios to Yale: The role of parenting strategies in Latino families. Hispanic Journal of Behavioral Sciences, 26(2), 171-186.

Chang, L., McBride-Chang, C., Stewart, S., \& Au, E. (2003). Life satisfaction, selfconcept, and family relations in Chinese adolescents and children. International Journal of Behavioral Development, 27(2), 182-189. 
Chang, J., \& Le, T. N. (2010). Multiculturalism as a dimension of school climate: The impact on the academic achievement of Asian American and Hispanic youth. Cultural Diversity and Ethnic Minority Psychology, 16(4), 485-492.

Chapa, J., \& Valencia, R. R. (1993). Latino population growth, demographic characteristics, and educational stagnation: An examination of recent trends. Hispanic Journal of Behavioral Sciences, 15(2), 165-187.

Chiswick, C. U. (2009). The economic determinants of ethnic assimilation. Journal of Population Economics, 22(4), 859.

Chudhuri, S. (2011). Social development and the family. Retrieved from https://www.eolss.net/Sample-Chapters/C11/E1-11-02-04.pdf.

City-Data. (2017). School in Sedalia, Milan, Branson. Retrieved from http://www.city-data.com/school/Sedalia-Missouri.html

Coleman, J. S., \& Hoffer, T. (1987). Public and private high schools: The impact of communities. New York: Basic Books.

Coleman, J. S. (1988). Social capital in the creation of human capital. American journal of sociology, 94, S95-S120.

Cohen, J., McCabe, L., Michelli, N. M., \& Pickeral, T. (2009). School climate: Research, policy, practice, and teacher education. Teachers college record, 111(1), 180-213.

Côté, S., \& Healy, T. (2001). The well-being of nations: The role of human and social capital. Paris: Organisation for Economic Co-operation and Development.

Creswell, J. W. (2013). Research design: Qualitative, quantitative, and mixed methods approaches. Sage publications.

Danes, S. M., Stafford, K., Haynes, G., \& Amarapurkar, S. S. (2009). Family capital of family firms: Bridging human, social, and financial capital. Family 


\section{Business Review.}

Davis, K. D., Lawson, K. M., Almeida, D. M., Kelly, E. L., King, R. B., Hammer, L., \& McHale, S. M. (2015). Parents' daily time with their children: A workplace intervention. Pediatrics, 135(5), 875-882.

Deaton, A., \& Stone, A. A. (2014). Evaluative and hedonic wellbeing among those with and without children at home. Proceedings of the National Academy of Sciences, 111(4), 1328-1333.

Diener, E. D., Emmons, R. A., Larsen, R. J., \& Griffin, S. (1985). The satisfaction with life scale. Journal of personality assessment, 49(1), 71-75.

Downs-Karkos, S. (2011). The Receiving Communities Toolkit: A Guide for Engaging Mainstream America in Immigrant Integration. Welcoming America.(October 2011). Retrieved from http://on. aaslh. org/Downs-Karkos.

Dozi, P. V. (2010). Impact of social networks on well-being: Evidence from Latino immigrants in non-urban Missouri communities. University of MissouriColumbia.

Edles, L. D. (2002). Cultural sociology in practice.

Engle, P. L. (2001). Father's money, mother's money, and parental commitment. Early Childhood Matters, 97.

Erickson, C. D. (1996). Parent Satisfaction and Alienation from Schools: Examining Ethnic Differences.

Espinoza, R. (2012). Working-class minority students' routes to higher education (Vol. 81). Routledge.

Estela Zarate, M., Bhimji, F., \& Reese, L. (2005). Ethnic identity and academic achievement among Latino/a adolescents. Journal of Latinos and Education, 4(2), 95-114. 
Farver, J. A. M., Xu, Y., Eppe, S., \& Lonigan, C. J. (2006). Home environments and young Latino children's school readiness. Early Childhood Research Quarterly, 21(2), 196-212.

Field, J. (2003). Social capital. Newyork, NY: Routledge.

Ferlander, S. (2007). The importance of different forms of social capital for health. Acta Sociologica, 50(2), 115-128.

Field, J. (2003). Social capital. New York, NY: Routledge.

Friedman, B. A., Bobrowski, P. E., \& Geraci, J. (2006). Parents' school satisfaction: ethnic similarities and differences. Journal of Educational Administration, 44(5), 471-486.

Friedman, B. A., Bobrowski, P. E., \& Markow, D. (2007). Predictors of parents' satisfaction with their children's school. Journal of Educational Administration, 45(3), 278-288.

Flora, C. B., Flora, J. L (2013). Rural communities: Legacy+ change. Fourth edition. Westview Press.

Grant, E. (2001). Social capital and community strategies: neighborhood development in Guatemala City. Development and Change, 32(5), 975-997.

Grindal, M., \& Nieri, T. (2015). An Examination of Ethnic Identity and Academic Performance: Assessing the Multidimensional Role of Parental Ethnic-Racial Socialization Among a Sample of Latino Adolescents. Race and Social Problems, 7(3), 242-255.

Goddard, R. D. (2003). Relational networks, social trust, and norms: A social capital perspective on students' chances of academic success. Educational evaluation and policy analysis, 25(1), 59-74.

Goetting, A. (1986). Parental satisfaction: A review of research. Journal of Family 
Issues, 7(1), 83-109.

Guzmán, M. R., Santiago-Rivera, A. L., \& Hasse, R. F. (2005). Understanding academic attitudes and achievement in mexican-origin youths: ethnic identity, other-group orientation, and fatalism. Cultural Diversity and Ethnic Minority Psychology, 11(1), 3.

Hawkins, R. L., \& Maurer, K. (2009). Bonding, bridging and linking: how social capital operated in New Orleans following Hurricane Katrina. British Journal of Social Work, 40(6), 1777-1793.

Hendrix, L. (1975). Nuclear family universals: Fact and faith in the acceptance of an idea. Journal of Comparative Family Studies, 125-138.

Hoffman, J., Hoelscher, M., \& Sorenson, R. (2006). Achieving sustained competitive advantage: A family capital theory. Family business review, 19(2), 135-145.

Hurtado-Ortiz, M. T., \& Gauvain, M. (2007). Postsecondary education among Mexican American youth: Contributions of parents, siblings, acculturation, and generational status. Hispanic Journal of Behavioral Sciences, 29(2), 181191.

Huston, S. J. (1995). The household education expenditure ratio: Exploring the importance of education. Family Economics and Resource Management Biennial, 1, 71-72.

Imig, D. R. Family Capital versus Family Social Capital: Different Boundaries, Different Processes. Retrieved from: https://msu.edu/ imig/abstract.htm, February 25, 2017.

Jung, E., \& Zhang, Y. (2016). Parental involvement, children's aspirations, and achievement in new immigrant families. The Journal of Educational Research, 109(4), 333-350. 
Kang, S. M. (2006). Measurement of acculturation, scale formats, and language competence their implications for adjustment. Journal of Cross-Cultural Psychology, 37(6), 669-693.

Kang, C. (2011). Family size and educational investments in children: Evidence from private tutoring expenditures in South Korea. Oxford Bulletin of Economics and Statistics, 73(1), 59-78.

Kao, G., \& Tienda, M. (1995). Optimism and achievement: The educational performance of immigrant youth. Social science quarterly, 1-19.

Kao, G. (2004). Social capital and its relevance to minority and immigrant populations. Sociology of Education, 77(2), 172-175.

Karberg, E., Guzman, L., Cook, E., Scott, M., \& Cabrera, N. (2017). A Portrait of Latino Fathers: Strengths and Challenges.

Kim, D. H., \& Schneider, B. (2005). Social capital in action: Alignment of parental support in adolescents' transition to postsecondary education. Social forces, 84(2), 1181-1206.

Khan, A. H., \& Khalid, U. (2012). Consumption patterns of male and female headed households in Pakistan: evidence from PSLM 2007-08. The Pakistan Development Review, 465-478.

Kleinbaum, D. G., \& Klein, M. (2010). Analysis of matched data using logistic regression. In Logistic regression (pp. 389-428). Springer New York.

Kelesidou, S., Chatzikou, M., Tsiamagka, E., Koutra, E., Abakoumkin, G., \& Tseliou, E. (2017). The role of parents' educational level and centre type in parent satisfaction with early childhood care centres: a study in Greece. European Early Childhood Education Research Journal, 25(5), 768-783.

Laerd Statistics (n.d.). Retrieved February 28, 2017, from 
https://statistics.laerd.com/premium/index.php

Lancee, B. (2012). Immigrant performance in the labour market: Bonding and bridging social capital (p. 192). Amsterdam University Press.

Lam, C. B., McHale, S. M., \& Updegraff, K. A. (2012). Gender dynamics in Mexican American families: Connecting mothers', fathers', and youths' experiences. Sex roles, 67(1-2), 17-28.

Lee, J. S., \& Bowen, N. K. (2006). Parent involvement, cultural capital, and the achievement gap among elementary school children. American educational research journal, 43(2), 193-218.

Leong, C. H., \& Ward, C. (2006). Cultural values and attitudes toward immigrants and multiculturalism: The case of the Eurobarometer survey on racism and xenophobia. International Journal of Intercultural Relations, 30(6), 799-810.

Lerman, R. I., \& McKernan, S. M. (2008). The effects of holding assets on social and economic outcomes of families: A review of theory and evidence.

Lin, N. (1999). Building a network theory of social capital. Connections, 22(1), 2851.

Lin, N. (2002). Social capital: A theory of social structure and action (Vol. 19). Cambridge university press.

Li, G. (2007). Home environment and second-language acquisition: The importance of family capital. British Journal of Sociology of Education, 28(3), 285-299.

Lee, J. S., \& Bowen, N. K. (2006). Parent involvement, cultural capital, and the achievement gap among elementary school children. American Educational Research Journal, 43(2), 193-218. 
Lloyd, C. B., \& Blanc, A. K. (1996). Children's schooling in sub-Saharan Africa: The role of fathers, mothers, and others. Population and development review, 265298.

Lofquist, D. (2012). Households and families: 2010. US Department of Commerce, Economics and Statistics Administration, US Census Bureau.

Magnuson, K., Lahaie, C., \& Waldfogel, J. (2006). Preschool and school readiness of children of immigrants. Social science quarterly, 87(5), 1241-1262.

Maralani, V. (2008). The changing relationship between family size and educational attainment over the course of socioeconomic development: Evidence from Indonesia. Demography, 45(3), 693-717.

Martin, N. D. (2013). Forms of social capital: Family resources, campus networks, and dominant class advantage at an elite university. In Networks, Work and Inequality (pp. 359-386). Emerald Group Publishing Limited.

Mcds.dese.mo.gov. (2017). Missouri Comprehensive Data System - District Info. [online] Available at: https://mcds.dese.mo.gov/quickfacts/SitePages/DistrictInfo.aspx [Accessed 24 Aug. 2017].

Mesch, G. S., \& Manor, O. (1998). Social ties, environmental perception, and local attachment. Environment and behavior, 30(4), 504-519.

Miller, M. (2013). The relationships between ethnic identity, social context, and depressive symptoms in adolescents (Doctoral dissertation, Rutgers University-Graduate School of Applied and Professional Psychology).

Murad, H., Fleischman, A., Sadetzki, S., Geyer, O., \& Freedman, L. S. (2003). Small samples and ordered logistic regression: Does it help to collapse categories of outcome?. The American Statistician, 57(3), 155-160. 
Murayama, H., Fujiwara, Y., \& Kawachi, I. (2012). Social capital and health: a review of prospective multilevel studies. Journal of Epidemiology, 22(3), 179187.

Nahapiet, J., \& Ghoshal, S. (1998). Social capital, intellectual capital, and the organizational advantage. Academy of management review, 23(2), 242-266.

National Academies of Sciences, Engineering, and Medicine. 2015. The Integration of Immigrants into American Society. Washington, DC: The National Academies Press. https://nces.ed.gov/pubs2016/2016014.pdf

Nikolaou, D. (2012). Happy Mothers, Successful Children: Effects of Maternal Life Satisfaction on Child Outcomes. Working paper, Department of Economics, Ohio State University.

Newton, K. (2001). Trust, social capital, civil society, and democracy. International Political Science Review, 22(2), 201-214.

Noguera, P. A. (2001). Transforming urban schools through investments in the social capital of parents. Psychology, 16, 725-50.

North, D. C. (2011). Institutions, institutional change and economic performance (3rd ed.). New York: Cambridge University Press.

O’Brennan, L., \& Bradshaw, C. (2013). Importance of school climate. Retrieved Octorber 16, 2017, from https://www.nea.org/assets/docs/15584_Bully_Free_Research_Brief-4pg.pdf

Ojeda, L., Navarro, R. L., Meza, R. R., \& Arbona, C. (2012). Too Latino and not Latino enough: The role of ethnicity-related stressors on Latino college students' life satisfaction. Journal of Hispanic Higher Education, 11(1), 1428. 
Parcel, T. L., \& Dufur, M. J. (2001). Capital at home and at school: Effects on student achievement. Social forces, 79(3), 881-911.

Park, N. (2004). The role of subjective well-being in positive youth development. The Annals of the American Academy of Political and Social Science, 591(1), 2539.

Patrinos, H. A., \& Psacharopoulos, G. (1997). Family size, schooling and child labor in Peru-An empirical analysis. Journal of population economics, 10(4), 387405.

Patton, M. Q. (1990). Qualitative evaluation and research methods. SAGE Publications, inc.

Pew Research Center's Hispanic Trends Project. (2017, October 31). Retrieved December 02, 2017, from http://www.pewhispanic.org/

Pérez, D. J., Fortuna, L., \& Alegria, M. (2008). Prevalence and correlates of everyday discrimination among US Latinos. Journal of community psychology, 36(4), 421-433.

Phinney, J. S. (1990). Ethnic identity in adolescents and adults: review of research. Psychological bulletin, 108(3), 499.

Plunkett, S. W., \& Bámaca-Gómez, M. Y. (2003). The relationship between parenting, acculturation, and adolescent academics in Mexican-origin immigrant families in Los Angeles. Hispanic Journal of Behavioral Sciences, 25(2), 222-239.

Plunkett, S. W., Behnke, A. O., Sands, T., \& Choi, B. Y. (2009). Adolescents' reports of parental engagement and academic achievement in immigrant families. Journal of Youth and Adolescence, 38(2), 257-268.

Putnam, R. D. (1996). The strange disappearance of civic America. Policy: A Journal 
of Public Policy and Ideas, 12(1), 3.

Putnam, R. D. (2001). Bowling alone: The collapse and revival of American community. Simon and Schuster.

Poutziouris, P., Smyrnios, K., \& Klein, S. (Eds.). (2008). Handbook of research on family business. Edward Elgar Publishing.

Pollmann-Schult, M. (2014). Parenthood and Life Satisfaction: Why Don't Children Make People Happy?. Journal of Marriage and Family, 76(2), 319-336.

Prasoon, R., \& Chaturvedi, K. R. (2016). Life Satisfaction: A Literature Review. International Journal of Management Humanities and Social Sciences, 1(2), 25-32.

Perreira, K. M., Chapman, M. V., \& Stein, G. L. (2006). Becoming an American parent: Overcoming challenges and finding strength in a new immigrant Latino community. Journal of Family Issues, 27(10), 1383-1414.

Perreira, K. M., Fuligni, A., \& Potochnick, S. (2010). Fitting in: The roles of social acceptance and discrimination in shaping the academic motivations of Latino youth in the US Southeast. Journal of Social Issues, 66(1), 131-153.

Prieto, L., Sagafi-nejad, T., \& Janamanchi, B. (2013). A Bourdieusian perspective on acculturation: Mexican immigrants in the United States. Administrative Sciences, 3(4), 290-305.

Quiocho, A. M., \& Daoud, A. M. (2006, September). Dispelling myths about Latino parent participation in schools. In The Educational Forum (Vol. 70, No. 3, pp. 255-267). Taylor \& Francis Group.

Rahn, W. M., \& Transue, J. E. (1998). Social trust and value change: The decline of social capital in American youth, 1976-1995. Political Psychology, 19(3), $545-565$. 
Rouxel, P. L., Heilmann, A., Aida, J., Tsakos, G., \& Watt, R. G. (2015). Social capital: theory, evidence, and implications for oral health. Community dentistry and oral epidemiology, 43(2), 97-105.

Santiago, D. (2015). Factbook: The condition of Latinos in education 2015. Washington, DC.

Schroeder, M. A. (1990). Diagnosing and dealing with multicollinearity. Western Journal of Nursing Research, 12(2), 175-187.

Schneider, B., Martinez, S., \& Owens, A. (2006). Barriers to educational opportunities for Hispanics in the United States. Hispanics and the future of America, 179-227.

Schüller, S. (2015). Parental ethnic identity and educational attainment of secondgeneration immigrants. Journal of Population Economics, 28(4), 965-1004.

Schwartz, S. J., Unger, J. B., Lorenzo-Blanco, E. I., Des Rosiers, S. E., Villamar, J. A., Soto, D. W., ... \& Szapocznik, J. (2014). Perceived context of reception among recent Hispanic immigrants: Conceptualization, instrument development, and preliminary validation. Cultural Diversity and Ethnic Minority Psychology, 20(1), 1.

Schwartz, S. J., Unger, J. B., Zamboanga, B. L., \& Szapocznik, J. (2010). Rethinking the concept of acculturation: implications for theory and research. American Psychologist, 65(4), 237.

Sedgwick, P. (2012). Pearson's correlation coefficient. Bmj, 345(7).

Sharma, R. (2013). The family and family structure classification redefined for the current times. Journal of family medicine and primary care, 2(4), 306.

Shields, M. K., \& Behrman, R. E. (2004). Children of immigrant families: analysis and recommendations. The Future of Children, 14(2), Children of Immigrant 
Families (Summer, 2004), pp. 4-15

Shin, H. (2008). Female-headed households, living arrangements, and poverty in Mexico. The University of Texas at Austin.

Shoji, K., Bock, J., Cieslak, R., Zukowska, K., Luszczynska, A., \& Benight, C. C. (2014). Cultivating secondary traumatic growth among healthcare workers: The role of social support and self-efficacy. Journal of Clinical Psychology, $70(9), 831-846$.

Snyder, T.D., de Brey, C., and Dillow, S.A. (2016). Digest of Education Statistics 2015 (NCES 2016-014). National Center for Education Statistics, Institute of Education Sciences, U.S. Department of Education. Washington, DC.

Suldo, S. M., Riley, K. N., \& Shaffer, E. J. (2006). Academic correlates of children and adolescents' life satisfaction. School Psychology International, 27(5), 567582.

Sorenson, R. L., \& Bierman, L. (2009). Family capital, family business, and free enterprise. Family Business Review, 22(3), 193-195.

Stanton-Salazar, R. (1997). A social capital framework for understanding the socialization of racial minority children and youths. Harvard educational review, 67(1), 1-41.

Steier, L. (2009). Where do new firms come from? Households, family capital, ethnicity, and the welfare mix. Family Business Review, 22(3), 273-278.

Stoltzfus, J. C. (2011). Logistic regression: a brief primer. Academic Emergency Medicine, 18(10), 1099-1104.

Swartz, T. T. (2008). Family capital and the invisible transfer of privilege: Intergenerational support and social class in early adulthood. New Directions for Child and Adolescent Development, 2008(119), 11-24. 
Szapocznik, J. (2014). Perceived context of reception among recent Hispanic immigrants: Conceptualization, instrument development, and preliminary validation. Cultural Diversity and Ethnic Minority Psychology, 20(1), 1.

Tilak, J. B. (2002). Determinants of household expenditure on education in rural India (No. 88). New Delhi: National Council of Applied Economic Research.

Throsby, D. (1999). Cultural capital. Journal of cultural economics, 23(1-2), 3-12.

Uphoff, E. P., Pickett, K. E., Cabieses, B., Small, N., \& Wright, J. (2013). A systematic review of the relationships between social capital and socioeconomic inequalities in health: a contribution to understanding the psychosocial pathway of health inequalities. International Journal for Equity in Health, 12(1), 54.

Valdivia, C., Dozi, P., Jeanetta, S., Flores, L. Y., Martínez, D., \& Dannerbeck, A. (2008). The impact of networks and the context of reception on asset accumulation strategies of Latino newcomers in new settlement communities of the Midwest. American Journal of Agricultural Economics, 90(5), 13191325.

Valdivia, C., \& Gilles, J. (2001). Gender and resource management: Households and groups, strategies and transitions. Agriculture and human values, 18(1), 5-9.

Valdivia, C., \& Flores, L. Y. (2012). Factors affecting the job satisfaction of Latino/a immigrants in the Midwest. Journal of Career Development, 39(1), 31-49.

Ward, C., \& Leong, C. H. (2006). Intercultural relations in plural societies. The Cambridge handbook of acculturation psychology, 484-503.

Warner, P. (2008). Ordinal logistic regression. Journal of Family Planning and Reproductive Health Care, 34(3), 169-170.

Wilkinson, K. P. (1986,). The small-town community: its character and survival. In 
Third Biennial GITAP Interdisciplinary Conference. Grand Forks, North Dakota.

Willingham, D. T. (2012). When Can You Trust the Experts? How to Tell Good Science from Bad in Education. John Wiley \& Sons.

Wisdom, J., \& Creswell, J. W. (2013). Mixed methods: integrating quantitative and qualitative data collection and analysis while studying patient-centered medical home models. Rockville, MD: Agency for Healthcare Research and Quality.

Wojtkiewicz, R. A., \& Donato, K. M. (1995). Hispanic educational attainment: The effects of family background and nativity. Soc. F., 74, 559.

Woolcock, M. (1998). Social capital and economic development: Toward a theoretical synthesis and policy framework. Theory and society, 27(2), 151208.

Woolcock, M. (2010). The rise and routinization of social capital, 1988-2008. Annual review of political science, 13, 469-487.

Zagefka, H., \& Brown, R. (2002). The relationship between acculturation strategies, relative fit and intergroup relations: immigrant-majority relations in Germany. European Journal of Social Psychology, 32(2), 171-188 


\section{VITA}

Aphiradee Wongsiri was born in Khon Kaen Province in Thailand. She earned a Bachelor of Arts degree in Social Development Management in 2006 from Khon Kaen University, Thailand. Aphiradee received the two-year Master in Public Administration (MPA) from Chulalongkorn University, Bangkok, Thailand. She has been a faculty appointment since 2010 as lecturer of Public Administration Department, Khon Kaen University - Nong Khai campus.

In 2013, she perused her Doctoral degree in Rural Sociology at University of Missouri-Columbia, USA. While she was doing her doctoral work, she served as a graduate research assistant at the Cambio Center and worked as a graduate assistant for Community Development Academy. 